\title{
El legado \\ de los Argensola
}

Edición de Jesús Gascón Pérez
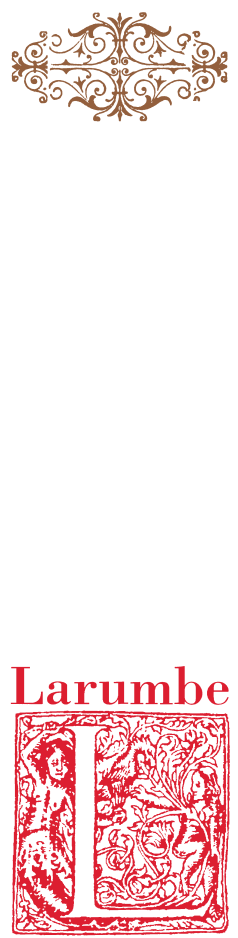

El legado de los Argensola 



\section{El legado de los Argensola}

Edición de Jesús Gascón Pérez

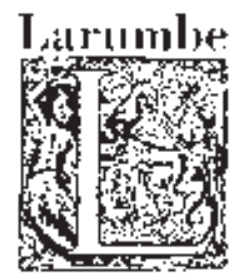

Prensas Universitarias de Zaragoza

Instituto de Estudios Altoaragoneses

Instituto de Estudios Turolenses

Depto. de Educación, Cultura y Deporte del Gobierno de Aragón 
El LEGADO de los Argensola / edición de Jesús Gascón Pérez. — Zaragoza : Prensas Universitarias de Zaragoza, 2009

153 p. ; $24 \mathrm{~cm}$. - (Larumbe : textos aragoneses)

Reprod. facs. de los testamentos otorgados por Lupercio y Bartolomé Leonardo de Argensola

Bibliografía: p. 34-39. - ISBN 978-84-92774-58-6

1. Leonardo de Argensola, Lupercio-Testamento. 2. Leonardo de Argensola, Bartolomé-Testamento

GASCÓN PÉREZ, Jesús

929Leonardo de Argensola, Lupercio

929Leonardo de Argensola, Bartolomé

(c) Jesús Gascón Pérez

(C) De la presente edición, Prensas Universitarias de Zaragoza, Instituto de Estudios Altoaragoneses, Instituto de Estudios Turolenses y Departamento de Educación, Cultura y Deporte del Gobierno de Aragón

1. a edición, 2009

Prensas Universitarias de Zaragoza. Edificio de Ciencias Geológicas, c/ Pedro Cerbuna, 12. 50009 Zaragoza, España. Tel.: 976761 330. Fax: 976761063

puz@unizar.es http://puz.unizar.es

Instituto de Estudios Altoaragoneses (Diputación de Huesca), c/ Parque, 10. 22002 Huesca, España. Apartado postal 53. Tel.: 974294 120. Fax: 974294122

iea@iea.es http://www.iea.es

Instituto de Estudios Turolenses (Diputación de Teruel), c/ Amantes, 15, 2. ${ }^{a}$ planta. 44001 Teruel, España. Tel.: 978617 860. Fax 978617861

ieturolenses@dpteruel.es http://www.ieturolenses.org

Departamento de Educación, Cultura y Deporte del Gobierno de Aragón. Edificio Pignatelli, paseo María Agustín, 36. 50004 Zaragoza, España

Impreso en España

Imprime: INO Reproducciones, S.A.

D.L.: Z-4108-2009 


\section{El legado patrimonial de «los Leonardos» a través de sus testamentos}

Jesús Gascón Pérez 

El testamento [...] nos pone en relación con la doble preocupación que rodea a los hombres ante su inminente tránsito a la otra vida. El ser humano [...] trata de poner en orden su vida con el fin de presentarse ante Dios con las manos lo más repletas posibles de buenas acciones. Por ello intentará redimir sus culpas y crearse un seguro espiritual mediante el encargo de oficios religiosos que le ayuden a borrar los males cometidos en la vida; pero simultáneamente se encargará de asegurar [...] la asistencia material de los seres que le rodearon durante su permanencia en este mundo, como otro medio más de agradar a Dios y favorecer la redención de su alma. ${ }^{1}$

Sin lugar a dudas, uno de los documentos más trascendentales que generan los seres humanos a lo largo de su vida es su testamento. No en vano, como se explica en el pasaje citado, este respondía a un doble estímulo, derivado de las creencias religiosas y de los intereses materiales de los testadores. Si las primeras aconsejaban preparar el camino hacia la otra vida, los segundos exigían planificar cuidadosamente la conservación del patrimonio familiar. Así, las últimas voluntades, lo mismo que las capitulaciones matrimoniales, resultaban instrumentos fundamentales para realizar tal planificación.

1 Testón Núñez (1983), p. 375. 
De este modo, la trascendencia de los testamentos afecta a lo terrenal tanto como a lo espiritual. En concreto, al detenerse en las edades media y moderna el investigador debe tener siempre presente el fuerte componente religioso que impregnaba la mentalidad de aquellas épocas. En este sentido, las últimas voluntades del testador forzosamente habían de incluir una serie de cláusulas destinadas a facilitarle su tránsito hacia el Más Allá y asegurarle un lugar entre los bienaventurados. Para lograr este objetivo, debía abandonar el mundo terrenal sin cuentas pendientes, y el testamento era el instrumento adecuado para saldarlas y aun para sumar nuevos méritos que le garantizasen el disfrute de la gracia reservada a los buenos cristianos tras la muerte. Por ello, como explica María Luz Rodrigo Estevan,

Los manuales de «bien morir», la presencia de clérigos, la continua repetición de oraciones e invocaciones divinas, la recepción de sacramentos, las imágenes de crucifijos, santos y escapularios, las velas encendidas, la concesión de perdones,... todo contribuía a transmitir la fortaleza necesaria al agonizante en sus últimos momentos y a alejar del lecho del moribundo a cualquier espíritu maligno. El descargo de la conciencia se completaba con el acto de testar. ${ }^{2}$

2 Rodrigo Estevan (2002), p. 33. 
Dicho acto, pues, se realizaba de modo habitual en la antesala de la muerte, pero tampoco era infrecuente que una persona tratase de anticiparse e hiciese testamento cuando concurrían en ella circunstancias que podían entrañar un riesgo para su vida. Así, como indica María del Carmen García Herrero, si bien «resulta abrumadora la mayoría que testa porque está enferma », también hacían uso de esta facultad quienes se preparaban para realizar un viaje - siendo especialmente reiterado el caso de las peregrinaciones-, quienes, aun gozando de buena salud, temían la cercanía de la muerte por su avanzada edad o, en el caso de las mujeres, aquellas que preveían un parto difícil. ${ }^{3}$

Para valorar en su justa medida la importancia que hombres y mujeres concedían en el Medievo y la Edad Moderna a la disposición de su última voluntad (y, por tanto, la gravedad que entrañaba el no poder manifestarla a tiempo), conviene preguntarse, como hace la misma investigadora, por las razones que les llevaban a testar. ${ }^{4}$ Entre ellas, la primera parece más que evidente: porque poseían algo que legar. Pero no se trataba solo de eso. Otra razón no menos importante era que se pretendía evitar problemas entre hijos y parientes por causa del reparto de los bienes familia-

3 García Herrero (1984), p. 210-211.

4 A este respecto, véase también Rodrigo Estevan (2002), pp. 53-60. 
res, algo, según explicó ya Philippe Ariès, asumido como un deber de conciencia reafirmado por el hecho de que «Morir intestado es origen de condena social pues es preciso intentar la continuidad evitando la ruptura dentro del orden de la familia». ${ }^{5} \mathrm{~A}$ estas razones se suma una tercera: el empeño en que se cumplieran una serie de mandatos que quizá no hubieran sido atendidos si no se hubieran puesto por escrito. Y por si esto fuera poco, como explica García Herrero, «Si bien la concordia de la unidad familiar y la seguridad de la propia intención cumplida son dos motivos de peso para hacer testamento, la salvación eterna y el logro de un sitio para el alma en el Paraíso constituyen el principal móvil del testador $\gg .{ }^{6} \mathrm{~A}$ la vista de estas consideraciones, queda claro que

En el testamento se disponía el reparto de los bienes para cuando no sirviesen al testador; pero con un matiz importante: una buena parte de esos bienes los aprovecharía el mismo testador en forma de oraciones, misas, y limosnas, pues las mandas pías ocupaban un lugar importantísimo entre sus disposiciones. Así, el testamento era considerado como un «pasaporte para el Cielo», según expresión de Le Goff, al disponerse de los bienes materiales en beneficio del alma cuando ya no podían aprovechar al cuerpo. ${ }^{7}$

5 García Herrero (1984), p. 212, donde se cita la obra La muerte en Occidente del investigador francés.

6 Ibídem, p. 213.

7 Cantera Montenegro (1986), p. 111. 
Desde este punto de vista, no debe extrañar que los investigadores hayan encontrado en los testamentos algo más que una mera fuente instrumental que nos ofrece información que ayuda a completar la biografía o la genealogía de los personajes históricos que los dictaron. Más allá de este «uso pasivo», por no decir «ingenuo», de las fuentes, circunscrito a la extracción de datos sueltos contenidos en ellas, una importante corriente historiográfica, particularmente fructífera desde la década de 1970, se ha interesado por las actitudes de los hombres ante la muerte y por los ritos funerarios derivados de ellas, lo cual ha llevado a analizar de forma seriada distintos tipos de documentos, entre ellos los testamentos. Convertida de este modo en «objeto autónomo de investigación $\gg,{ }^{8}$ esta fuente se ha revelado de gran riqueza, pues ha permitido realizar estudios sobre temas tan interesantes como «los gestos, imágenes y ritos funerarios, la religiosidad y piedad populares, los elementos mágicos y supersticiosos, los lugares de enterramiento o los modelos de muerte $\gg .{ }^{9}$ En suma, como explica otra investigadora especializada en esta línea de trabajo,

8 La expresión es empleada por Castro Cuenca y Aranda Pérez (1991), p. 65.

9 Rodrigo Estevan (2002), p. 11. En las páginas precedentes, la autora presenta una sucinta revisión historiográfica sobre el asunto, con indicación de estudios en los que obtener más información al respecto. Véase también, para la Edad Moderna, Testón Núñez (1983), pp. 371-372. 
Desde el siglo XI al XIV, en el que se difunde la práctica social [de testar], hasta comienzos del siglo XIX y quizás hasta la época contemporánea, el testamento proporciona un «soporte formal homogéneo» para estudiar los comportamientos sociales y mentales ante la muerte. Sus mandas pueden llevar a conclusiones en lo que se refiere a la evolución en la historia de la religiosidad, del amor, de las devociones, de la vida material y particularmente de la muerte. ${ }^{10}$

Teniendo en cuenta lo escrito hasta aquí, se ha de advertir que la pretensión de estas líneas no es tan ambiciosa como para elevar a categoría general su contenido. Al fin y al cabo, no tienen otro objetivo que servir de acompañamiento a la edición de los testamentos de dos aragoneses universales que vivieron a caballo de los siglos XVI y XVII, los hermanos Lupercio y Bartolomé Leonardo de Argensola, cuyos dos apellidos — conviene aclararlo aquí- son usados, tanto juntos como por separado, de modo indistinto en la documentación de la época para identificarlos, si bien en nuestros días el uso común ha acabado por preterir la filiación paterna en beneficio de la materna.

Dicho esto, quizá sea conveniente advertir al lector que ni los Argensola ni su obra han sido hasta la fecha objeto de muchos estudios. Como ha expuesto recientemente Isabel Pérez Cuenca,

10 Gómez Nieto (1991), p. 313. 
pese a la atención que les dispensaron sus coetáneos, bien perceptible en las numerosas copias manuscritas de su obra que circularon en su época, «parecen estar algo olvidados por la crítica moderna ». ${ }^{11}$ Por lo que a sus biografías se refiere, solo cabe sumar un trabajo reciente ${ }^{12}$ a los publicados desde el último cuarto del siglo XVIII hasta mediados del XX por Pellicer, Latassa, De la Sala, Mir, Aznar Molina, Green y Oliván Baile. ${ }^{13}$ En cuanto a su obra poética, la edición más actual de las Rimas sigue siendo la que con excelencia preparó Blecua hace más de media centuria. ${ }^{14}$ Otros escritos literarios, como los diálogos, sátiras, epístolas y tragedias, han tenido algo más de fortuna, pero, pese a ello, el repertorio de textos reunido por el conde de la Viñaza a fines del siglo XIX solo se ha visto aumentado en el $\mathrm{xx}$ por un puñado de estudios. ${ }^{15} \mathrm{Y}$ por lo que respecta a su obra historiográfica, a las escuetas aportaciones hechas en su día por Del Arco, Green y Delgado, solo es posi-

11 Pérez Cuenca (2007), p. 410.

12 Catalán Marín (2006).

13 Pellicer y Saforcada (1778), Latassa y Ortín (1798-1802), De la Sala Valdés (1882), Mir y Noguera (1891), Aznar Molina (1939), Green (1933) y (1945) y Oliván Baile (1959).

14 Blecua Teijeiro (ed.) (1950-1951) y, después, Blecua Teijeiro (ed.) (1972) y (1974). También hay que mencionar el breve apunte bibliográfico de Dadson (1986-1987).

15 Sin afán de ser exhaustivo, citaré aquí, junto a Viñaza (ed.) (1887) y (1889), las obras de Green (1935) y (1956-1957), Blecua Teijeiro (1983), Gotor López (ed.) (1984), Schwartz Lerner (1993) y (1998), Ezpeleta Aguilar (1993), (1997) y (1998), Sánchez Laílla (1999), Giuliani (2000), Marina Sáez et álii (2002) y Pérez Cuenca (2007). 
ble añadir unos pocos trabajos más, debidos a Lorente Usán, Colás Latorre y Gil Pujol, ${ }^{16}$ y sendas ediciones de tres de sus tratados (la Información, de Lupercio, y la Conquista de las islas Malucas y las Alteraciones populares de Zaragoza, de Bartolomé), todas ellas aparecidas en la primera mitad de la década de $1990 .{ }^{17}$

A la vista de tan parca bibliografía, merece reseñarse que entre los títulos publicados es posible hallar sendas transcripciones de los dos testamentos que ahora se reproducen. El de Bartolomé fue incluido como cuarto apéndice de la biografía que le dedicó a fines del siglo XIX el padre Miguel Mir, ${ }^{18}$ mientras que el de Lupercio fue transcrito en 1959 por Francisco Oliván Baile, que lo publicó con una breve introducción en la revista Argensola, editada por el entonces denominado Instituto de Estudios Oscenses. ${ }^{19}$ Este mismo centro, cuyo nombre ha cambiado al actual de Instituto de Estudios Altoaragoneses, ha promovido con Prensas Universitarias de Zaragoza la presente edición conjunta de ambas piezas, proyecto que se incluye dentro de las actividades previstas para conmemorar, en este año 2009, el 450 aniversario del nacimiento del mayor de los hermanos Argensola.

16 Del Arco y Garay (1941) y (1950), Green (1952), Delgado León (1979), Lorente Usán (1990), Colás Latorre (1991) y (1995) y Gil Pujol (1991).

17 L. Leonardo de Argensola (1991) y B. Leonardo de Argensola (1992) y (1995).

18 Mir y Noguera (1891), pp. 124-134.

19 Oliván Baile (1959). 
A la hora de preparar este volumen se ha elaborado una nueva transcripción a la vista de los testamentos originales, que se conservan en el Archivo Histórico de Protocolos Notariales de Zaragoza, ${ }^{20}$ si bien, como no podía ser de otra manera, se han tenido en cuenta los trabajos previos de Mir y Oliván Baile. También se ha utilizado una copia del testamento de Bartolomé de Argensola que se custodia en el Archivo Diocesano de Barbastro y que incluye, además de sus últimas voluntades, una insolutundación que establece el cumplimiento de una de sus cláusulas, la relativa al pago de 20000 sueldos jaqueses al notario barbastrense Miguel de Pilares. Dado que en la presente publicación se ofrece la reproducción fotográfica de ambos testamentos, se ha optado por transcribir su texto actualizando la ortografía y la puntuación, como modo de facilitar su consulta por el lector actual. Y con el mismo fin, se indican a continuación una serie de asuntos relevantes por lo que hace a la naturaleza y al contenido de los documentos ahora editados.

En primer lugar, llama la atención su temprana redacción si se tiene en cuenta el tiempo transcurrido entre esta y el óbito de los testadores. Así, Lupercio de Argensola dictó sus últimas voluntades

20 En concreto, el testamento de Lupercio de Argensola se encuentra en el Archivo Histórico de Protocolos Notariales de Zaragoza, Diego Fecet, 1613, f. 530v-539, y el de su hermano Bartolomé, en el mismo fondo, Juan Jerónimo Navarro, 1631, f. 549v-573. En adelante citaré ambos documentos, respectivamente, como «Lupercio»y «Bartolomé», con indicación del folio correspondiente. 
el 18 de marzo de 1610, en vísperas de su viaje a Nápoles como secretario del conde de Lemos, y precisamente falleció en esta ciudad el 2 de marzo de 1613, mientras que su hermano testó el 17 de agosto de 1616 y no murió hasta el 4 de febrero de 1631. Por tanto, entre las fechas de los testamentos y las de las muertes median casi tres años justos en el primer caso, y algo menos de catorce años y medio en el segundo. Un espacio de tiempo desacostumbrado, pues lo habitual es que haya más proximidad entre el acto de testar y el fallecimiento, sobre todo cuando, como hizo Bartolomé, ejecutó aquel «estando con alguna indisposición de mi persona». ${ }^{21}$ Pese a ello, una vez recuperado de su enfermedad ya no introdujo modificaciones en las cláusulas estipuladas ni llegó a dictar otro testamento posterior, algo que tampoco hubiera resultado extraño en aquella época.

En ambos casos se trata de testamentos cerrados, es decir, redactados por los interesados y puestos en manos del notario «en una plica de papel cosida, cerrada y sellada $\gg .{ }^{22}$ Para guardar todas las formalidades, dicha plica se entregó en presencia de dos testigos, «cerrada y alrededor con hilo blanco cosida y con dos sellos en hostia colorada sobre papel impresos en el dorso de la dicha y presente plica sellada ${ }^{23}$ y el notario se obligó a conservarla in-

21 «Bartolomé», f. 554.

22 «upercio», f. 531, y «Bartolomé», f. 551-551v.

23 «upercio», f. 533 . La fórmula utilizada es prácticamente idéntica en «Bartolomé», f. 553. 
tacta hasta el momento de ser abierta por muerte del testador. El depositario de los dos testamentos fue Diego Fecet, uno de los principales notarios zaragozanos, cuyos protocolos recogen abundantes instrumentos públicos emanados de la nobleza, el alto clero y las principales familias de la burguesía de la capital. De hecho, Fecet fue quien abrió el testamento de Lupercio de Argensola el 6 de mayo de 1613, a petición del cuñado del fallecido, micer Jusepe Trillo, tras aportar este el acto público de su muerte, hecho el 2 de marzo del mismo año por el notario napolitano Andrea Fasano. La muerte impidió a Fecet cumplir el mismo papel en el momento de fallecer Bartolomé de Argensola. De hecho, la última voluntad de este quedó, como el resto de sus papeles y notas, en poder de Juan Jerónimo Navarro, que fue el encargado de darle pública lectura el 4 de febrero de 1631, en esta ocasión a requerimiento del sobrino del finado, Gabriel Leonardo de Albión.

Otro dato de interés es que el testamento de Lupercio de Argensola tiene carácter mancomunado, pues lo firmó juntamente con su esposa, doña Mariana Bárbara de Albión. De hecho, entre los siglos XVI y XIX fue esta una práctica relativamente habitual entre los matrimonios aragoneses, y aun con posterioridad, como explica Elena Bellod Fernández de Palencia, ha sido siempre admitida por la legislación aragonesa, incluso en contra del criterio recogido en el Código Civil, que «consideró que era una figura incómoda, que podía plantear problemas y la condenó alegando, 
entre otras razones, una posible captación de voluntades de los cónyuges otorgantes». ${ }^{24}$ En el caso que nos ocupa, quedan al albedrío del cónyuge superviviente asuntos tan importantes como la elección del lugar de enterramiento, la determinación del número de misas y sacrificios a realizar «por sufragio del alma y en remisión de los pecados del premoriente», el pago de las deudas pendientes y el disfrute de los bienes de la unidad familiar en condición de heredero universal, aunque, eso sí, «con cargo, pacto, vínculo y obligación que el tal sobreviviente haya de disponer y ordenar de todos los bienes del premoriente en el dicho Gabriel Leonardo de Albión, nuestro hijo, o en hijos o descendientes de aquel, en el tiempo y con los pactos y condiciones, vínculos y cargos y así según y de la manera que al tal sobreviviente y heredero del premoriente parecerá $\gg .{ }^{25}$

Curiosamente, el testamento de los Leonardo Albión resulta de lo más escueto. No incluye ninguna relación de los bienes que componen su patrimonio, «los cuales queremos aquí haber y habemos por nombrados y confrontados $\gg,{ }^{26} \mathrm{ni}$ especifica las deudas contraídas, ni establece el modo de abonarlas. Tan solo es

24 Bellod Fernández de Palencia (1997), pp. 22-23. Rodrigo Estevan (2002), p. 69, cifra la cantidad de testamentos mancomunados en un $20 \%$ del total de documentos consultados para elaborar su estudio.

25 «upercio», f. 536v-537.

26 Ibídem, f. 536v. 
posible encontrar una vaga mención a la cancelación de las obligaciones contraídas con Lupercio Leonardo de Argensola por el duque de Villahermosa don Fernando de Aragón y por micer Juan Jerónimo de Espés y Sola, ${ }^{27}$ así como una cláusula genérica que establece el modo de satisfacer el derecho de legítima herencia de sus hijos y de «cualesquiera otras personas que parte y derecho de legítima herencia en los dichos nuestros bienes puedan pretender, haber y alcanzar»: a cada uno de ellos se le entregarían 5 sueldos por los bienes muebles y una arroba de tierra en los montes comunes de la ciudad por los bienes sitios. ${ }^{28}$

Entre los pocos nombres propios reflejados, lógicamente aparecen los de los dos hijos de los testadores: Gabriel Leonardo de Albión, «nuestro amado y único hijo», ${ }^{29}$ fruto de su matrimonio, celebrado en 1587, y Jerónima Zaporta, «hija de mí, la dicha doña Mariana de Albión $\gg,{ }^{30}$ nacida en 1575 de un enlace anterior: el concertado en 1574 con el mercader e infanzón Luis Zaporta, fallecido en 1581. De ellos sabemos que Gabriel casó en 1620 con Juana del Barrio, con quien tuvo un hijo, Miguel, y que Jerónima, a su vez, se desposó en 1591 con Alonso Luis de Villalpando, a quien sobrevivió, pues murió hacia 1650, mientras que su esposo lo

27 Ibídem, f. 535-535v.

28 Ibídem, f. 536. Una cláusula idéntica, en «Bartolomé», f. 557.

29 «upercio», f. 536.

30 Así se la identifica ibídem, f. 536 y 537v. 
hizo en $1630 .{ }^{31}$ Llama la atención que el nombre de Jerónima fuese incluido a posteriori en la cláusula relativa al derecho de legítima herencia, como lo denota el hecho de que aparezca interlineado y escrito de mano distinta a la que compuso el cuerpo del texto, ${ }^{32}$ y que también de mano distinta se añadieran dos cláusulas tras el párrafo que comienza «Este es nuestro último testamento [...]», fórmula con la que suele concluir este tipo de documentos. Los beneficiarios de dichas cláusulas fueron la citada Jerónima Zaporta, a quien se lega «una joya de oro o plata de valor de doscientos ducados o el precio de ella, lo que ella más quisiere», y la iglesia de Nuestra Señora de la Sagrada, del lugar de Monzalbarba, a la que se dejan 400 sueldos «para la cosa más necesaria que entonces se ofreciere a juicio y voluntad del capítulo de la cofradía de la Sagrada, con intervención del vicario del dicho lugar». ${ }^{33}$

Más extenso y rico en información es el testamento de Bartolomé Leonardo de Argensola, que comienza, como el de su hermano mayor, con la invocación del favor de Dios y la súplica de que acoja su alma en la gloria. ${ }^{34}$ Como se explicó líneas atrás, en las épocas medieval y moderna lo religioso tenía una gran importan-

31 Tomo estos datos de Gómez Zorraquino (1987), pp. 44-45. La fecha del matrimonio de Gabriel Leonardo, es mencionada por Blecua Teijeiro (ed.) (1972), p. XVII.

32 «upercio», f. 536.

33 Ibídem, f. 537v.

34 «Bartolomé», f. 554-555v. Cf. «Lupercio», f. 534-534v. 
cia como medio de asegurarse la gracia divina. Así, no es extraño que Bartolomé, habida cuenta de su condición de canónigo de la Seo zaragozana, disponga este templo metropolitano como lugar para su enterramiento y dedique varias cláusulas a ordenar medidas en descargo de su conciencia. La primera, la celebración de mil misas «por sufragio de mi alma y en remisión de mis pecados». La segunda, la fundación de cuatro aniversarios perpetuos: uno en favor de su hermano Lupercio, y tres en favor del propio testador y de sus padres y hermanos. La tercera, el encargo de mil misas en sufragio del alma del duque de Villahermosa don Fernando de Aragón. La cuarta, la entrega de 2000 sueldos jaqueses a los pobres del Hospital Real y General de Nuestra Señora de Gracia y sendas partidas de 200 sueldos a cada uno de los hospitalicos de niños y niñas huérfanos de la ciudad de Zaragoza, a la capilla de la Madre de Dios del Pilar y al monasterio de Nuestra Señora de Montserrat. La quinta, el reparto de limosnas entre los pobres por valor de 10000 sueldos, a discreción de los ejecutores de su última voluntad. ${ }^{35} \mathrm{Y}$ la última, la donación a los principales templos zaragozanos de cuatro viriles de cristal que le remitía desde Milán el hijo del conde de Benavente: dos habían de entregarse a la Seo y otros dos a la iglesia de Nuestra Señora del Pilar. En ambos casos

35 «Bartolomé», f. 555v-556v. A los 4000 sueldos establecidos en la séptima cláusula del testamento, Argensola añade otros 6000 en la disposición final, «de manera que en todo sean diez mil sueldos» (ibídem, f. 570v-571). 
debían emplearse «para que sirvan al Santísimo Sacramento», exponiéndolo en ellos. ${ }^{36}$

En cuanto a los bienes materiales, Bartolomé Leonardo de Argensola nombró heredero universal a su sobrino Gabriel, de quien se ha hablado en párrafos precedentes, y dispuso que se devolvieran algunas pertenencias a su hermana Ana María, a quien legó además 20000 sueldos jaqueses, «los cuales mis ejecutores infrascritos le hayan de asignar y dar en uno de los mejores censales que yo tuviere», con la prevención de establecer que, en caso de disolverse su matrimonio con el antes citado Jusepe Trillo, dicho censal se transmitiese íntegro a sus herederos. Y no acaban aquí las atenciones para con su hermana, pues además estipuló que los ejecutores de su testamento le consignasen, en caso necesario, una renta vitalicia «para ayuda de su vivienda y gastos», con la facultad de disponer que su marido la disfrutase en todo o en parte en caso de que ella muriese antes que él. ${ }^{37}$

También tuvo en mente a los hijos de Isabel Tudela (hermana de su madre, Aldonza Tudela de Argensola), a quienes destinó otros 20000 sueldos, encargando a sus ejecutores testamentarios que los repartiesen entre aquellos «atendiendo a la necesidad y

37 Ibídem, f. 555-556. 
virtud que cada uno de ellos tuviere». ${ }^{38}$ Otras partidas de dinero fueron para el notario barbastrense Miguel de Pilares (20 000 sueldos), Ángela de Requeséns (2000 sueldos), el notario real Jerónimo Requeséns (1000 sueldos), su criado Pedro Monroy (2000 sueldos), «por lo bien que me ha servido», ${ }^{39}$ y los criados y criadas de su hermana (600 sueldos) que le estaban atendiendo durante su enfermedad, «por el trabajo que en ella tienen».40

Igualmente dispuso la satisfacción de «todas mis deudas, aquellas que por buena verdad constará que yo deberé a cualesquiera persona o personas, en cualquiera manera y por cualquiera causa o razón », ${ }^{41}$ y dejó instrucciones especiales a su cuñada doña Mariana de Albión para que comprobase si se había extinguido su deuda con la dama napolitana doña Isabel del Campo, que ascendía a cincuenta ducados en moneda de dicho reino, y, en caso de ser necesario, «se le paguen luego de mis bienes».42 Mención aparte merece la cláusula relativa a la reclamación del doctor Juan Berbegal, canónigo de la Seo, que pretendía recuperar los 2000 sueldos que tiempo atrás había confiado a Bartolomé de Argensola para que los entregase en Madrid a su hermano, el capitán Berbegal,

38 Ibídem, f. 558v-559.

39 Ibídem, f. 561.

40 Ibídem, f. 571v.

41 Ibídem, f. 556v.

42 Ibídem, f. 562v-563. 
pues, según él, nunca llegaron a manos de este. Sobre dicho asunto, Argensola confiesa que «no tengo ninguna noticia, acuerdo ni memoria », pero, ante la duda, y a fin de evitar la posibilidad de abandonar el mundo de los vivos con esta cuenta pendiente, perspectiva que, como se ha dicho líneas atrás, resultaba terrible en la época, estipula lo siguiente:

[...] pero tampoco quiero que por razón de ello me quede ningún género de escrúpulo, por tanto, quiero que en razón de los dichos dos mil sueldos se haya de estar y esté a lo que el dicho doctor Juan Berbegal dijere, de manera que si él dijere que tiene satisfacción que los dichos dos mil sueldos no fueron pagados al dicho capitán Berbegal, su hermano, se le paguen luego a él. ${ }^{43}$

A continuación conviene mencionar algunos bienes citados en el legado del menor de los Argensola. Sin afán de ser exhaustivo, podemos encontrar una medalla de oro con la efigie en relieve del papa Paulo V, dotada con «muchas indulgencias», ${ }^{44}$ un relicario con una cadenilla de oro, quince piedras ornamentales y un conjunto de joyas cuya custodia encomienda a su hermana y su sobrino, con el fin de que este, en el momento de contraer matrimonio, las diese «en señal de amormío a la mujer con quien se casare». Los objetos que integran esta partida son «un relojico que tengo de

44 Ibídem, f. 559v. 
Milán, labrado de cristal y muy curioso», «un librico de oro esmaltado», una cadena de broches con sesenta piezas, un relicario de oro esmaltado en el que se representa a san Jerónimo, y seis sortijas: cuatro de esmeraldas, una con un diamante y «otra que tengo de un camafeo que se hubo de la almoneda del rey nuestro señor y tiene el retrato de la majestad del rey don Felipe Segundo». ${ }^{45}$

Dejando aparte el ajuar de su casa, se mencionan algunas prendas interesantes, como «una ropa que tengo de damasco aforrada en martas $\gg,{ }^{46}$ varias piezas de tela de Cambrai y unos ceñidores traídos de Italia, que destina a los sacristanes y ministros de la sacristía de la Seo. Junto a estos enseres encontramos un cuadro de la Adoración de los Reyes que Argensola dice tener en particular estima, por lo cual lo lega a su sobrino encareciéndole que «lo deje vinculado al que fuere señor de su casa y a los que le sucedieren en ella $\gg,{ }^{47}$ y se mencionan también las reliquias, bálsamos, rosarios, cosas de olores y otros efectos procedentes de Italia, aunque aclarando que «son más de curiosidad que de valor». ${ }^{48}$

Capítulo aparte merecen los libros y papeles, comenzando por «mi breviario con que rezo», que Argensola lega al arzobispo

45 Ibídem, f. 562-562v.

46 Ibídem, f. 560v.

47 Ibídem, f. 564.

48 Ibídem, f. 561. 
de Zaragoza por derecho de legítima. ${ }^{49}$ Otros $\ll$ dos breviarios primero y segundo, muy curiosos y buenos, que vienen entre mis libros», fueron para el canónigo de la Seo don Enrique de Castro, mientras que otro miembro de dicho capítulo eclesiástico, el licenciado Juan Pérez de Artieda, recibió «un Tertuliano que tengo con comento de Pamelio.$^{50}$ Un ciudadano zaragozano, Martín Lamberto Íñiguez, fue el destinatario de «todas las obras que tengo del Marín y las vulgares italianas que vienen en las gavetas de mi escritorio grande de ébano». ${ }^{51} \mathrm{Y}$ a la duquesa de Villahermosa doña Juana de Pernstein (Pernestán, en el original) se consignó un breviario forrado de terciopelo carmesí. Dicho breviario había pertenecido a la madre de la duquesa, doña María Manrique, y otra de sus hijas, la princesa de Caserta, se lo había regalado a Bartolomé. En sus últimas voluntades, este dispuso que se hiciera llegar a doña Juana para que lo entregase a la infanta Margarita o a una tercera hija de su anterior poseedora, la religiosa sor Luisa de las Llagas. ${ }^{52}$

Resulta de interés comprobar que en el momento de testar Bartolomé de Argensola seguía atento a sus obligaciones como

49 Ibídem, f. 557-557v.

50 Ibídem, f. 559v.

51 Ibídem, f. $559 \mathrm{v}-560$.

52 Ibídem, f. 561-561v. Las mujeres aludidas son la infanta Margarita de Austria, hija de la emperatriz María, y doña Luisa de Pernstein, hermana de la duquesa de Villahermosa. Ambas eran monjas profesas en el convento de las Descalzas Reales, donde se había retirado la emperatriz, y se da la circunstancia de que tomaron los hábitos juntas. Cf. Gascón Pérez (2008), pp. 192-193. 
cronista, que meses atrás le habían llevado a censurar el segundo volumen de los Consejos del marqués de Murcone (Morcón, en el original) cuando descubrió en él un pasaje «muy perjudicial al presente reino de Aragón», relacionado con la rebelión de 1591 contra Felipe II. Pendiente como estaba de que el marqués enmendase su escrito, dejó instrucciones sobre el modo de proceder en caso de que enviase un texto alternativo. ${ }^{53} \mathrm{Y}$ si de libros y escritos hablamos, forzoso es citar la cláusula donde el ya ex secretario del virrey de Nápoles encomendó a su sobrino que recogiese «todos los registros, cartas, cosas y papeles» relacionados con el desempeño de tal oficio, a fin de conservarlos por si se le exigiera rendir cuentas de su actuación. En la segunda parte de la misma cláusula, Argensola añadió el siguiente mandato, relativo a sus escritos literarios o, como él dice, «de buenas letras»:

Y asimismo quiero que el dicho mi sobrino recoja todos los demás papeles que tengo de buenas letras y que yo, por mi particular curiosidad y gusto, he trabajado, los cuales quiero que guarde para sí y su entretenimiento, sin que se esparzan ni vayan a manos ajenas. Que en fe de esto, no mando que se quemen todos. ${ }^{54}$

53 «artolomé», f. 563v-564. Se trata de la obra Consiliorum sive Juris responsorum volumen secundum, publicada en Nápoles en 1616. Sobre este asunto, véase Gascón Pérez (2000), vol. I, pp. 196-198.

54 «artolomé», f. 566v-567. 
Por último, conviene indicar que los testamentos de los Argensola, y en particular el de Bartolomé, nos ofrecen información sobre su círculo de parientes, amistades y relaciones personales. Entre los destinatarios de sus mandas encontramos a hombres y mujeres con quienes trataron en vida, llegando en ocasiones a forjar vínculos muy estrechos. De hecho, de las noticias mencionadas en las líneas precedentes se infiere sin dificultad la cercanía de ambos hermanos a la casa de Villahermosa. Sabido es que Lupercio fue secretario del quinto duque, don Fernando de Aragón (1546-1592), quien también tuvo al hermano menor a su servicio como rector de la parroquia de la localidad que daba nombre a su estado. Como hemos visto, el duque mereció ser recordado por ambos testadores y Bartolomé dispuso que a su viuda, doña Juana de Pernstein (1566-1631), se le devolviese un breviario que había pertenecido a su madre.

La prolongada relación entre los Argensola y los Villahermosa pudo comenzar a forjarse a raíz de la actuación del padre de los primeros, Juan Leonardo, como secretario del emperador Maximiliano II (1527-1576)..$^{55}$ En la corte imperial coincidió con el noble bohemio Wratislaw de Pernstein (1530-1582), canciller de la corona de Bohemia, y con su esposa, la citada doña María Manrique, 
camarera mayor de la emperatriz María de Austria (1528-1603). Y allí pudo conocer también a la hija de ambos, que entró al servicio de la emperatriz y la acompañó en su viaje de regreso a España en 1582. De hecho, ambas llegaron juntas hasta Zaragoza, donde se celebraron los esponsales de doña Juana con don Fernando de Aragón, en los que María de Austria fue quien hizo la entrega de la novia. ${ }^{56}$ Así pues, parece más que probable que la nueva duquesa de Villahermosa pudiera tener un papel decisivo a la hora de favorecer la entrada de los hijos de Juan Leonardo al servicio de su esposo, del mismo modo que, tras la muerte de este en 1592, facilitó su acceso al círculo cortesano formado en torno a la emperatriz en su retiro del convento de las Descalzas Reales. Dicho círculo, por otra parte, resultó un apoyo fundamental para que la casa ducal aragonesa recuperase la confianza de la corte tras el castigo sufrido por don Fernando por su implicación en la rebelión de 1591 y para lograr integrarse en las redes de poder tejidas sucesivamente por el duque de Lerma y el conde duque de Olivares en el siglo XVII..$^{57}$

Teniendo en cuenta esta información, no es de extrañar que en una de las últimas cláusulas de su testamento Bartolomé de Argensola suplique a la duquesa de Villahermosa y a sus hijos que reciban a su servicio a su sobrino, Gabriel Leonardo de Albión,

57 Sobre este asunto he llamado la atención en Gascón Pérez (2008), pp. 192-195. 
«reconociendo siempre que su padre y él y yo somos hechuras de las manos de sus excelencias $\gg .{ }^{58} \mathrm{Dicho}$ ruego se complementa con la petición de amparo y protección a los condes de Lemos, don Pedro Fernández de Castro (1576-1622) y doña Catalina de Rojas y Sandoval (1580-1648), a quienes además solicita que avalen a su sobrino ante el duque de Lerma (1553-1625), padre de la condesa, y doña Catalina de Zúñiga (1555-1628), madre del conde, «para que se le haga merced» en atención a sus buenas cualidades y al afán que tiene de servirles. ${ }^{59}$

En suma, como se expuso páginas atrás, con este tipo de cláusulas se trataba de garantizar el buen orden y la prosperidad de la propia familia, como medio de asegurarse la salvación. En este sentido, resulta de aplicación para la Edad Moderna el pasaje donde María Luz Rodrigo Estevan explica que

A través de las últimas voluntades, los hombres y mujeres del siglo XV tejieron una red de solidaridades, complementaria de la desarrollada en vida, que anulaba la separación entre el mundo de los vivos y el de los muertos. Los testadores deseaban ser recordados después de su muerte a través de misas, ofrendas y sacrificios en los que sus familiares, vecinos y parroquianos participaban. Lograron controlar la vida de los supérstites, mediante disposiciones que perduraban más allá de la propia muerte

58 «artolomé», f. 570v.

59 Ibídem, f. 569-570. 
y del paso de los años. En último término, el nombramiento de albaceas se convertía en un instrumento que reforzaba los vínculos solidarios, obligando de manera ineludible a los que todavía permanecían en este mundo a ocuparse de la salvación de aquellos que ya habían iniciado su viaje al Más Allá. ${ }^{60}$

A veces, sin embargo, los testadores no conseguían su objetivo. Así ocurrió en el caso de Bartolomé de Argensola, por mor del tiempo transcurrido entre la ordenación y la ejecución de sus últimas voluntades. De hecho, por la insolutundación antes aludida sabemos que en 1631 solo vivían dos de los ocho ejecutores testamentarios que había nombrado en 1616: su hermana y su sobrino. Para entonces también habían fallecido el conde de Lemos, su madre y el duque de Lerma. E igualmente habían muerto algunos beneficiarios de sus mandas testamentarias, como fray Jerónimo Batista de Lanuza (1553-1624). Así las cosas, mal pudieron cumplirse todas las disposiciones del testador, lo que evidencia el acierto de la fórmula que advierte: «como persona alguna en carne puesta de la muerte corporal escapar no pueda, y no haya en el mundo cosa alguna más cierta que la muerte, ni más incierta que su hora, la cual en el ánimo de todo fiel cristiano debe estar presente $[\ldots] \gg .^{61}$

60 Rodrigo Estevan (2002), p. 186.

61 «Bartolomé», f. 554. 


\section{Relación de obras citadas}

ARCO Y GaraY, Ricardo del (1941), «Dos manuscritos de la obra inédita de Bartolomé de Argensola Alteraciones populares de Zaragoza de 1591», Correo Erudito. Gaceta de las Letras y de las Artes, año II, entrega 5.a, pp. 175-177.

- (1950), «Una obra inédita de Bartolomé L. de Argensola sobre las alteraciones de Teruel y Albarracín en el siglo XVI», Teruel. Órgano Oficial de la Institución, n. ${ }^{\circ}$ 3, pp. 27-31.

Aznar Molina, Joaquín (1939), Los Argensola, Zaragoza, Librería General.

Bellod Fernández de Palencia, Elena (1997), El testamento mancomunado. Estudios de documentos notariales aragoneses desde el siglo XVI hasta la actualidad, Zaragoza, El Justicia de Aragón.

Blecua Teijeiro, José Manuel (1983), «Los Argensola: El lugar poético de Lupercio y la sátira de Bartolomé Leonardo», en Francisco Rico (dir.), Historia y crítica de la Literatura española, Barcelona, Crítica, t. III, pp. 705-710.

- (ed.) (1950-1951), Rimas de Lupercio y Bartolomé Leonardo de Argensola, Zaragoza, Institución «Fernando el Católico», 2 vols.

- (ed.) (1972), Lupercio Leonardo de Argensola, Rimas, Madrid, Espasa-Calpe.

- (ed.) (1974), Bartolomé Leonardo de Argensola, Rimas, Madrid, Espasa-Calpe, 2 vols.

Cantera Montenegro, Margarita (1986), «Religiosidad en la Rioja bajomedieval a través de los testamentos (siglos XIII-XV)», Berceo. Revista Riojana de Ciencias Sociales y Humanidades, n. ${ }^{\circ}$ 110-111, pp. 111-154. 
Castro Cuenca, Jesús, y Francisco José Aranda Pérez (1991), «El análisis del discurso. Una metodología para el estudio de la historia social en la Edad Moderna», en Santiago Castillo (coord.), La historia social en España. Actualidad y perspectivas. Actas del I Congreso de la Asociación de Historia Social, Zaragoza, septiembre 1990, Madrid, Siglo XXI, pp. 65-86.

Catalán Marín, María Soledad (2006), Los hermanos Argensola, [Zaragoza], UnaLuna.

COlÁs LATORRE, Gregorio (1991), «Las “revoluciones" de 1591 y Bartolomé Leonardo de Argensola», Cuadernos de Estudios Borjanos, vol. XXV-XXVI, pp. 109-187.

- (1995), «Bartolomé Leonardo de Argensola y la rebelión aragonesa de 1591», en Bartolomé Leonardo de Argensola (1995), pp. 7-79.

DADSON, Trevor J. (1986-1987), «Breve nota bibliográfica sobre Bartolomé Leonardo de Argensola y las "Rimas" de 1634», Cuadernos de investigación filológica, vol. XII-XIII, pp. 157-160.

Delgado León, Feliciano (1979), «Un nuevo manuscrito de Bartolomé Leonardo de Argensola», Archivo de Filología Aragonesa, vol. XXIV-XXV, pp. 275-283.

EzPeleta Aguilar, Fermín (1993), «Los diálogos lucianescos de Bartolomé Leonardo de Argensola y la tradición del género dialogal clásico», en José María Maestre Maestre y Joaquín Pascual Barea (coords.), Humanismo y pervivencia del mundo clásico. I. Actas del I Simposio sobre humanismo y pervivencia del mundo clásico, Alcañiz, 8 al 11 de mayo de 1990, Alcañiz, Instituto de Estudios Turolenses; Cádiz, Universidad de Cádiz, vol. I, pp. 441-449.

- (1997), «La traducción del diálogo de Alberti Virtus por Bartolomé Leonardo de Argensola», en José María Maestre Maestre, Luis 
Charlo Brea y Joaquín Pascual Barea (coords.), Humanismo y pervivencia del mundo clásico. II. Homenaje al profesor Luis Gil, Alcañiz, Ayuntamiento de Alcañiz; Cádiz, Universidad de Cádiz, vol. II, pp. 995-1003.

EzPeleta Aguilar, Fermín (1998), «El diálogo Dédalo, de Bartolomé Leonardo de Argensola», en Túa Blesa (ed.), Mitos. Actas del VII Congreso Internacional de la Asociación Española de Semiótica, celebrado en la Universidad de Zaragoza del 4 al 9 de noviembre de 1996, Zaragoza, Asociación Española de Semiótica, vol. II, pp. 306-313.

García Herrero, María del Carmen (1984), «La muerte y el cuidado del alma en los testamentos zaragozanos de la primera mitad del siglo XV», Aragón en la Edad Media, n. ${ }^{\circ}$ 6, pp. 209-245.

GASCÓN PÉREZ, Jesús (2000), La rebelión aragonesa de 1591, tesis doctoral, Zaragoza, Universidad de Zaragoza, 2 vols.

- (2008), «El reino de Aragón a principios del siglo XVII», en La Monarquia de Felipe III. Los reinos. Volumen IV, Madrid, Fundación MAPFRE-Instituto de Cultura, pp. 173-196.

Gil Pujol, Xavier (1991), «Lupercio Leonardo de Argensola, historiador, en la historiografía de su época», en Lupercio Leonardo de Argensola (1991), pp. VII-XLVIII.

GiUliani, Luigi (2000), Las tragedias de Lupercio Leonardo de Argensola, tesis doctoral, Barcelona, Universitat Autònoma de Barcelona.

GÓMEZ NiETo, Leonor (1991), «Los testamentos, fuente para la historia social», en Santiago Castillo (coord.), La historia social en España. Actualidad y perspectivas. Actas del I Congreso de la Asociación de Historia Social, Zaragoza, septiembre 1990, Madrid, Siglo XXI, pp. 311-313. 
GÓMEZ ZORRAQUINO, José Ignacio (1987), La burguesia mercantil en el Aragón de los siglos XVI y XVII (1516-1652), Zaragoza, Diputación General de Aragón.

Gotor LópeZ, José Luis (ed.) (1984), Bartolomé Leonardo de Argensola, Fortuna y providencia. Cuatro epistolas inéditas, Barcelona, Humanitas.

Green, Otis Howard (1933), «The Literary Court of the Conde de Lemos at Naples, 1610-1616», Hispanic Review. A Quarterly Journal Devoted to Research in the Hispanic Languages and Literatures, vol. I, n. ${ }^{\circ} 4$, pp. 290-308.

- (1935), «Notes on the Lucianesque Dialogues of Bartolomé Leonardo de Argensola », Hispanic Review. A Quarterly Journal Devoted to Research in the Hispanic Languages and Literatures, vol. III, pp. 275-294.

- (1945), Vida y obras de Lupercio Leonardo de Argensola, trad. de Francisco Ynduráin, Zaragoza, Institución «Fernando el Católico» [orig. ing., 1927].

- (1952), «Bartolomé Leonardo de Argensola y el Reino de Aragón», Archivo de Filología Aragonesa, t. IV, pp. 7-112.

- (1956-1957), «Cuerpo y alma en la "Carta a un Gran Personaje" (Postdata a AFA, IV, 32-37)», Archivo de Filología Aragonesa, vol. VIII-IX, pp. 175-177.

LATASSA Y ORTÍn, Félix de (1798-1802), Biblioteca nueva de los escritores aragoneses que florecieron desde el año de 1500 hasta 1599, Pamplona, Joaquín de Domingo, 6 vols. [hay reed., Zaragoza, Real Sociedad Económica Aragonesa de Amigos del País / Ibercaja, 2004, 5 vols.]

LeOnARdo de ARgensola, Bartolomé (1992), Conquista de las islas Malucas, Madrid, Miraguano / Polifemo [ed. orig., Madrid, Alonso 
Martín, 1609; hay reed. con pról. de Miguel Mir, Zaragoza, Imprenta del Hospicio Provincial, 1891].

LeONARdo de ARgensola, Bartolomé (1995), Alteraciones populares de Zaragoza. Año 1591, ed., est. y n. de Gregorio Colás Latorre, Zaragoza, Institución «Fernando el Católico».

LEONARDO DE ARGENSOLA, Lupercio (1991), Información de los sucesos del Reino de Aragon, introd. de Xavier Gil Pujol, Zaragoza, Edizions de l'Astral / El Justicia de Aragón, ed. facs. [ed. orig., Madrid, Imprenta Real, 1808].

LORENTE UsÁn, Francisca (1990), Bartolomé Leonardo de Argensola, literato e historiador, tesis doctoral, Zaragoza, Universidad de Zaragoza.

MARINA SÁEZ, Rosa María, et álii (2002), El horacianismo en Bartolomé Leonardo de Argensola, Madrid, Huerga y Fierro.

Mir y Noguera, Miguel (1891), Bartolomé Leonardo de Argensola, Zaragoza, Imprenta del Hospicio Provincial.

Oliván BaILE, Francisco (1959), «El testamento de Lupercio Leonardo de Argensola», Argensola. Revista de Ciencias Sociales del Instituto de Estudios Altoaragoneses, n. ${ }^{\circ}$ 40, pp. 331-340.

Pellicer y SAforcada, Juan Antonio (1778), Ensayo de una bibliotheca de traductores españoles, Madrid, Antonio de Sancha.

Pérez CuenCA, Isabel (2007), «La obra manuscrita de los hermanos Argensola», en Beatriz Mariscal y María Teresa Miaja de la Peña (coords.), Actas del XV Congreso de la Asociación Internacional de Hispanistas «Las dos orillas», Monterrey, México, del 19 al 24 de julio de 2004, México, Fondo de Cultura Económica, vol. 2, pp. 401-410.

Rodrigo Estevan, María Luz (2002), Testamentos medievales aragoneses. Ritos y actitudes ante la muerte (siglo XV), La Muela (Zaragoza), Ediciones 94. 
SAla VALDÉs, Mario de la (1882), «Biografía del doctor Bartolomé Leonardo de Argensola», Almanaque del Diario de Avisos de Zaragoza.

SÁNCHEZ Laílla, Luis (1999), «Los Argensola y el drama: apuntes de reflexión literaria», Alazet, n. ${ }^{\circ} 11$, pp. 99-115.

SCHWARTZ Lerner, Lía (1993), «Modelos clásicos y modelos del mundo en la sátira áurea: los diálogos de Bartolomé Leonardo de Argensola», en Manuel García Martín (coord.), Estado actual de los estudios sobre el Siglo de Oro. Actas del II Congreso Internacional de Hispanistas del Siglo de Oro, Salamanca, Universidad de Salamanca, pp. 75-93.

- (1998), «Las “alteraciones aragonesas" y los Argensola», en José Martínez Millán (ed.), Actas del Congreso Internacional «Felipe II (1598-1998). Europa dividida: la Monarquia Católica de Felipe II» (Universidad Autónoma de Madrid, 20-23 abril 1998), Madrid, Parteluz, t. I, parte primera, pp. 815-832.

TESTÓN NÚÑEZ, Isabel (1983), «El hombre cacereño ante la muerte: testamentos y formas de piedad en el siglo XVII», Norba. Revista de arte, geografia e historia, n. ${ }^{\circ}$ 4, pp. 371-382.

ViÑAZA, Conde de la [Cipriano Muñoz y Manzano] (ed.) (1887), Algunas sátiras inéditas de Lupercio y Bartolomé Leonardo de Argensola, Zaragoza, Imprenta del Hospicio Provincial.

- (ed.) (1889), Obras sueltas de Lupercio y Bartolomé Leonardo de Argensola, Madrid, Imprenta y Fundición de M. Tello, 2 vols. 

Reproducción facsimilar y transcripción de los testamentos de los hermanos Argensola 

Lupercio Leonardo de Argensola

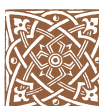






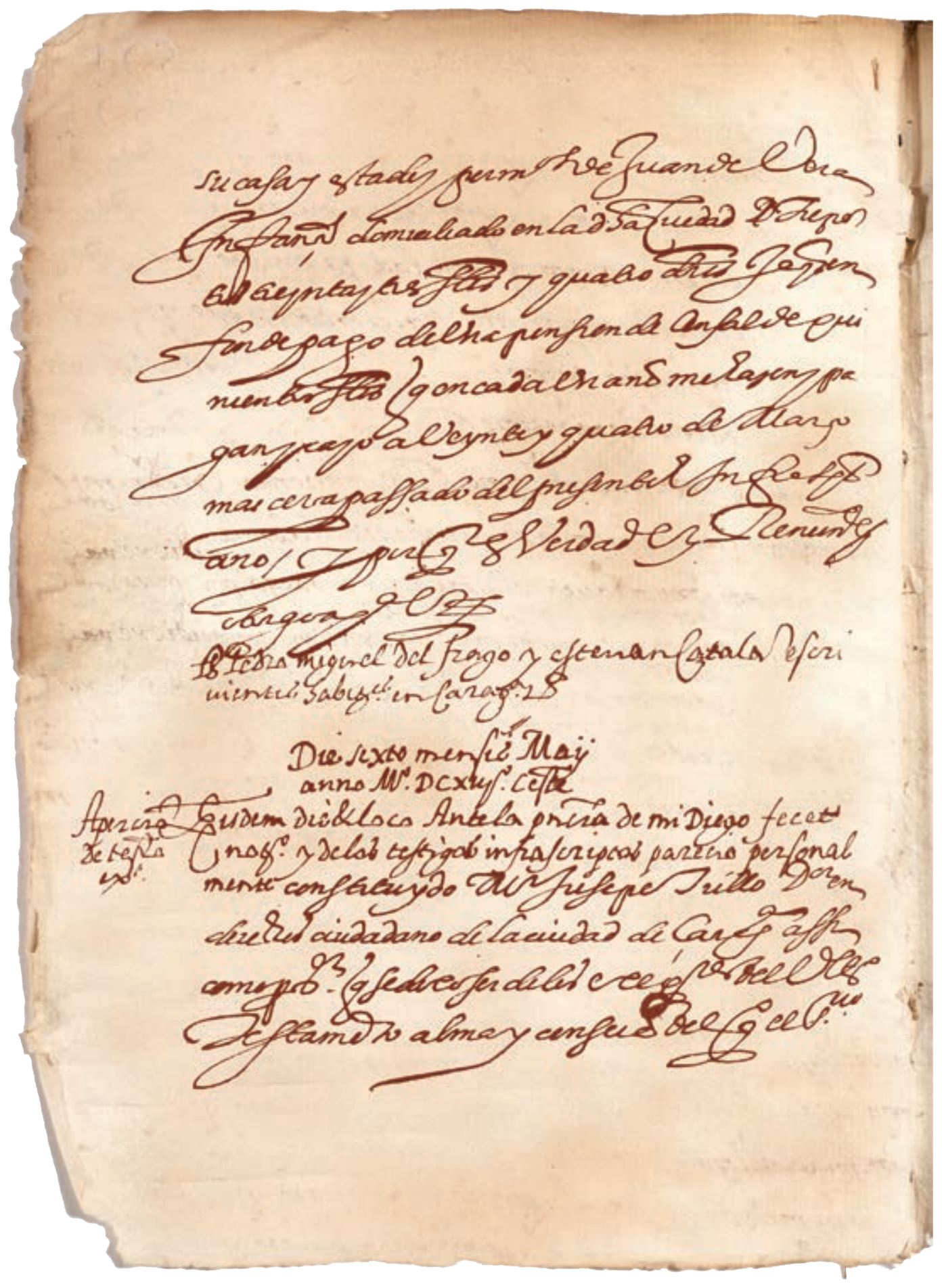




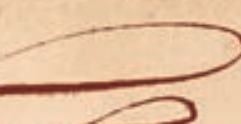

$$
\text { S } 31 .
$$

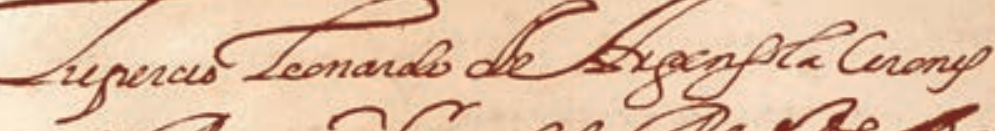

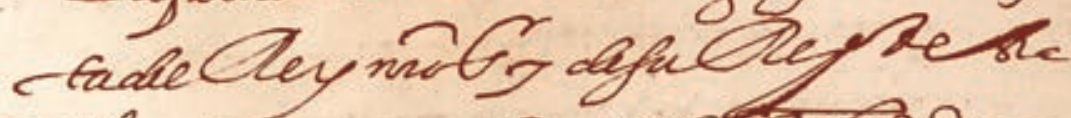

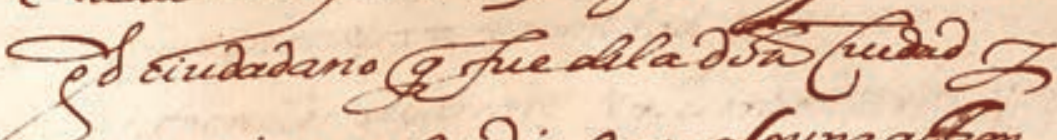
Came quien patendiatinu afouna abion

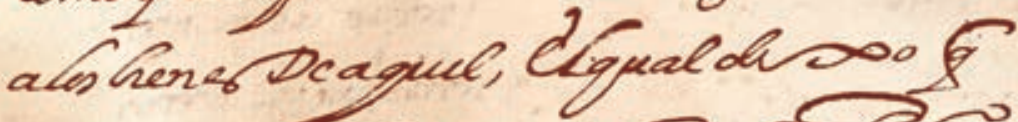

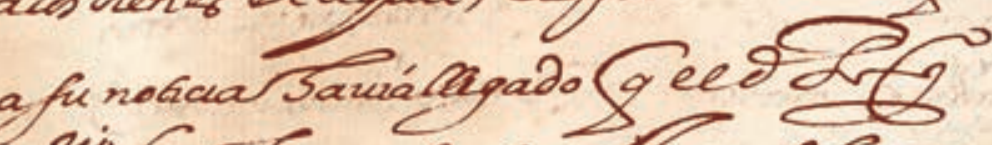

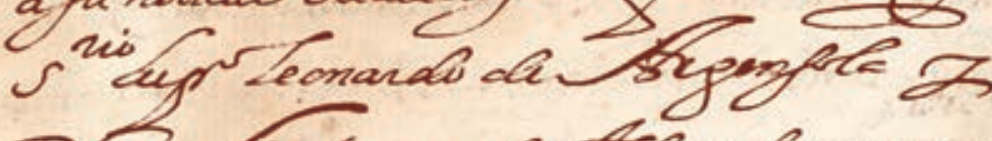
CDona llaríana destrenfum mupers

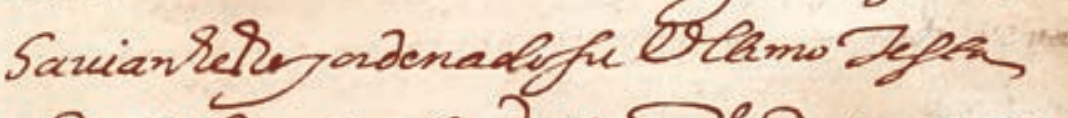

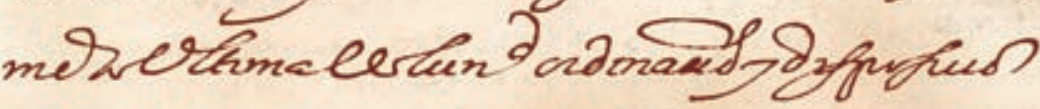

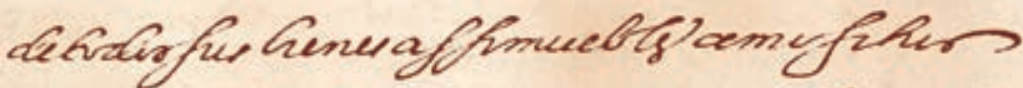
dondeg Ce Saviderspulaun elqualis

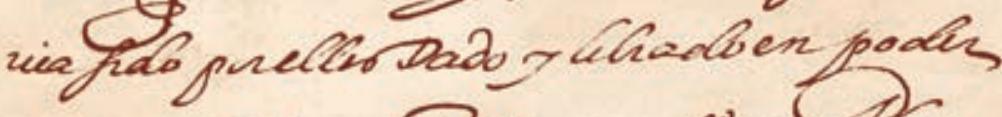

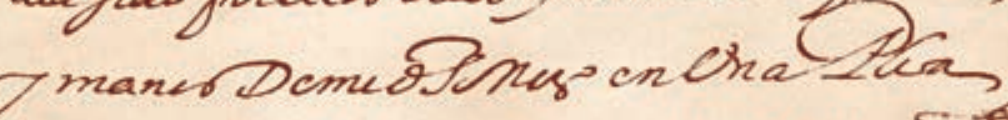

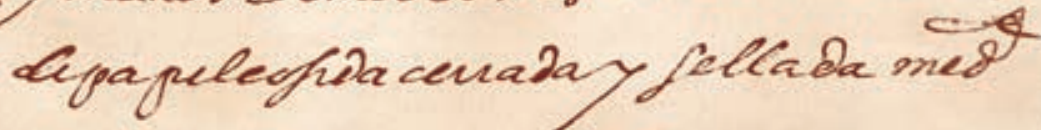




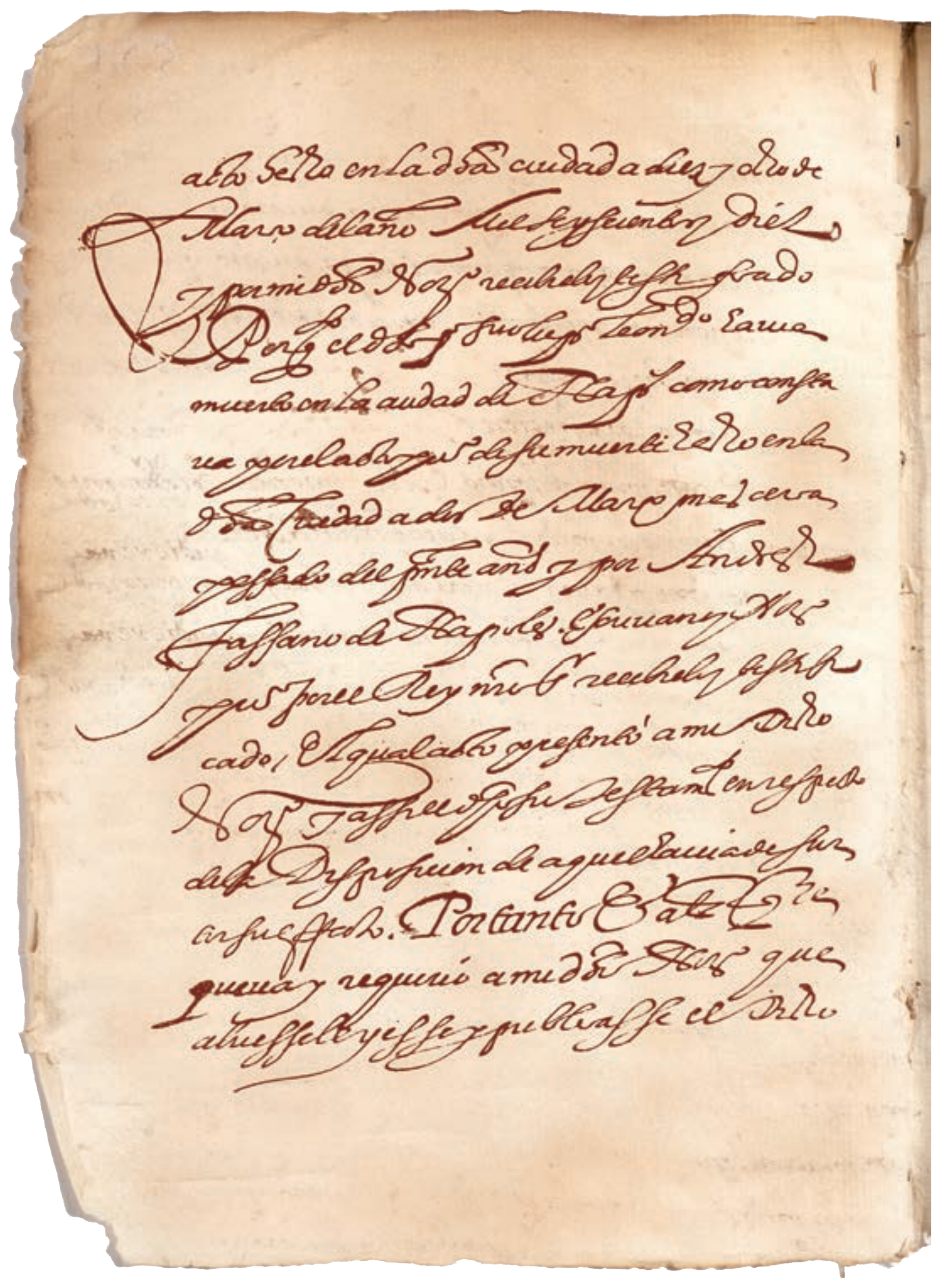


1
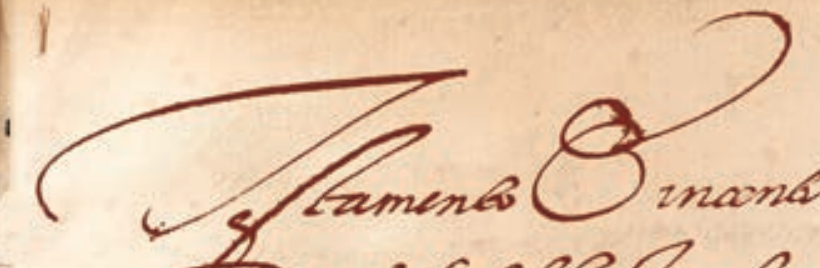

$\$ 32$.

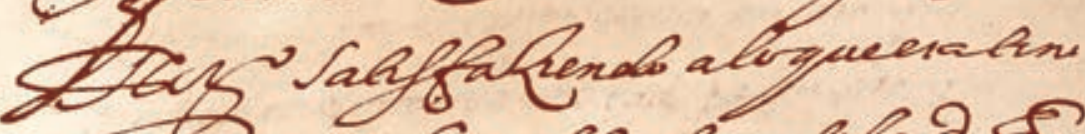

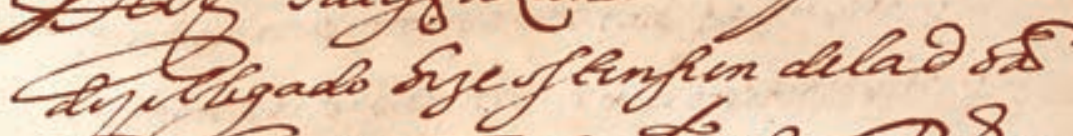

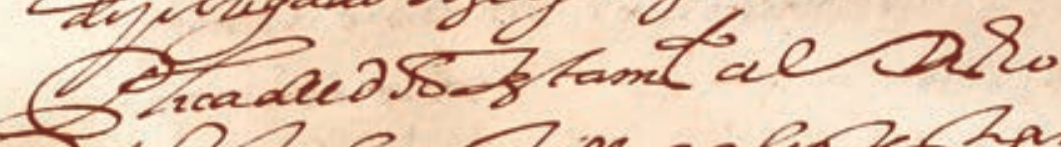

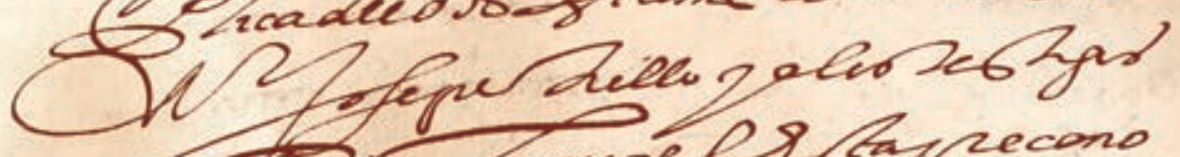
ingur Caguale 28 lay recono

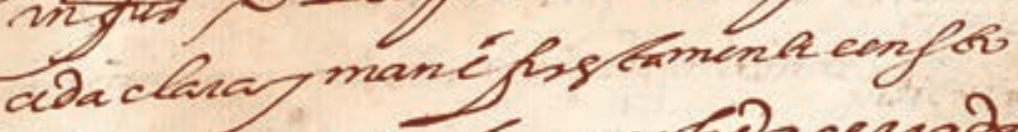

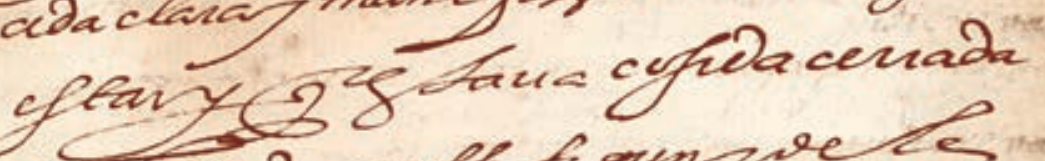

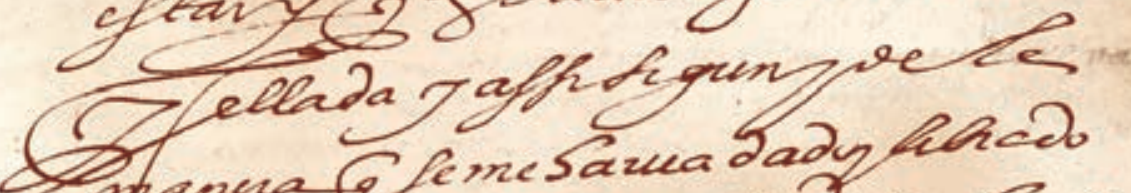

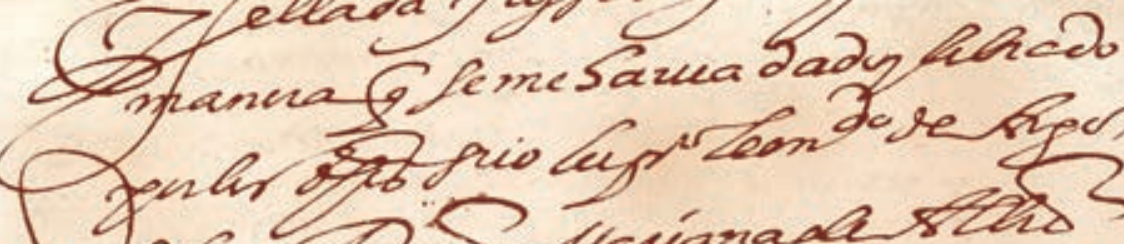

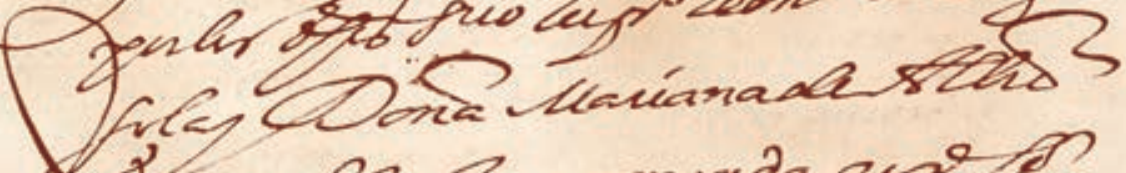

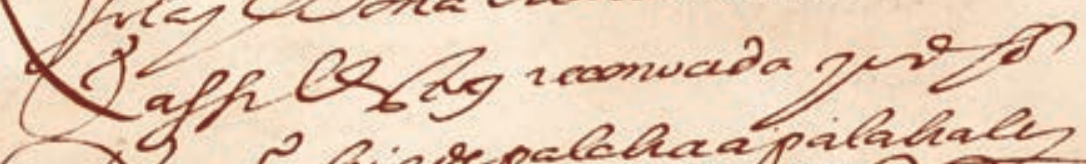
$\longrightarrow \%$ alu prepalabar pilahales

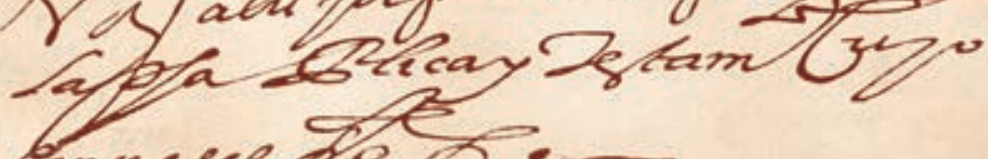
benesee ofp 60 


$$
\begin{array}{|r|r|}
\hline & 3 \\
3 & 3 \\
3 & 3 \\
3 & 3 \\
3 & 3 \\
3 & 3 \\
3 & 3 \\
3
\end{array}
$$




$$
\text { \$ } 33 .
$$

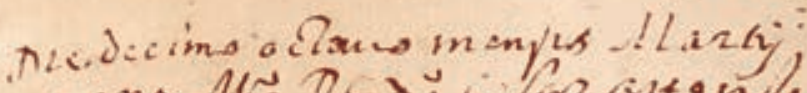

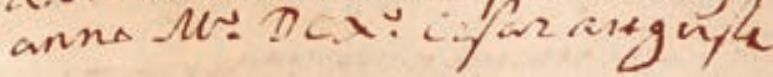

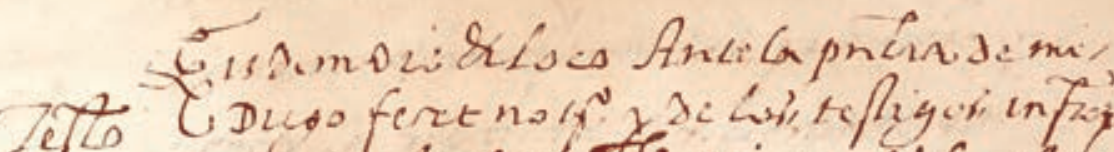

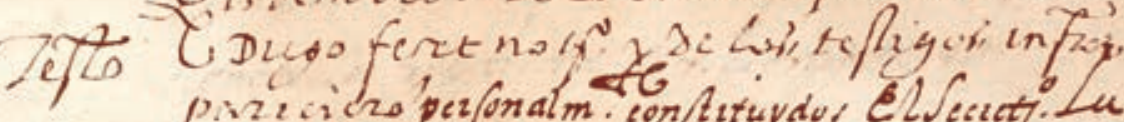

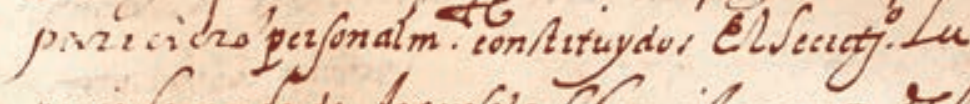
peciso Leonardo de Argenfola CSoronita mayor ors Quynzo senoz mor Pyidiela coiona dectugon (2) Dambien cheronitia Dal Eey. de Azegon civo Dadano dela cuidad delaung a. Dona Grazianna ro

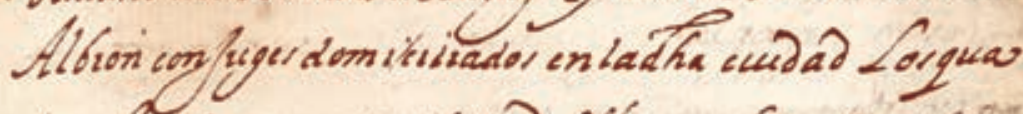
les cifandio con enteza Saluad etfyenvubuen Servo et phe

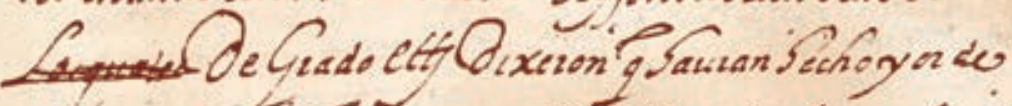
nado untrimo Deitamintu ett elqual etruua equia

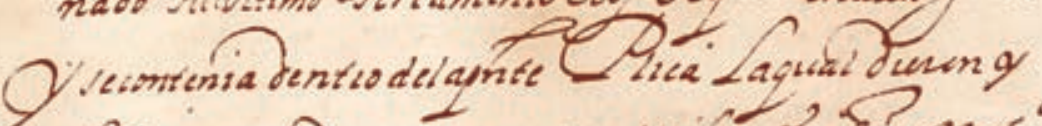

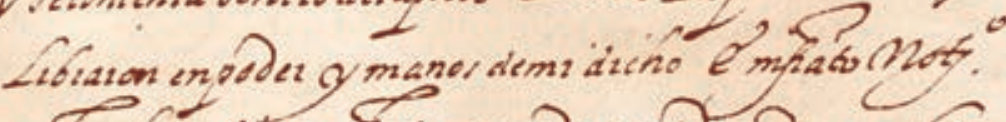

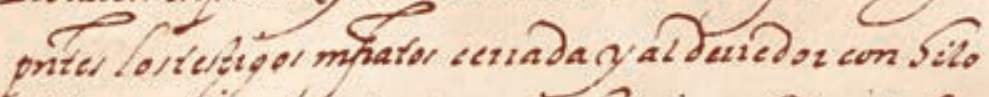

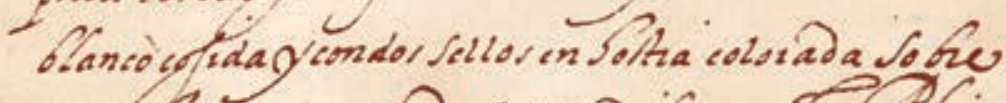

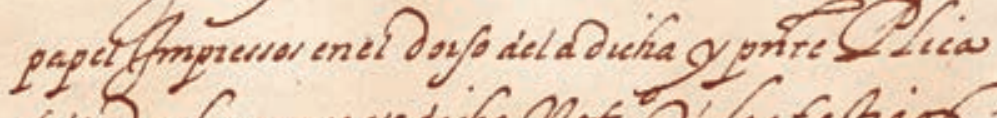

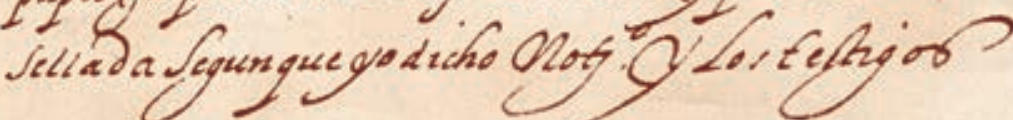




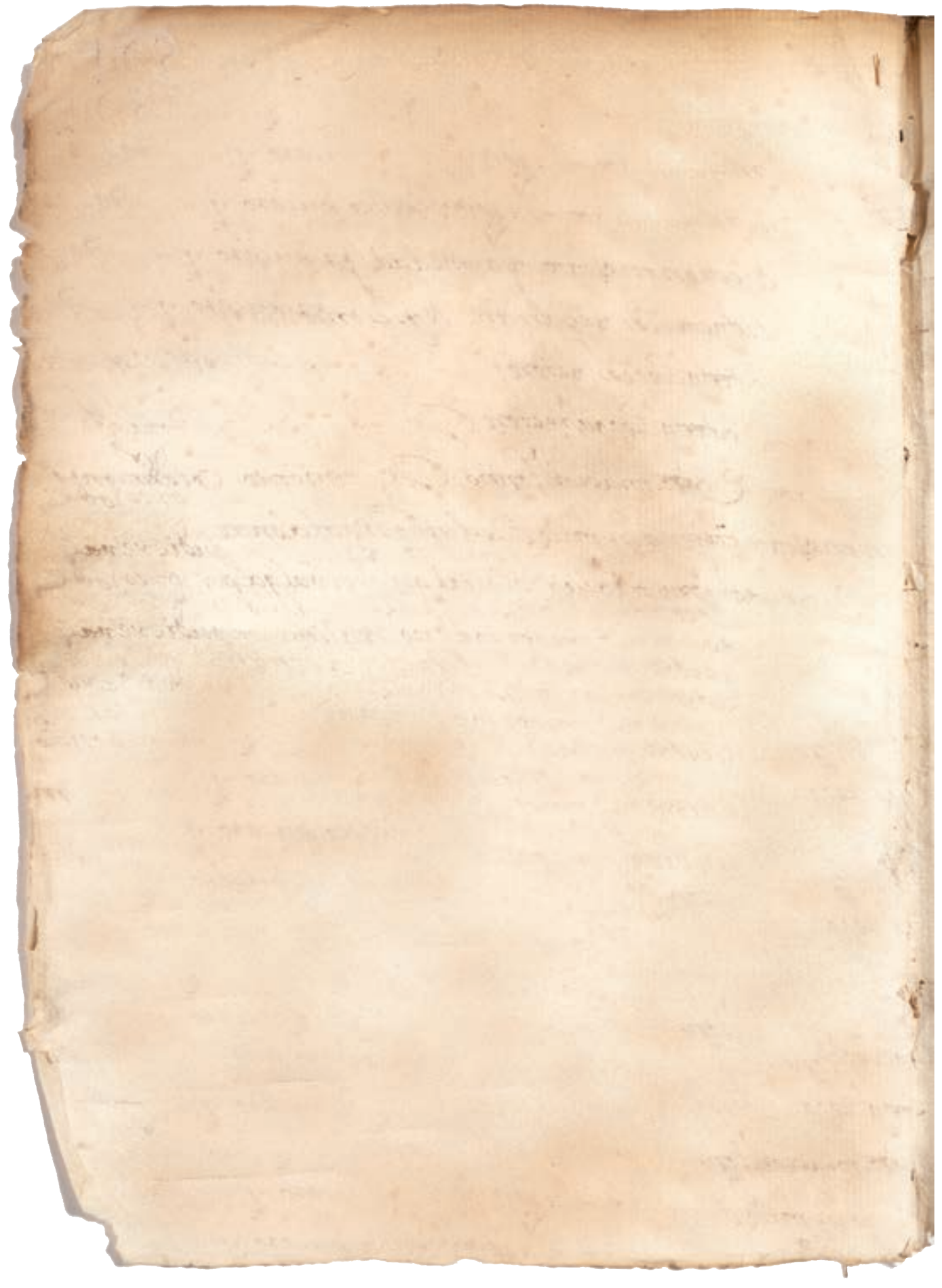

52 


\section{4}

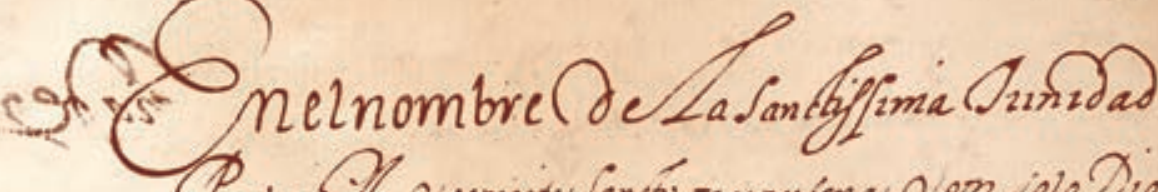

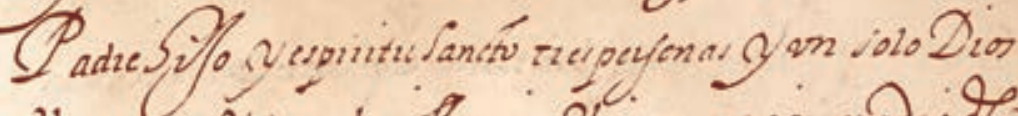
(Veziaduo Qdelaglondfinma Wugen mazia madzedo

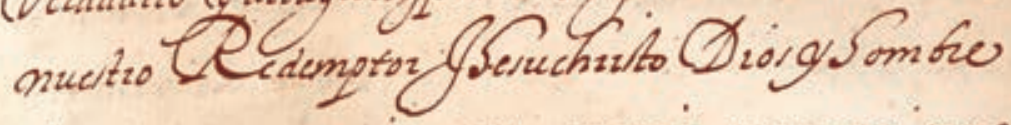
Qezdadero pozqueninguna pieuenczon paza mozz pue

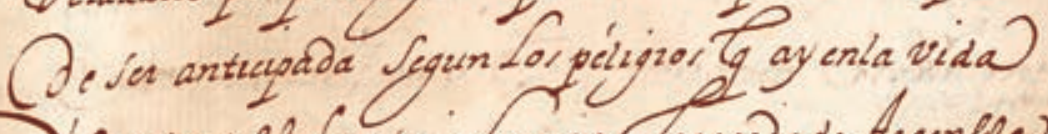

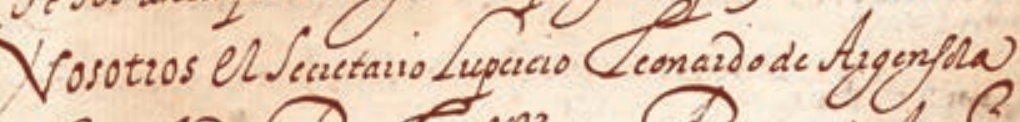

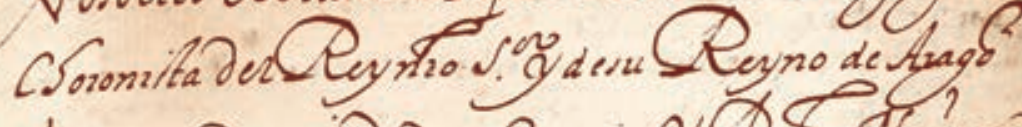

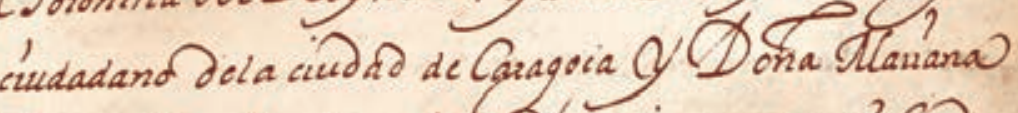

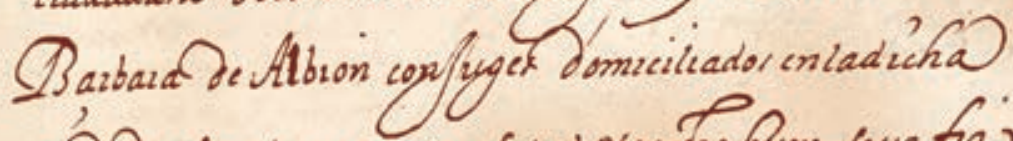

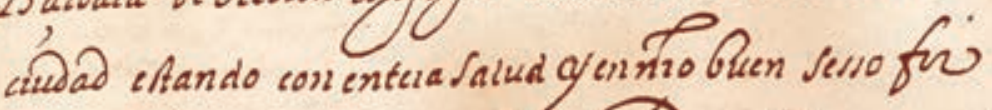
me memoria g palabia manzicta Pcuocandocianmel lando como poztenor del pnte Cuocamor Quannullames Ypor Otuocadorgenullor damor Saumorgs buenquere mor todor q qualequizine Seftamentor Codzcillorgotiar

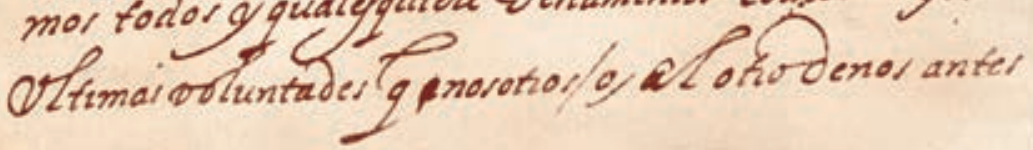


Deahora ayammo Sccho yoringario abrades nucu. Saleng o oroenamior nivo Ortimotets

Ottema volun. andinacion cyaliforicion of

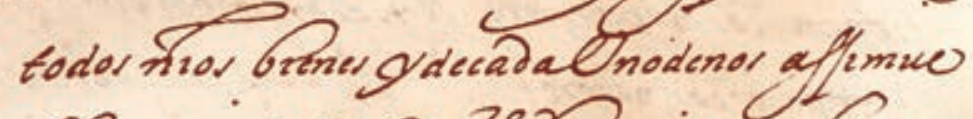
Aler como sitior Dondeq. Saurdergen Sawe en Lamaneza Prumente

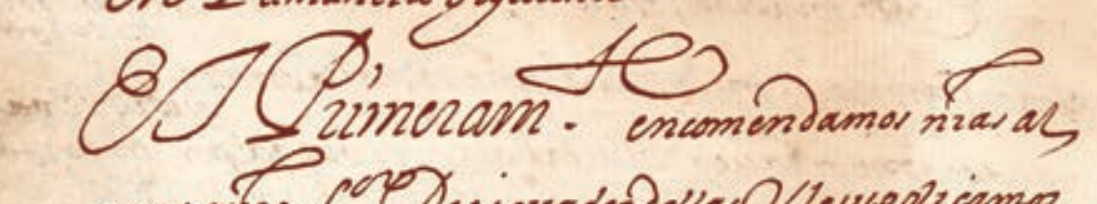
mas anzo por poicuadordellar. Vlerupplzicamos

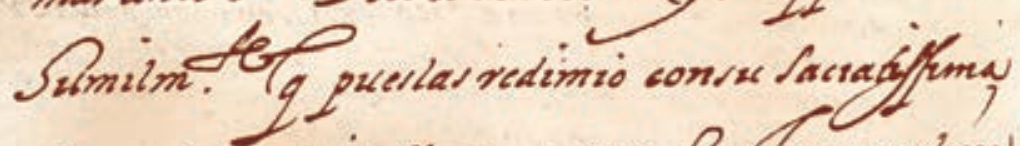
Sanguelaiquzera icollocaz consus anctor enjugloual

Cfforn Quezunorymandamostaremputg ef pieñonente denor muzice sucuerpo sea entedado

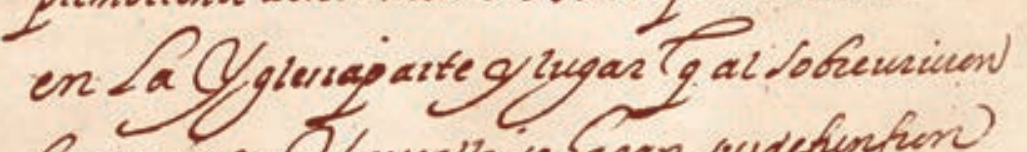

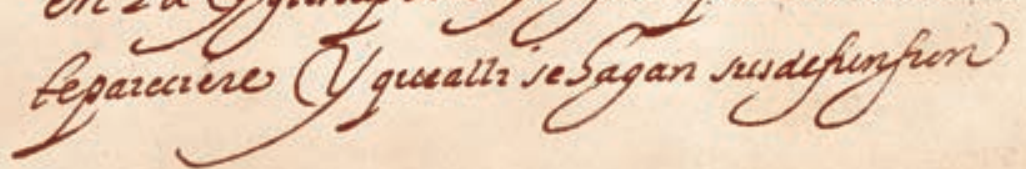

54 
5 35.

Mounaquiuodeans sinpompa arguna gattandefe Ioneuffariog alsobutuzizente denos bien vitu

Cfom queremos ondenamosamandamostg por

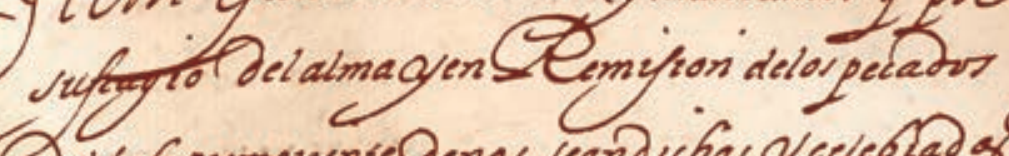

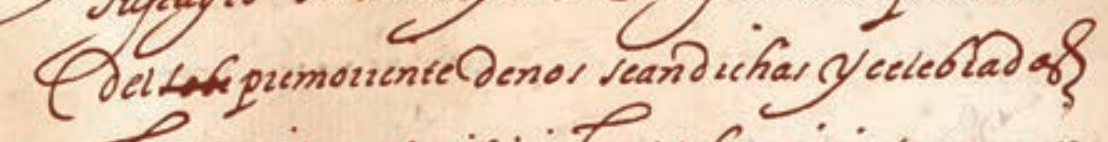

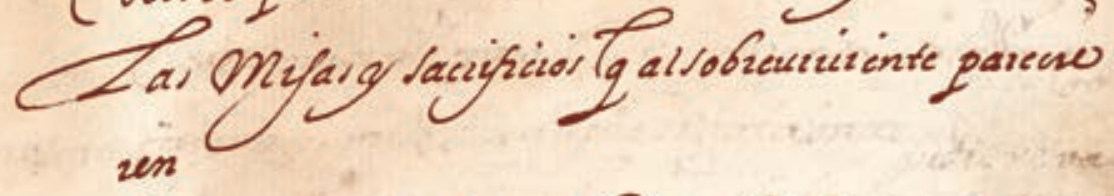

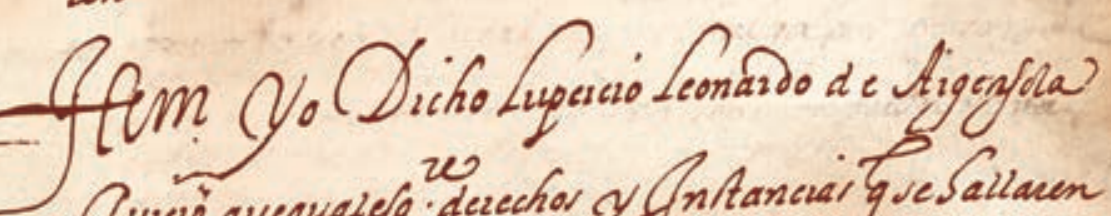

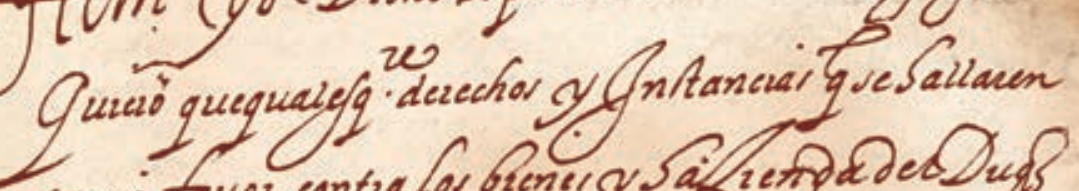

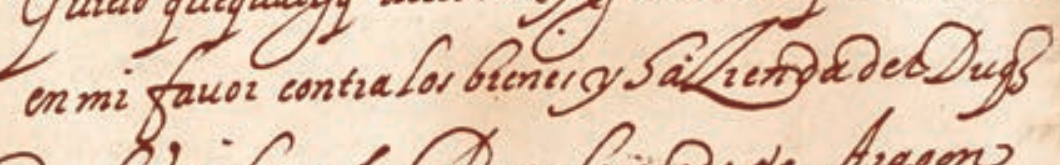

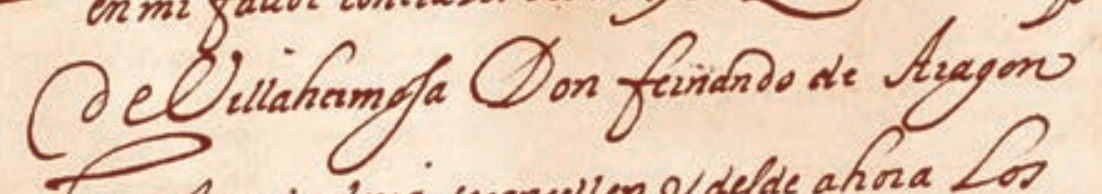
Te ette cniaglozia secancelien ydefde ahou los

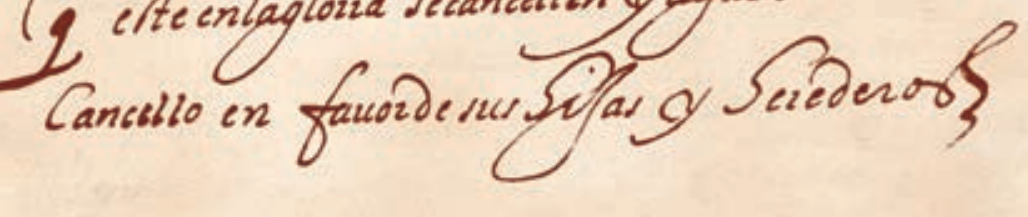

55 
Sino fuere encefolq pozparted Dellos pidreffen cuen talo/ quifuesion cobraidelor mios qiqunasquents

Dader porque en erte cafoqurers tongan tw eficiacia of firmeca como ahora latienen CI L mifmorigo dequalefg. (Derechostg mepurenelicaro por cyion otargada en mi fauor por Arien fruans

Guonimo Jefoer a sola pozque etorivealm tै

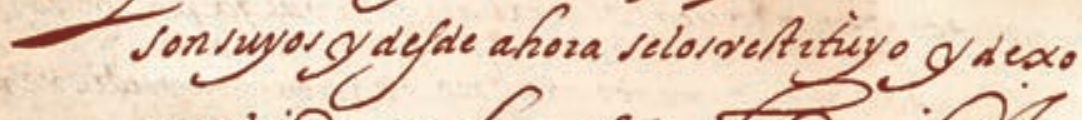

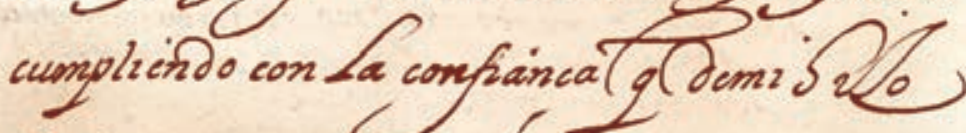

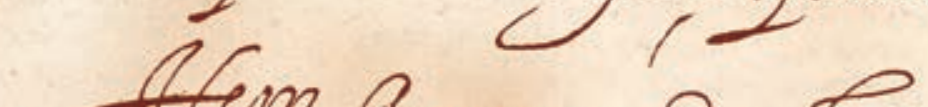

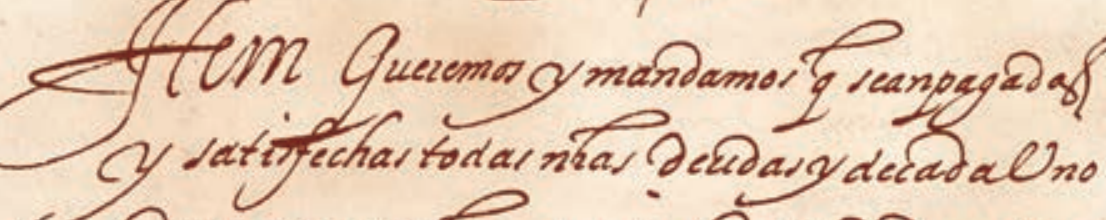
Denor aquellar toen realidad Deverdad contara

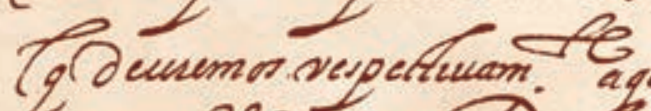

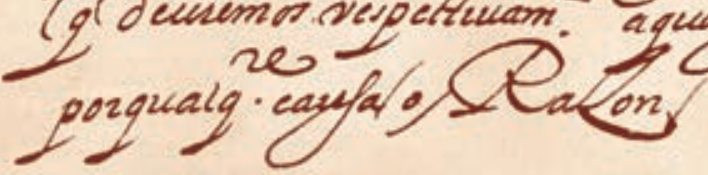




$$
536 .
$$

Itom Dexamor porparte y dexelho Delegutiona

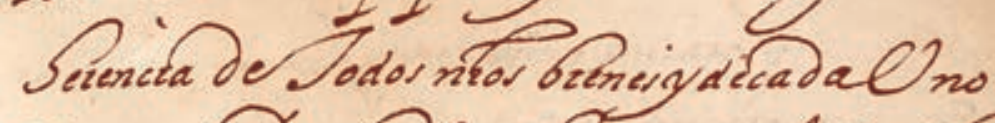
Conor a Gabred Lonarode Aloron nzos.

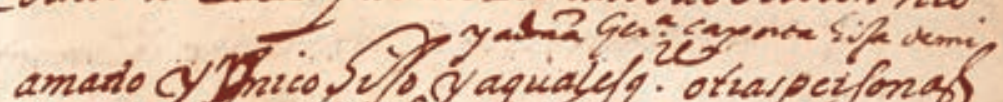

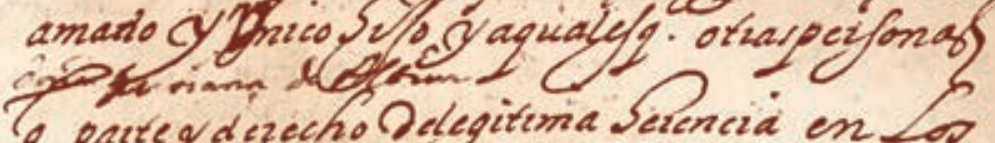
q parteg derecho Nelegituma Serencia en los

Dichor muer bienerpuedan puerender Sauergas

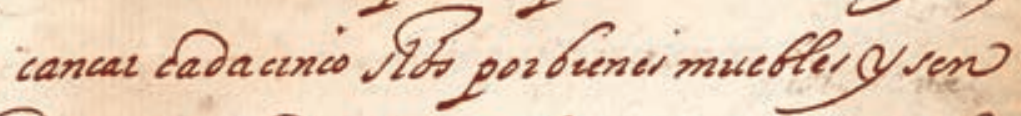

(Da, azobasdeticiza en for monter comun of

Deladichayphte curdad por brenes sitios con to qualquiciëgmanda Eadalnodenortq reayan

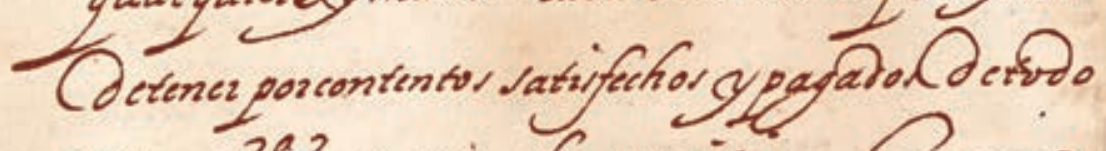

Q qualg. Parte diencho dielegitima Sonencia

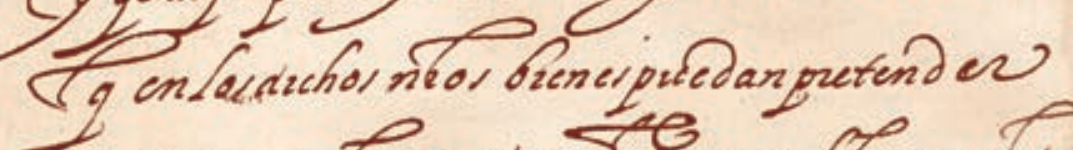
(1) aleancar of tansolam. alcancen Cogporegonte nio QL fimo betho leig freiedexaro

57 


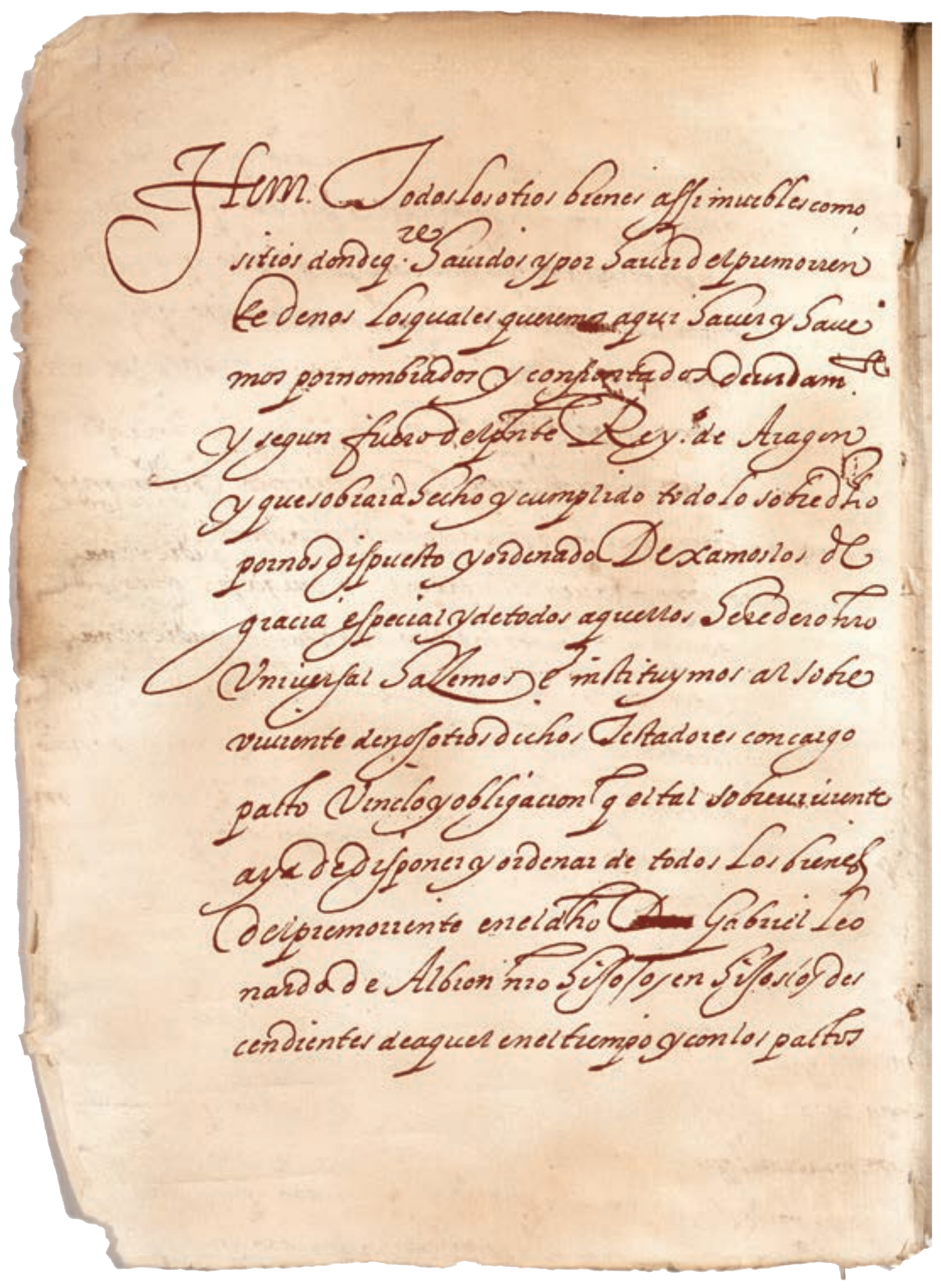


(3).

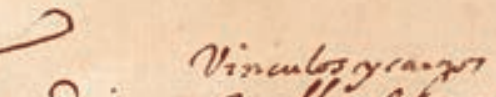

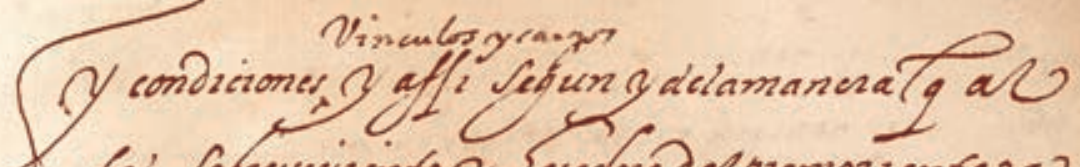

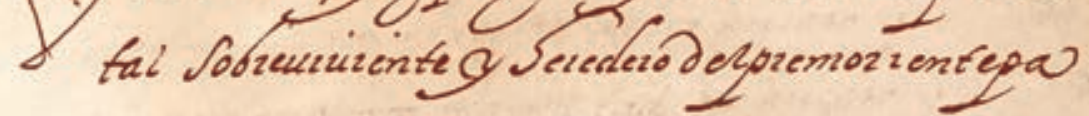
zecera

Gitecsind vitimi Vetamento Vtima)

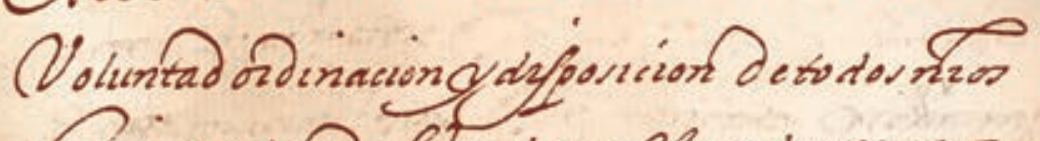
Gener gdecadalenodenor elqualquismos

Q mandamos 9 ayadevaiengvalga ponderechs

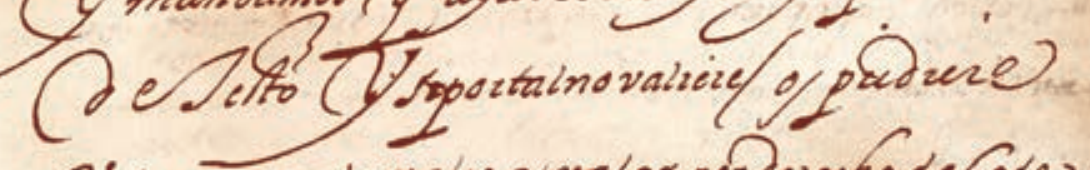

Valezqueayade valen oralga poz dezechodelods cillo orspoiztalnovaliend of preze valu Gaya

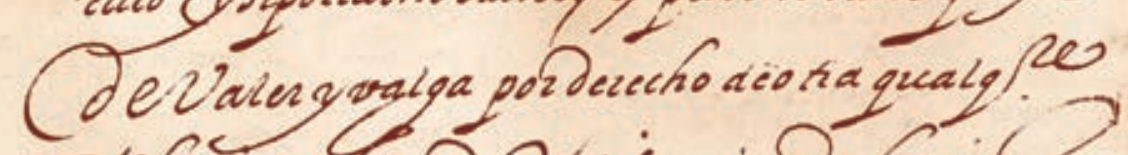

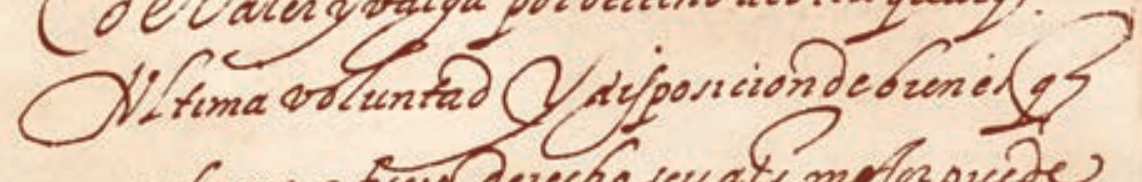

conforme a hicerd Derecho reu ats moforpicese

(E) Deuevales?

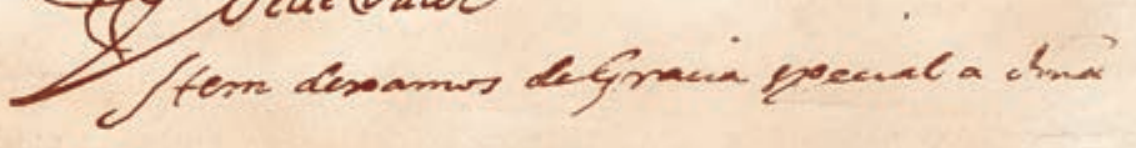

59 


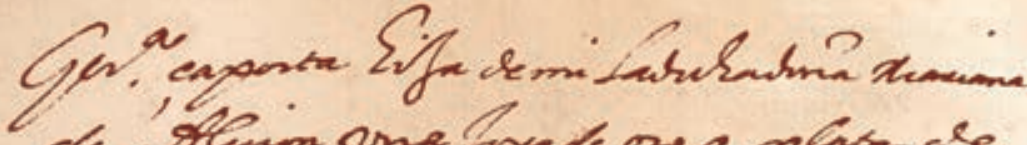
de gitum une oy de ow o, polite ele

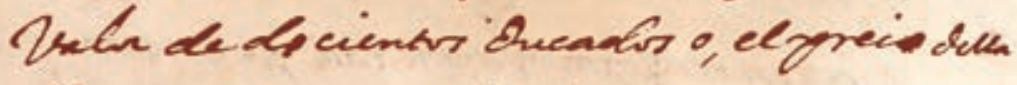
isque elle marguifiere

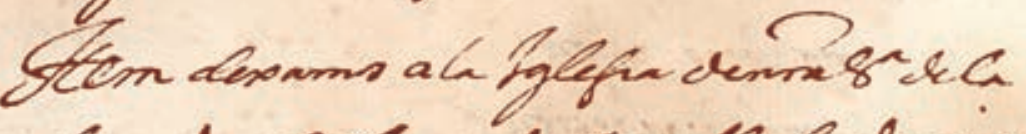

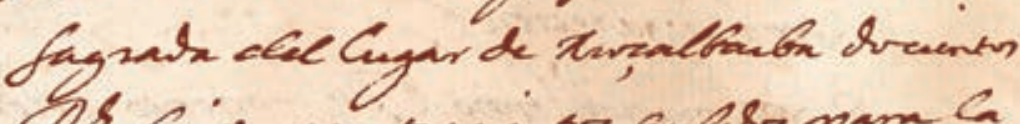

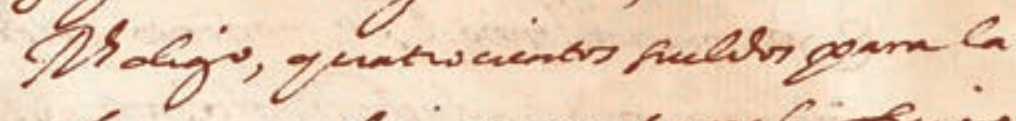

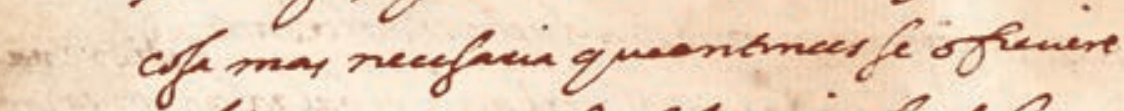

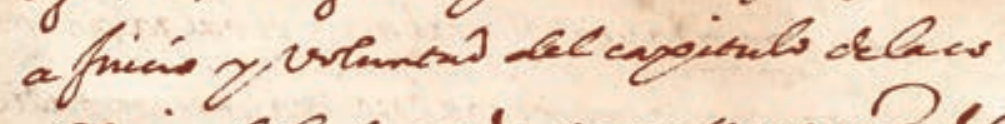

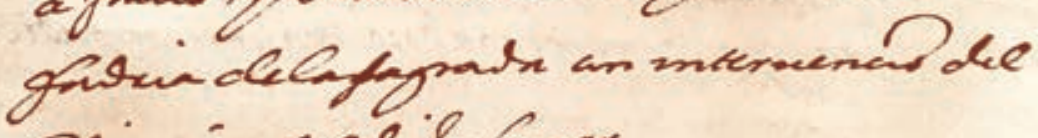

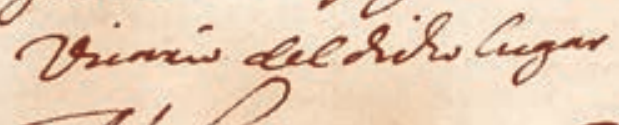

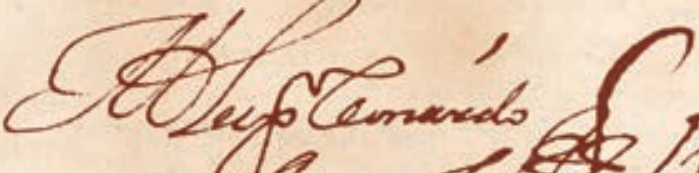

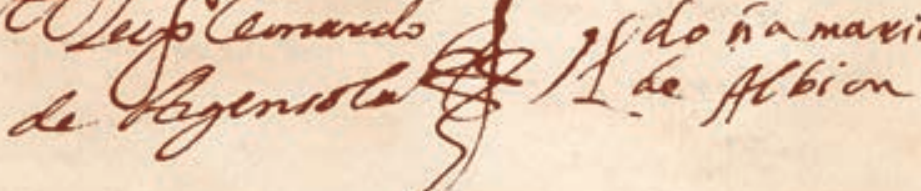

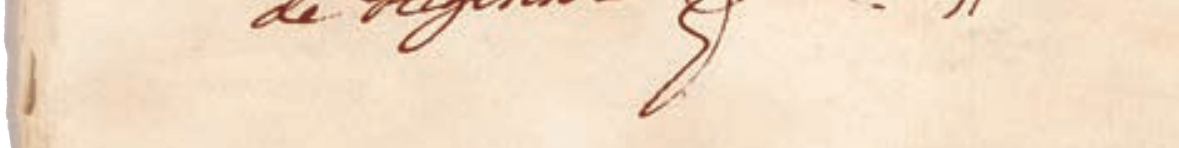




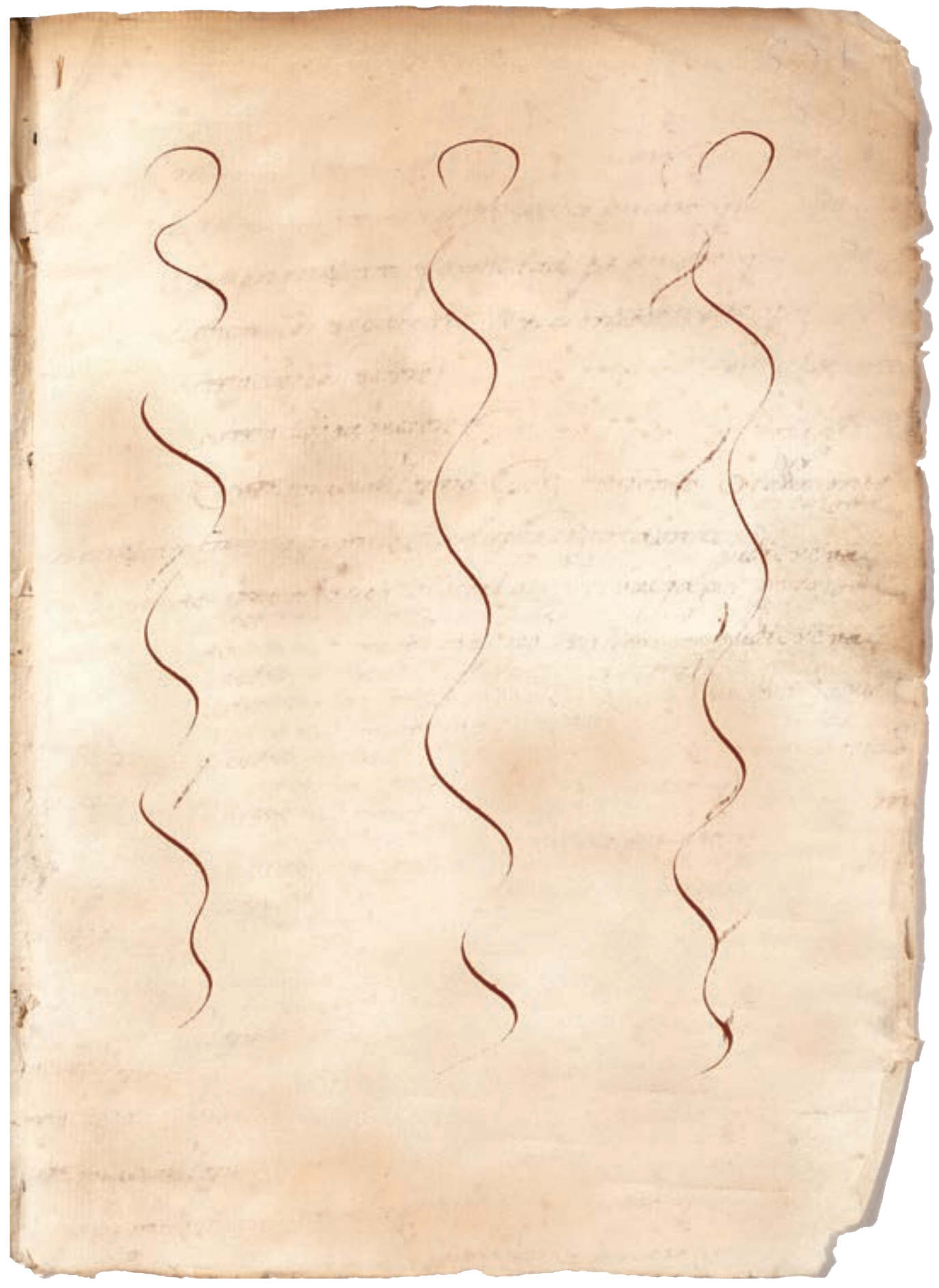




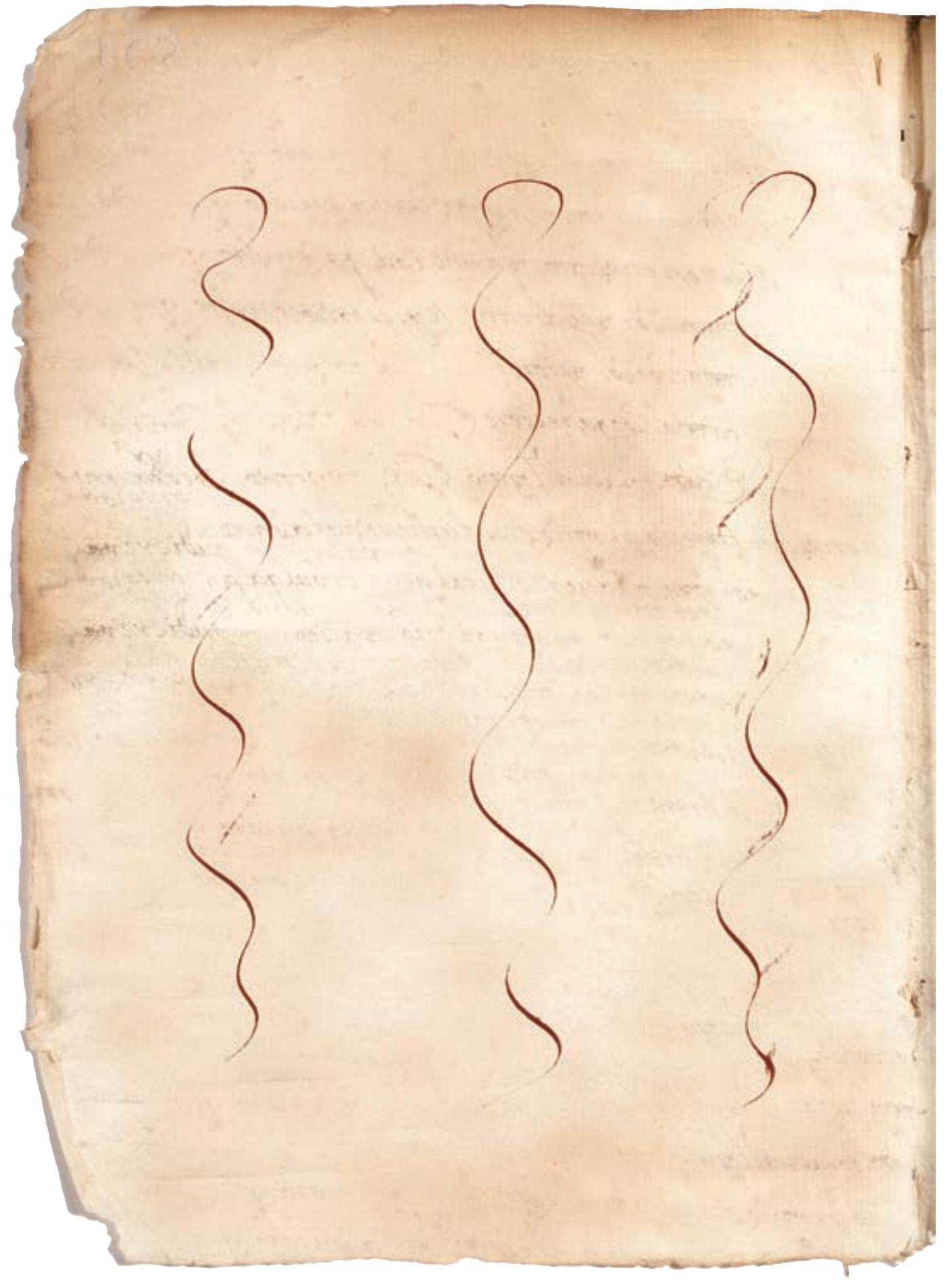

62 


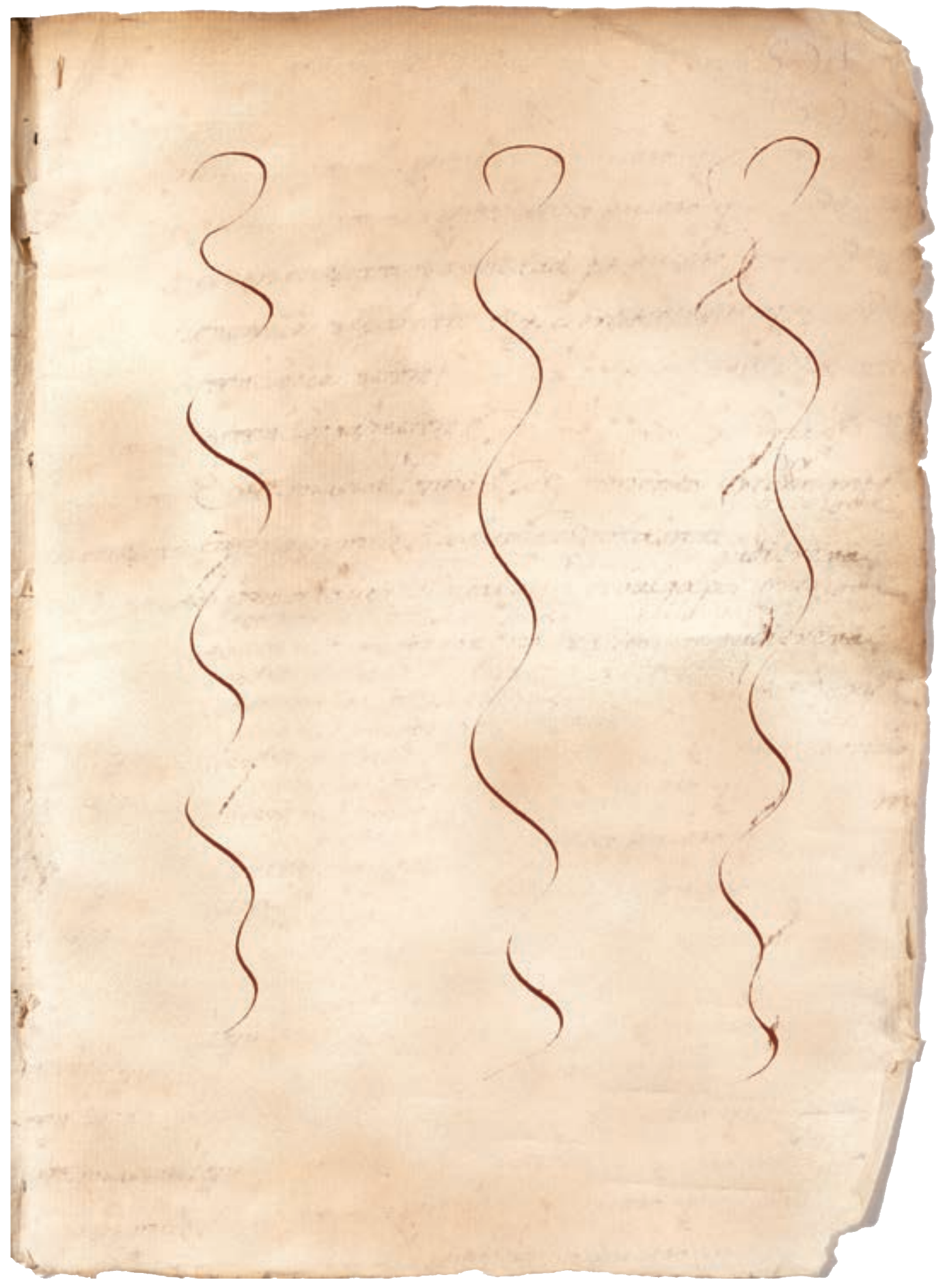




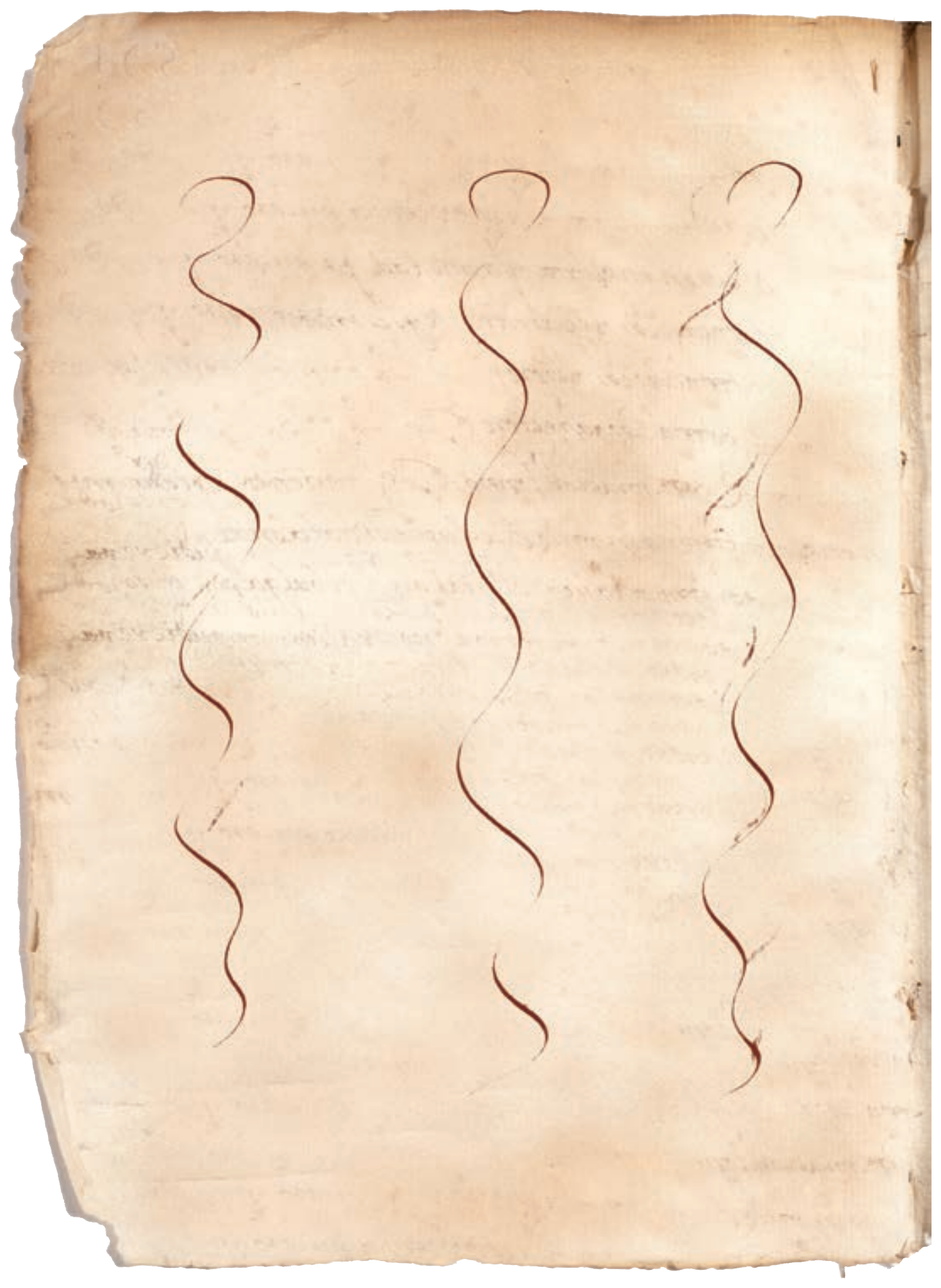




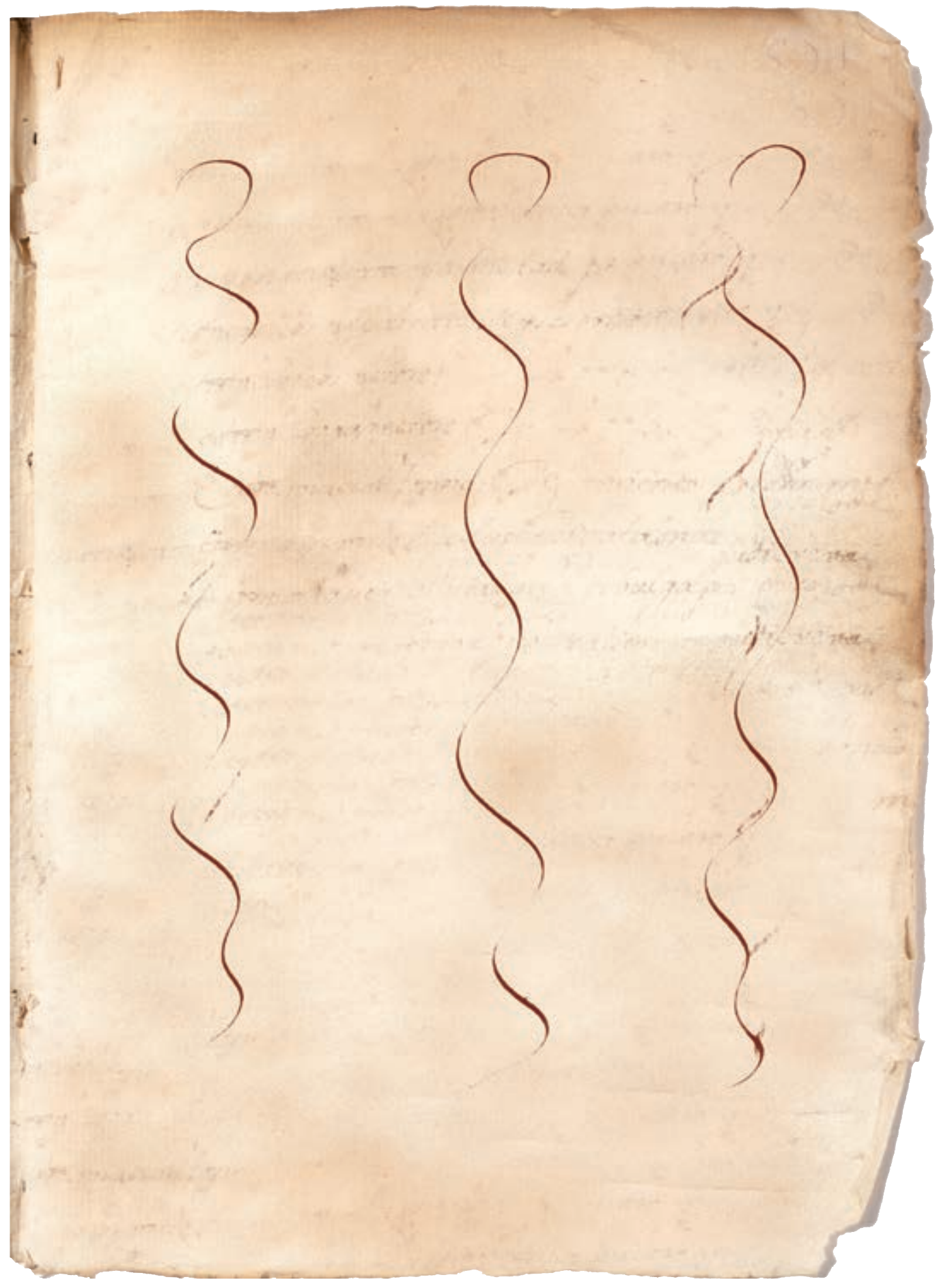

65 


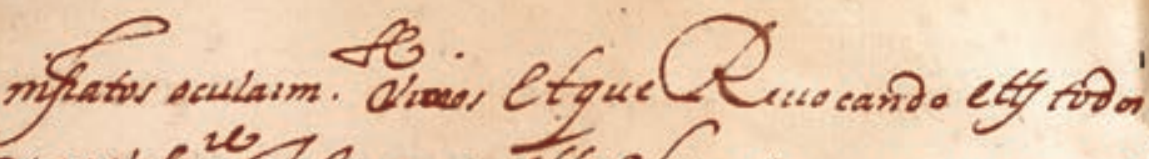

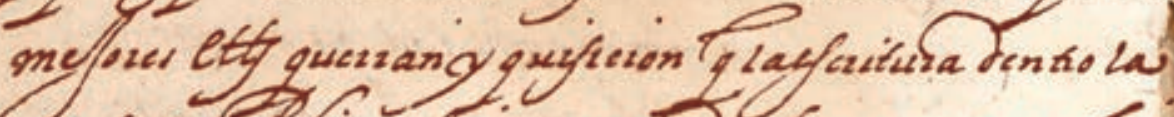

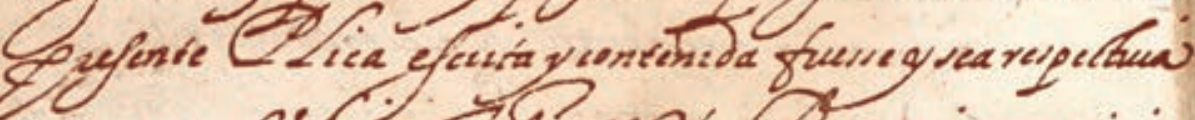

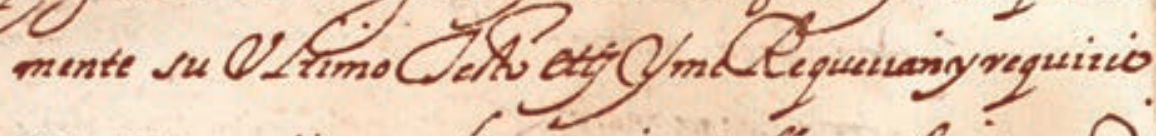

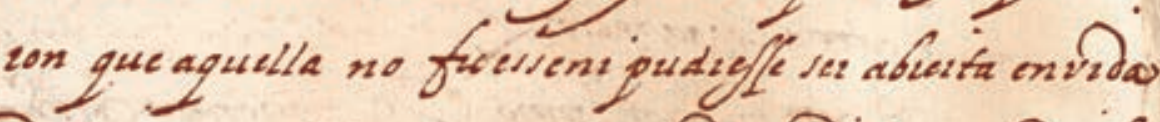

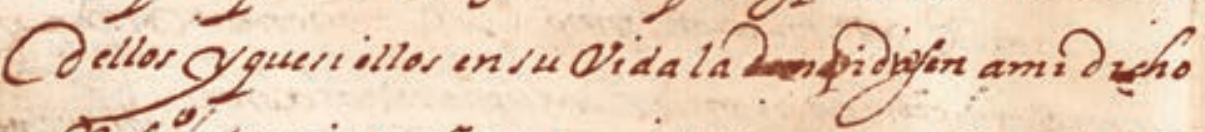

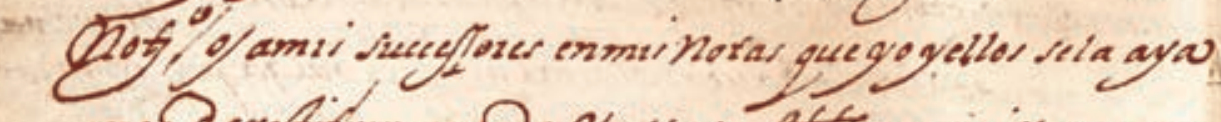

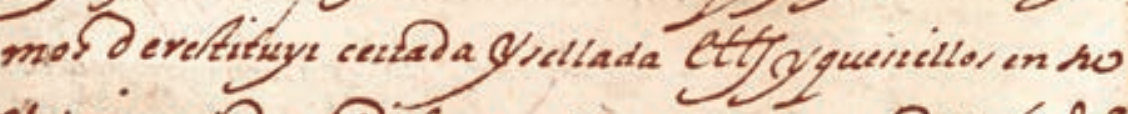

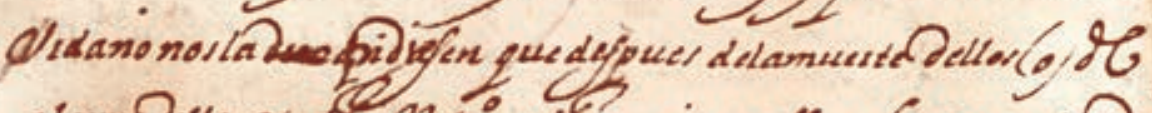

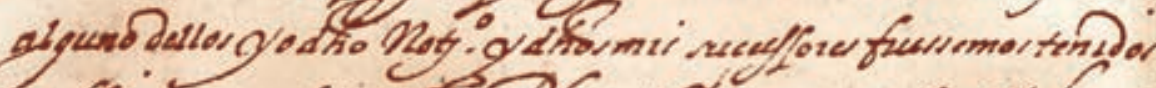

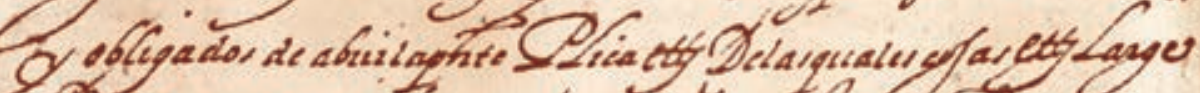

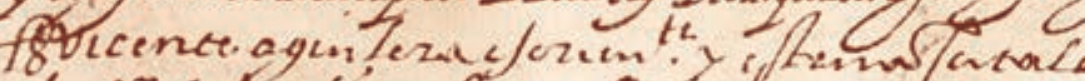

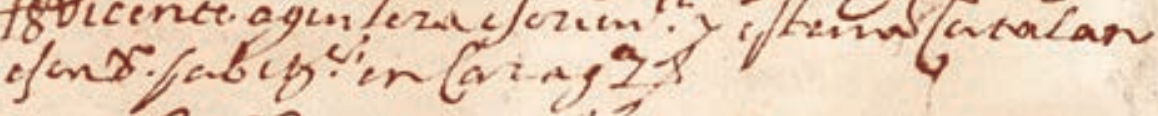

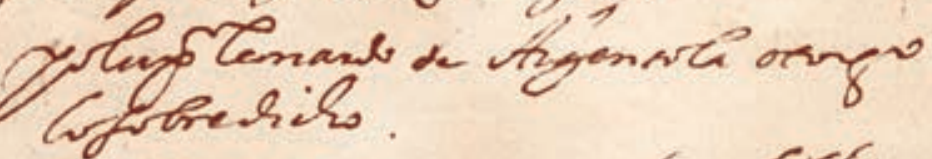

Yo tonia mariax a de fition opigo lo fobre dacino

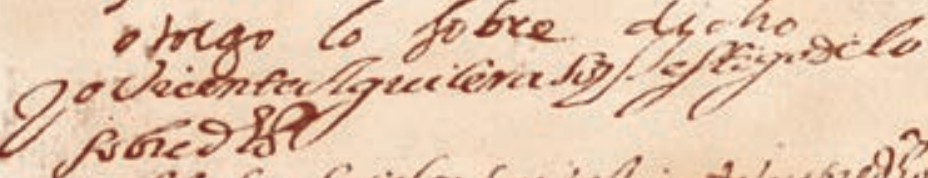
cyorestife

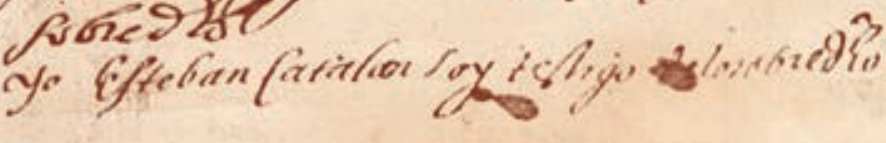




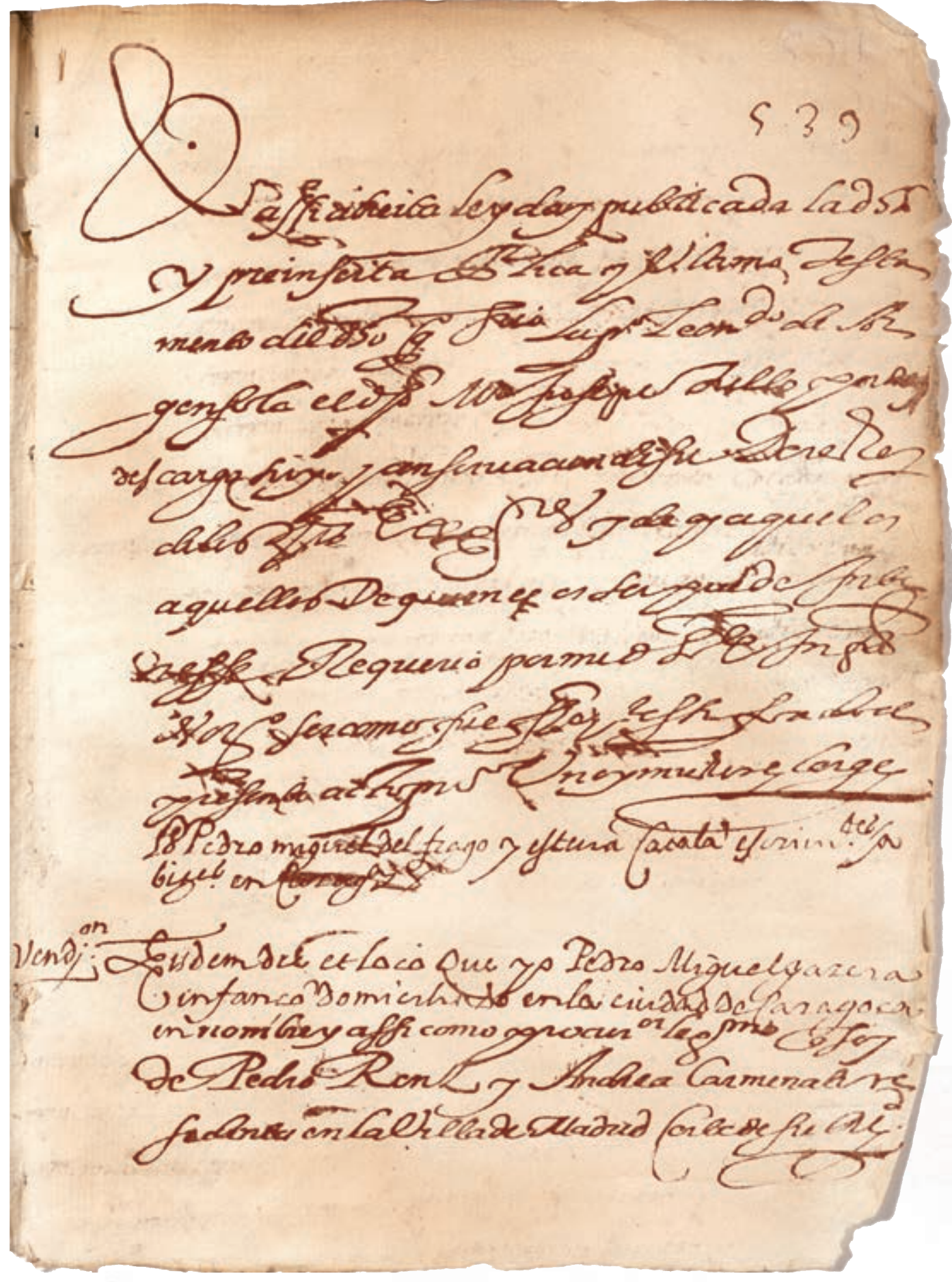





\section{Lupercio Leonardo de Argensola}

Fuente: Archivo Histórico de Protocolos Notariales de Zaragoza, Diego Fecet, 1613, f. 530v-539

[f. 530v] Die sexto mensis maii anno M. ${ }^{\circ}$ DCXIII. ${ }^{\circ}$ Cesarauguste.

[Nota al margen: «Aperción de testamento»] Eisdem die et loco, ante la presencia de mí, Diego Fecet, notario, y de los testigos infrascritos pareció personalmente constituido micer Jusepe Trillo, doctor en Derecho, ciudadano de la ciudad de Zaragoza, así como procurador que se dijo ser de los ejecutores del último testamento, alma y conciencia del quondam el secretario [f. 531] Lupercio Leonardo de Argensola, cronista del rey nuestro señor y de su reino de Aragón, ciudadano que fue de la dicha ciudad, y como quien pretendía tener alguna acción a los bienes de aquel, el cual dijo que a su noticia había llegado que el dicho quondam secretario Lupercio Leonardo de Argensola y doña Mariana de Albión, su mujer, habían hecho y ordenado su último testamento, última voluntad, ordinación y disposición de todos sus bienes, así muebles como sitios, dondequiere habederos y por haber, el cual había sido por ellos dado y librado en poder y manos de mí, dicho notario, en una plica de papel cosida, cerrada y sellada mediante [f. 531v] acto hecho en la dicha ciudad a dieciocho de marzo del año mil seiscientos diez, y por mí, dicho notario, recibido y testificado. Por cuanto el dicho quondam secretario Lupercio Leonardo había muerto en la ciudad de Nápoles, como constaba por el acto público de su muerte, hecho en la dicha ciudad a dos de marzo más cerca pa- 
sado del presente año y por Andrés Fasano, de Nápoles, escribano y notario público por el rey nuestro señor recibido y testificado, el cual acto presentó a mí, dicho notario, y así el dicho su testamento en respecto de la disposición de aquel había de surtir su efecto.

Por tanto, et álii, requería y requirió a mí, dicho notario, que abriese, leyese y publicase el dicho [f. 532] testamento, et incontinenti yo, dicho notario, satisfaciendo a lo que era tenido y obligado, hice ostensión de la dicha plica del dicho testamento al dicho micer Jusepe Trillo y a los testigos infrascritos, la cual, vista y reconocida clara y manifiestamente, constó estar y que estaba cosida, cerrada y sellada y así según y de la manera que se me había dado y librado por los dichos secretario Lupercio Leonardo de Argensola y doña Mariana de Albión. Y así, vista y reconocida, yo, dicho notario, abrí y de palabra a palabra leí la dicha plica y testamento, cuyo tenor es el siguiente: [el f. 532v está inutilizado por el notario mediante tres líneas espirales trazadas verticalmente]

[f. 533] Die decimo octavo mensis martii anno M..$^{\circ}$ DCX. ${ }^{\circ} \mathrm{Ce}-$ sarauguste.

[Nota al margen: «Testamento»] Eisdem die et loco, ante la presencia de mí, Diego Fecet, notario, y de los testigos infrascritos parecieron personalmente constituidos el secretario Lupercio Leonardo de Argensola, cronista mayor del rey nuestro señor en los reinos de la Corona de Aragón y también cronista del reino de Aragón, 
ciudadano de la ciudad de Zaragoza, y doña Mariana de Albión, cónyuges, domiciliados en la dicha ciudad, los cuales, estando con entera salud, etcétera, y en su buen seso, etcétera, de grado, etcétera, dijeron que habían hecho y ordenado su último testamento, etcétera, el cual estaba escrito y se contenía dentro de la presente plica, la cual dieron y libraron en poder y manos de mí, dicho e infrascrito notario, presentes los testigos infrascritos, cerrada y alrededor con hilo blanco cosida y con dos sellos en hostia colorada sobre papel impresos en el dorso de la dicha y presente plica sellada, según que yo, dicho notario, y los testigos [el f. 533v está en blanco, y el texto sigue en el f. 538v]

[f. 534] En el nombre de la Santísima Trinidad, Padre, Hijo y Espíritu Santo, tres personas y un solo Dios verdadero, y de la gloriosísima Virgen María, madre de nuestro redentor Jesucristo, Dios y hombre verdadero, porque ninguna prevención para morir puede ser anticipada, según los peligros que hay en la vida, nosotros, el secretario Lupercio Leonardo de Argensola, cronista del rey nuestro señor y de su reino de Aragón, ciudadano de la ciudad de Zaragoza, y doña Mariana Bárbara de Albión, cónyuges, domiciliados en la dicha ciudad, estando con entera salud y en nuestro buen seso, firme memoria y palabra manifiesta, revocando y anulando, como por tenor del presente revocamos y anulamos y por revocados y nulos damos, habemos y haber queremos, todos y cualesquiera testamentos, codicilos y otras últimas voluntades que 
nosotros o el otro de nos antes [f. 534v] de ahora hayamos hecho y otorgado, ahora de nuevo hacemos y ordenamos nuestro último testamento, última voluntad, ordinación y disposición de todos nuestros bienes y de cada uno de nos, así muebles como sitios, dondequiere habidos y por haber, en la manera siguiente:

Et primeramente, encomendamos nuestras almas a Nuestro Señor Dios, criador de ellas, y le suplicamos humilmente que, pues las redimió con su sacratísima sangre, las quiera colocar con sus santos en su gloria.

Ítem, queremos y mandamos que, siempre que el premoriente de nos muriere, su cuerpo sea enterrado en la iglesia, parte y lugar que al sobreviviente pareciere, y que allí se hagan sus defunción, [f. 535] novena y cabo de año, sin pompa alguna, gastándose lo necesario y al sobreviviente de nos bien visto.

Ítem, queremos, ordenamos y mandamos que por sufragio del alma y en remisión de los pecados del premoriente de nos sean dichas y celebradas las misas y sacrificios que al sobreviviente parecieren.

Ítem, yo, dicho Lupercio Leonardo de Argensola, quiero que cualesquiera derechos e instancias que se hallaren en mi favor contra los bienes y hacienda del duque de Villahermosa don Fernando de Aragón, que esté en la gloria, se cancelen, y desde ahora los cancelo en favor de sus hijas y herederos, [f. 535v] si no fuere en caso 
que por parte de ellos pidiesen cuenta o quisiesen cobrar de los míos algunas cantidades, porque en este caso quiero que tengan su eficacia y firmeza, como ahora la tienen, y lo mismo digo de cualesquiera derechos que me pertenezcan por cesión otorgada en mi favor por micer Juan Jerónimo de Espés y Sola, porque estos realmente son suyos y desde ahora se los restituyo y dejo, cumpliendo con la confianza que de mí hizo.

Ítem, queremos y mandamos que sean pagadas y satisfechas todas nuestras deudas y de cada uno de nos, aquellas que en realidad de verdad constará que deberemos, respectivamente, a cualesquiera personas por cualquiera causa o razón.

[f. 536] Ítem, dejamos por parte y derecho de legítima herencia de todos nuestros bienes y de cada uno de nos a [tachado: «don»] Gabriel Leonardo de Albión, nuestro amado y único hijo [interlineado, de otra mano: «y a doña Jerónima Zaporta, hija de mí, doña Mariana de Albión»], y a cualesquiera otras personas que parte y derecho de legítima herencia en los dichos nuestros bienes puedan pretender, haber y alcanzar, cada, cinco sueldos por bienes muebles y sendas arrobas de tierra en los montes comunes de la dicha y presente ciudad por bienes sitios, con lo cual quiere y manda cada uno de nos que se hayan de tener por contentos, satisfechos y pagados de todo y cualquiera parte y derecho de legítima herencia que en los dichos nuestros bienes puedan pretender 
y alcanzar, y que tan solamente alcancen lo que por el presente nuestro último testamento les fuere dejado.

[f. 536v] Ítem, todos los otros bienes, así muebles como sitios, dondequiere habidos y por haber, del premoriente de nos, los cuales queremos aquí haber y habemos por nombrados y confrontados, debidamente y según fuero del presente reino de Aragón, y que sobrarán hecho y cumplido todo lo sobredicho por nos dispuesto y ordenado, dejámoslos de gracia especial, y de todos aquellos heredero nuestro universal hacemos e instituimos al sobreviviente de nosotros, dichos testadores, con cargo, pacto, vínculo y obligación que el tal sobreviviente haya de disponer y ordenar de todos los bienes del premoriente en el dicho [tachado: «don»] Gabriel Leonardo de Albión, nuestro hijo, o en hijos o descendientes de aquel, en el tiempo y con los pactos [f. 537] y condiciones, [interlineado: «vínculos y cargos»] y así según y de la manera que al tal sobreviviente y heredero del premoriente parecerá.

Este es nuestro último testamento, última voluntad, ordinación y disposición de todos nuestros bienes y de cada uno de nos, el cual queremos y mandamos que haya de valer y valga por derecho de testamento. Y si por tal no valiere o pudiere valer, que haya de valer y valga por derecho de codicilo. Y si por tal no valiere o pudiere valer, que haya de valer y valga por derecho de otra cualquiera 
última voluntad y disposición de bienes que conforme a fuero, derecho seu áliis mejor puede y debe valer.

[Desde aquí hasta las firmas, añadido de otra mano] Ítem, dejamos de gracia especial a doña [f. 537v] Jerónima Zaporta, hija de mí, la dicha doña Mariana de Albión, una joya de oro o plata de valor de doscientos ducados o el precio de ella, lo que ella más quisiere.

Ítem, dejamos a la iglesia de Nuestra Señora de la Sagrada, del lugar de Monzalbarba, doscientos reales, digo, cuatrocientos sueldos, para la cosa más necesaria que entonces se ofreciere a juicio y voluntad del capítulo de la cofradía de la Sagrada, con intervención del vicario del dicho lugar.

Lupercio Leonardo de Argensola / Doña Mariana de Albión

[Siguen dos folios sin numerar, cuyos rectos y versos están inutilizados mediante tres líneas onduladas trazadas verticalmente. A continuación sigue el f. 538, también inutilizado de la misma forma.] [f. 538v] infrascritos ocularmente vimos, et que revocando, etcétera, todos y cualesquiera testamentos, etcétera, ahora de nuevo en aquellas mejores, etcétera, querían y quisieron que la escritura dentro la presente plica escrita y contenida fuese y sea respectivamente su último testamento, etcétera, y me requerían y requirieron que aquella no fuese ni pudiese ser abierta en vida de ellos, y 
que si ellos en su vida la pidiesen a mí, dicho notario, o a mis sucesores en mis notas, que yo y ellos se la hayamos de restituir cerrada y sellada, etcétera, y que si ellos en su vida no nos la pidiesen, que después de la muerte de ellos o de alguno de ellos yo, dicho notario, y dichos mis sucesores fuésemos tenidos y obligados de abrir la presente plica, etcétera. De las cuales cosas, etcétera, large.

Testes Vicente Aguilera, escribiente, y Esteban Catalán, escudero, habitantes en Zaragoza.

Yo, Lupercio Leonardo de Argensola, otorgo lo sobredicho.

Yo, doña Mariana de Albión, otorgo lo sobredicho.

Yo, Vicente Aguilera, soy testigo de lo sobredicho.

Yo, Esteban Catalán, soy testigo de lo sobredicho.

[f. 539] Et así abierta y leída y publicada la dicha y preinserta plica y último testamento del dicho quondam secretario Lupercio Leonardo de Argensola, el dicho micer Jusepe Trillo, por descargo suyo y conservación de su derecho y de los dichos ejecutores y de aquel o aquellos de quien es o ser puede interesse, requirió por mí, dicho infrascrito notario, ser, como fue hecho y testificado, el presente acto público una y muchas [veces] et large.

Pedro Miguel del Frago y Esteban Catalán, escribientes, habitantes en Zaragoza. 
Bartolomé Leonardo de Argensola 


delgicholugar, por pesrode placa miconteste quesigo novabia escri Hithogmenclore fente alo no hay Sorepustor ranos enmendader

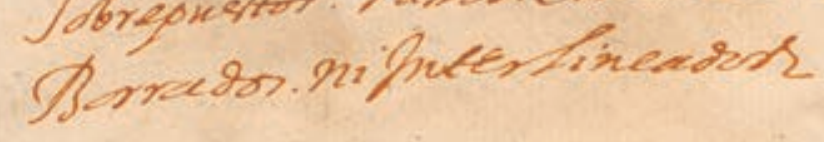

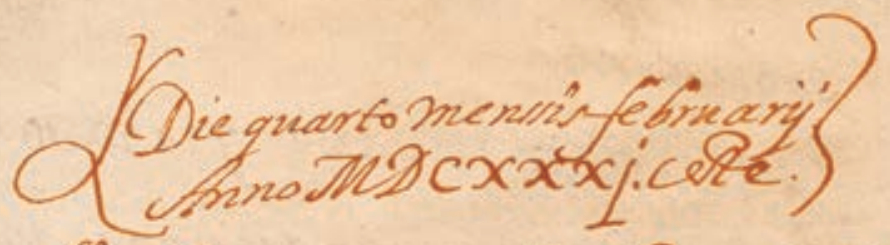

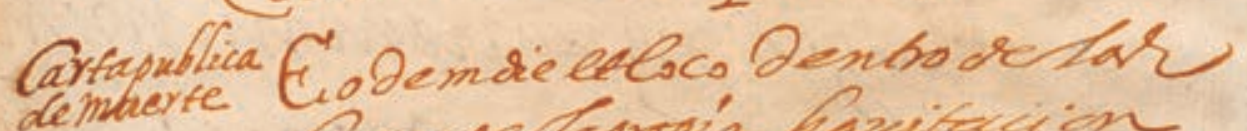

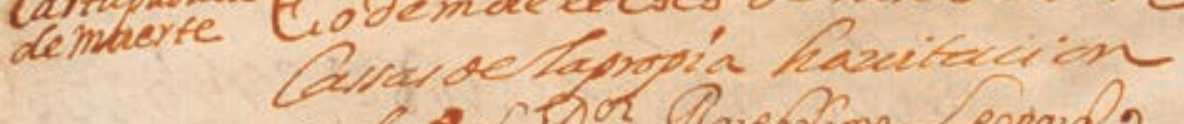

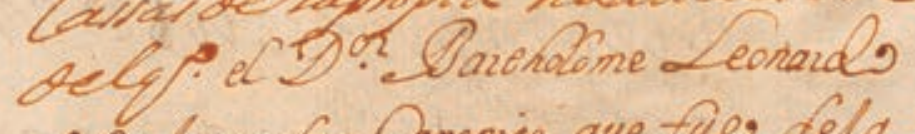
oletioeriola Canonio que fue dela,

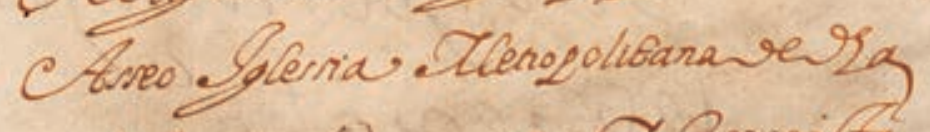
cudad ar Caragocas el eoronitis

80 


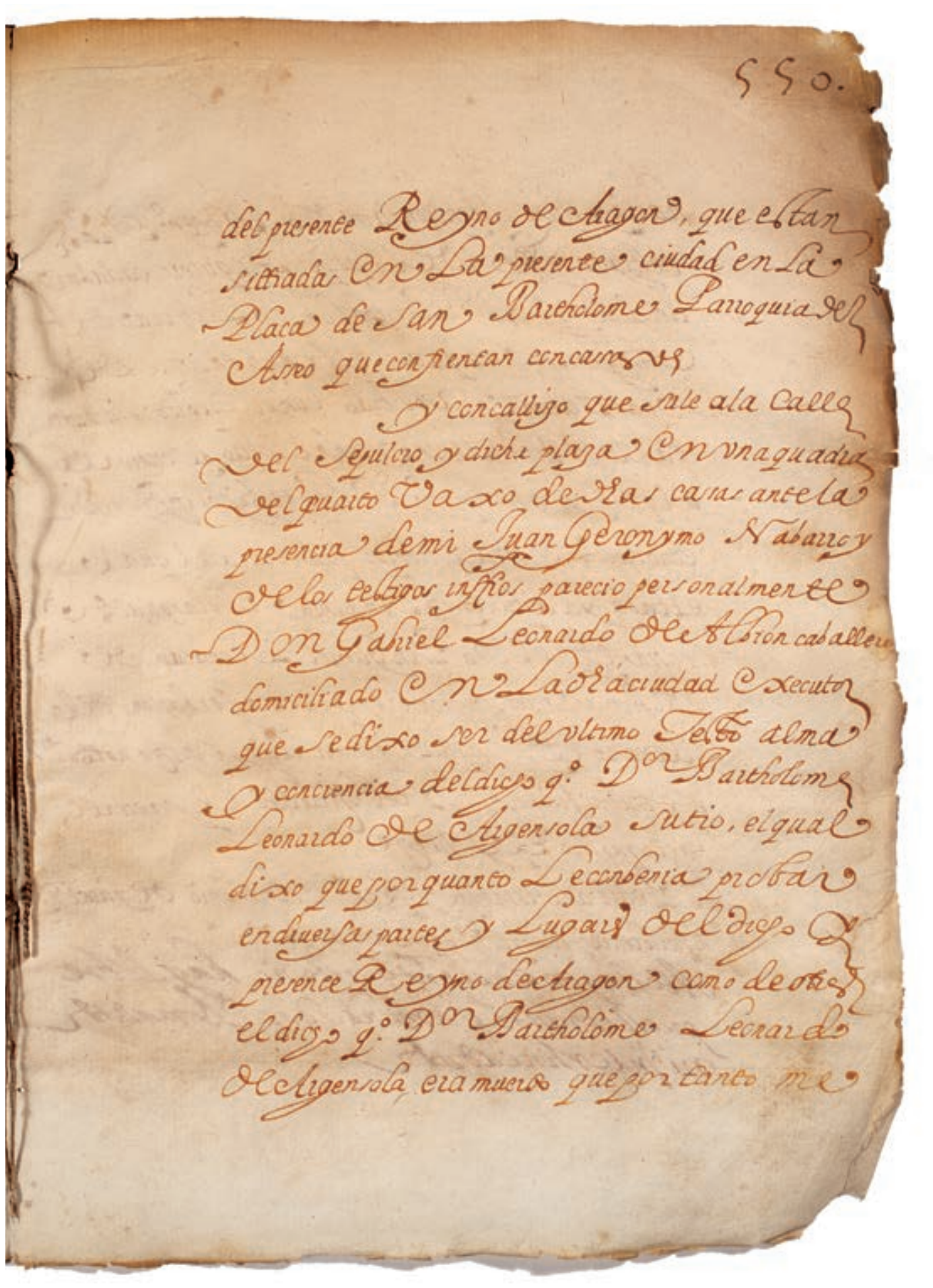




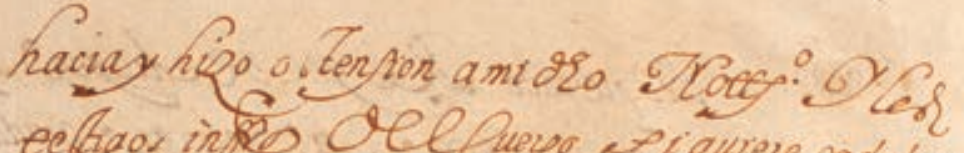

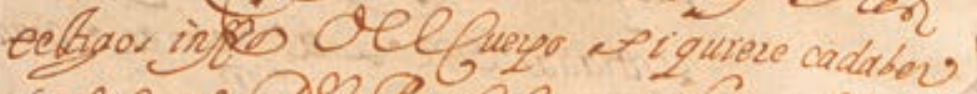
deldicio g. Dor Darchatome Leonards ore. cospental elqual cltaba encma ve

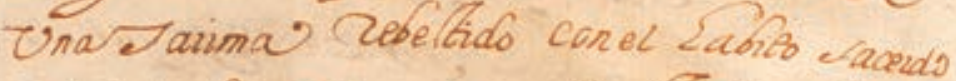
eal vo dini tews cance zaba de cubru to

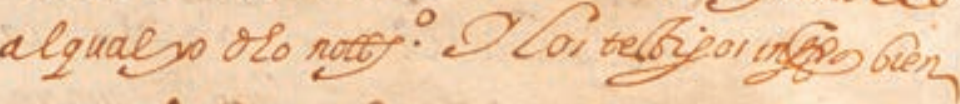
conocimas Onel Aempo que viaia el qual etafa va difinco g inalma. Delaygualso cossa el Tro Don Garrec Lecnardo of cttorion Endicin nombre por conferbacior del

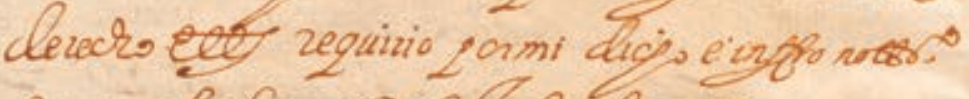
Sercoms fuenes 2 alafrado el verents acto publico eeer large.

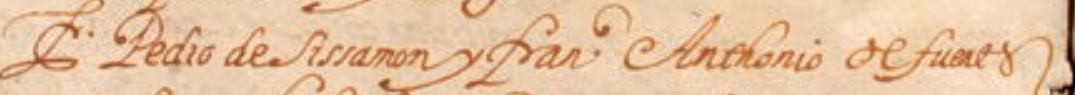
ef cubrenter habie? en Caragozas Afeltogre enelprte arto no hey lobe

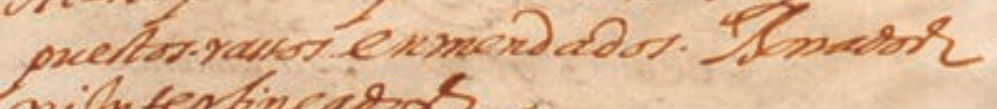
nifutertincioss 
Aprercian Ooden dreet aco. In Contrenciarny 1. de Detion. quarri continus ctree La preventia de mi dicho Juan Geronmo stabanoy oc as? eechor intro parecio el oro Don Labicel ecnarao de thrien como excuer que? raixo or corredicen oelvro Otimo zis oldices 2. Dod Dartholom a L conardo recrigenota' ques, a unchia Labra

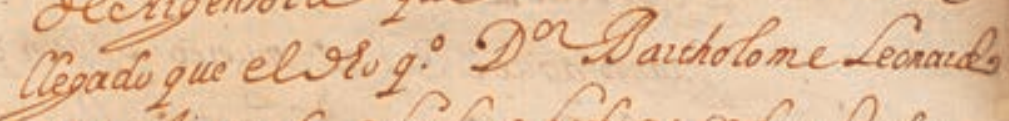
oletrienda nasia nevioy ordenado ho

Oirimo leter Thima volunead ondinacions difpurion derodos mbiens asrimobigh cumo retion habidos apor laber dondexis. elquar labiadadoo Librado en poctery

- marar delq. Diejo cere notes. pubar del numero que quevela ria curdad onvaluea of sace?

83 
cenada corrialay elladar medianie actoreces inv Ladiced fiudad of ? Carayoca adiez orete dia del mg

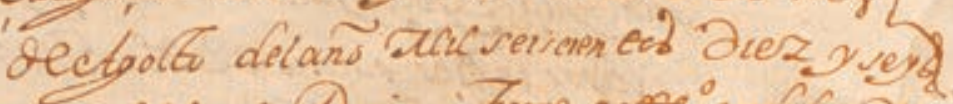
ponelroq: Drejo : Tecee nom: zecerido. 2

C. Eelaficado. Crelqual ro Devor preterdias, quechro q:D0 Sarchotomer Leonandorog etrpenola Lo dexara execuior épor? quarto aquil eva muetes zoun quejorenerow del Ria prox". Granizado acs pulicudy nmuere confaba sor anio quere? queriay Requirio a mi dich ejofor note jomo omis. quen dela norer decorog. Drefo

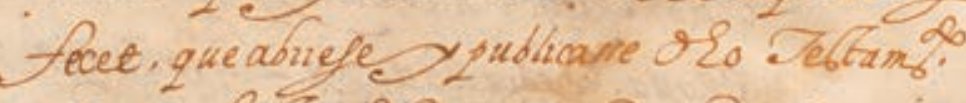
ain yeferto oeponer encexecurion Lavoluniad reliro velader. ce Carinena .odro Troa exifa. orendo a lo que eza cenids gobligado 


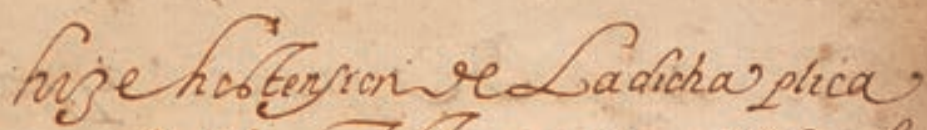
ollro. Tetameneo acicho Pon Ganiel eonardo deish

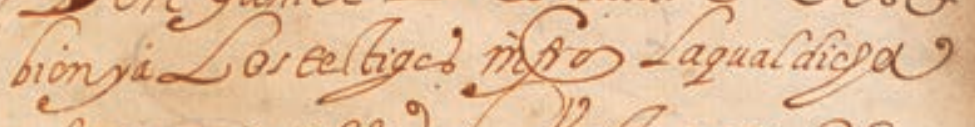

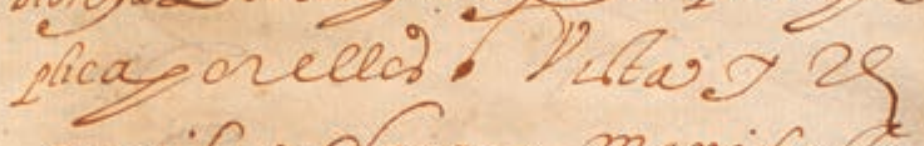
conocida, daras manifiera. mente Les contu eltars que eltáa cenadá cosvida $z$. rellada, usri e e equn que alvog: Dieforfecet LeEana. ido dada y. On. Cregada por dicho 9. D or Da? tholome Lecondo olesis tensula. Ean Vilta. - 2econocida ov gro rotario

85 
abri. Oe palabia ajalabia $-e^{2}$

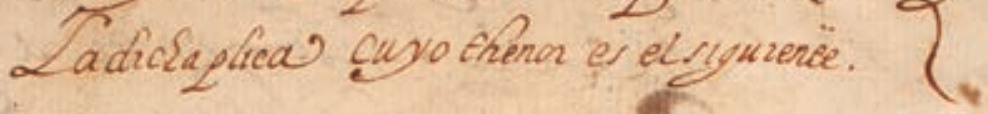
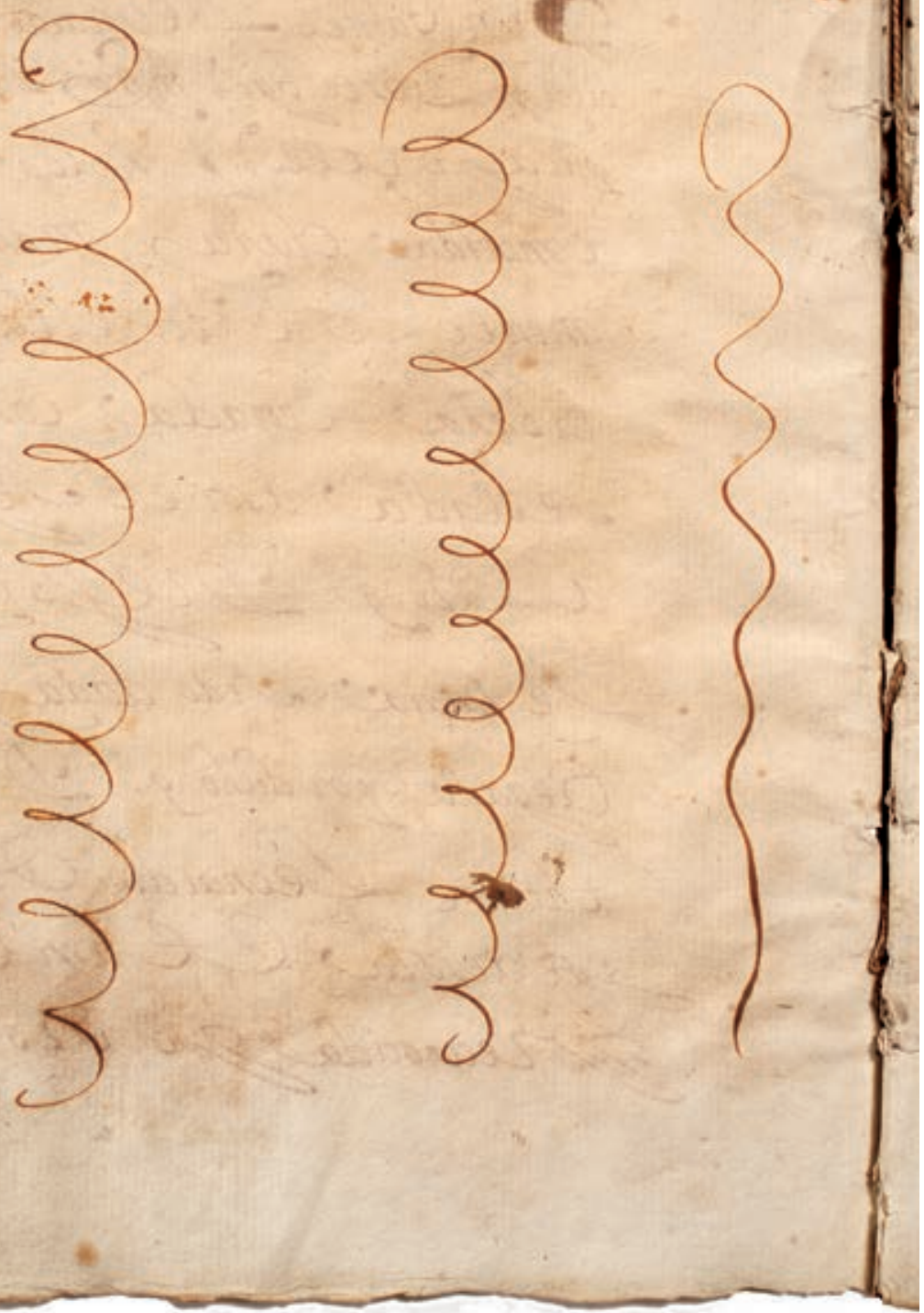
Die decims reptimo men 2 b laran है?

- Ptógusim di ct loco Antela pricia de mi

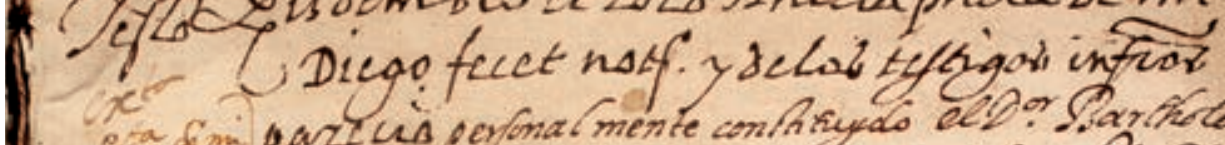

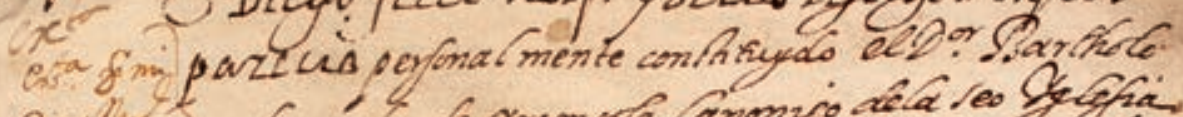

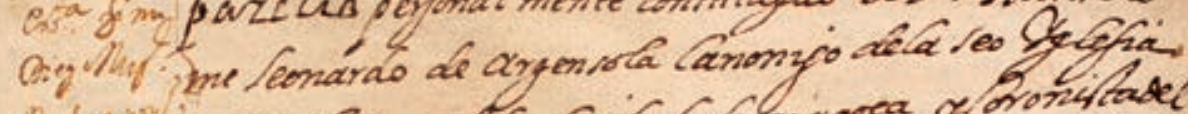

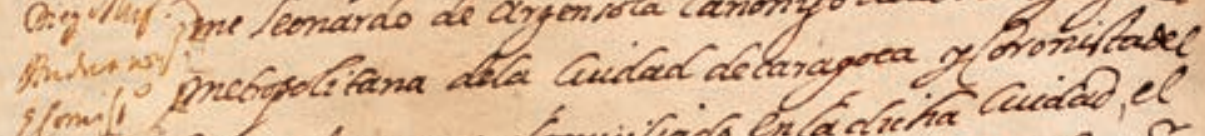

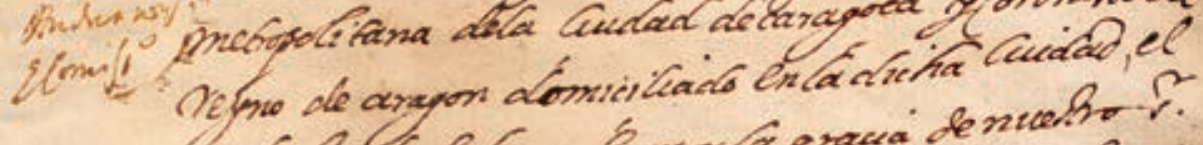

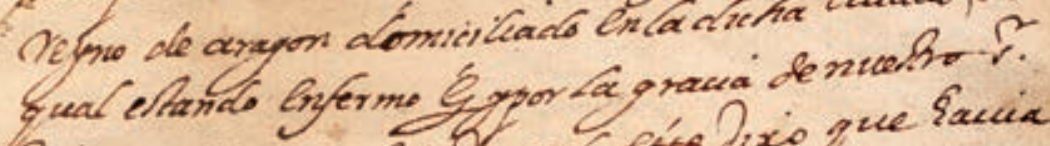

Drsi ensubuen. Ar ets Deqrado éét Dxo que Saucia

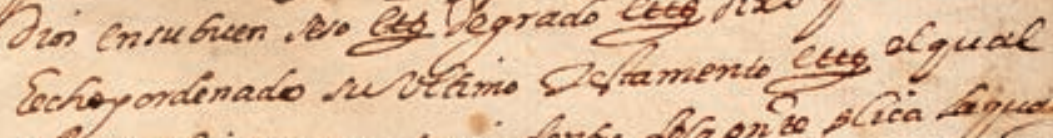

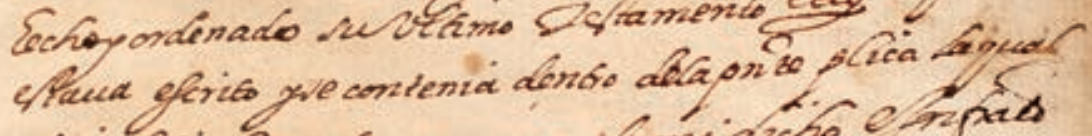
dugictio enpoder ymanos de mi warho o-mpats hotaico preventer los telzion inpaveritos cerranay.

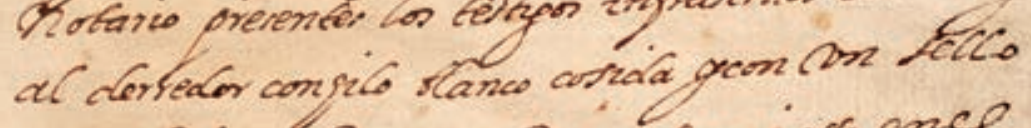
bre holia cotorada, shepapel zmpresto once

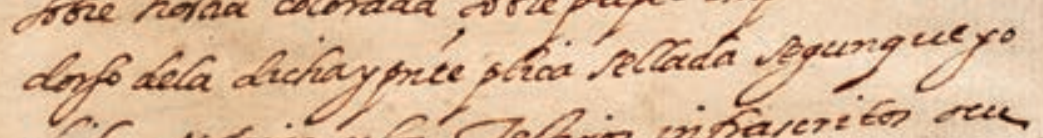

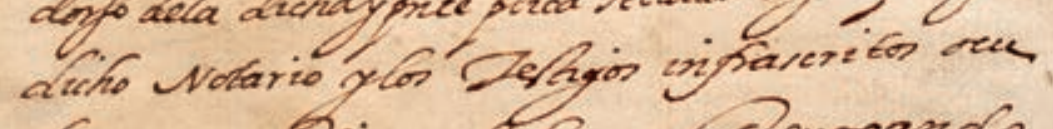
carmenes Simos Etque Cloursando

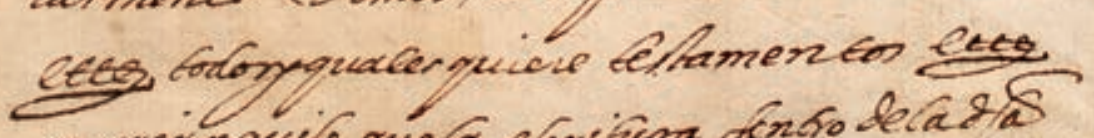
querionguif quela efcritiona dinfo detahs

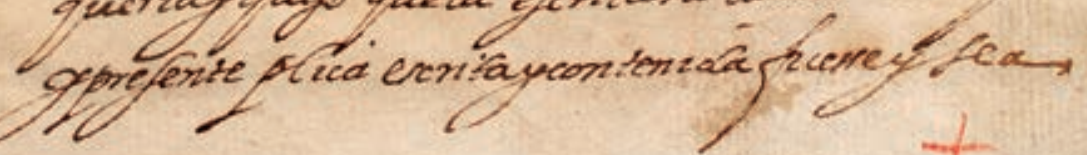

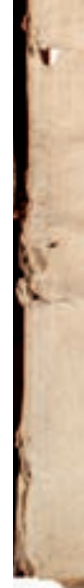

87 


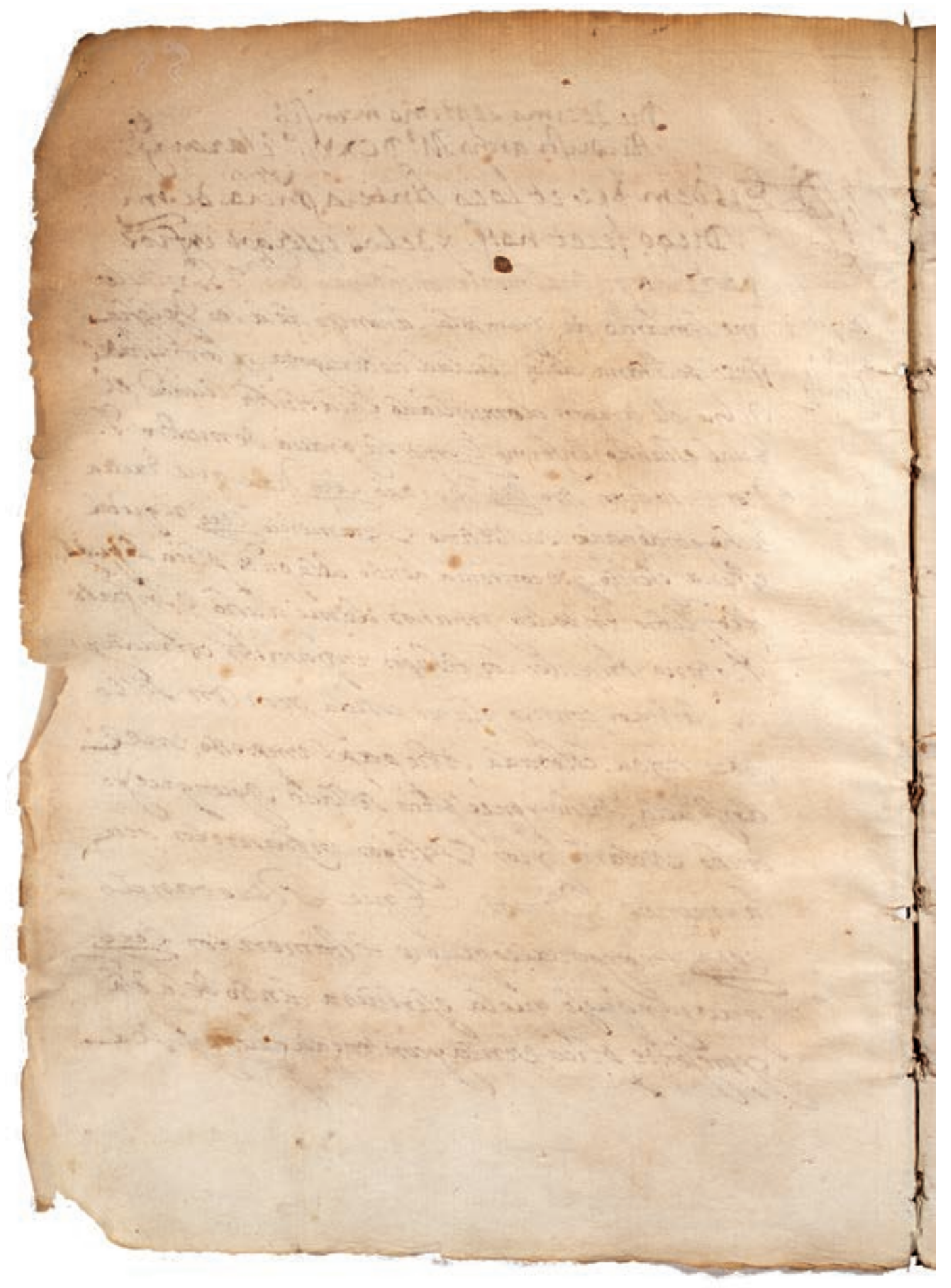




\section{tit}

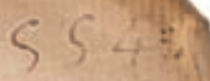

\section{E1 N OWMREDEDN CESTR}

Senor Dios y de la quajisima Lingen Taria indere ruyay lenona UNeftra, Camoperiona alquna encanepueta de lannuereconfonie? efapar nopucia y no aya enelmindo cona alquina marcierta que lamuer te mimas in cierta que su hona iaqual onel amino defodo

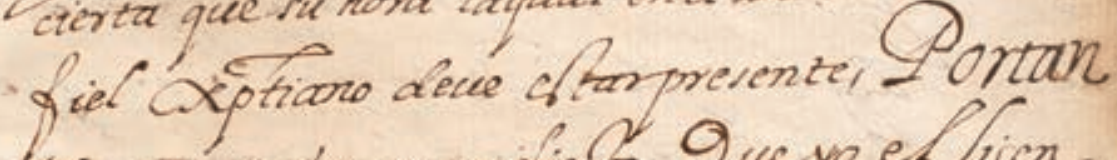
to sex atodos manifielo que yo el Licn

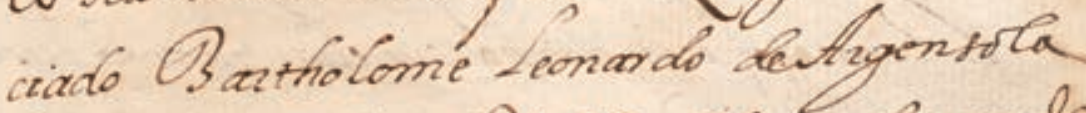

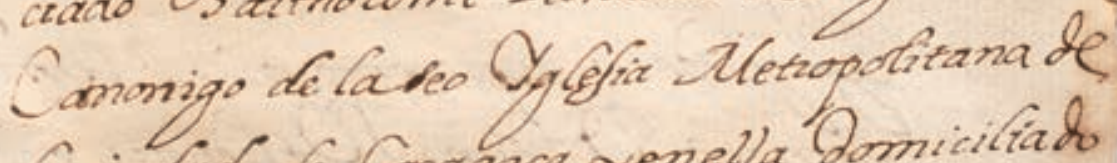
Caciudad de Caragoca yenella Dominitia ho

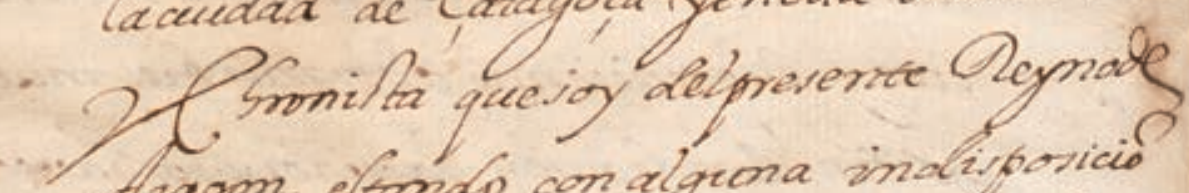
Aragon, etimalo con alquona inalisoricio demperfana ypor lagracia tenueliov de

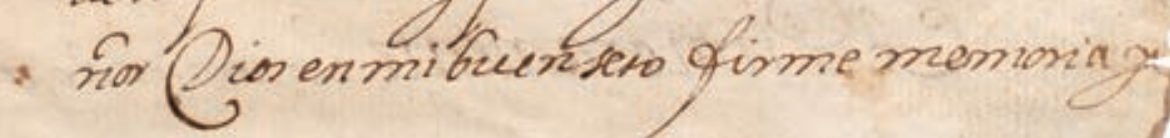


Databra manifieta Aciocandoy annul Condo como portenor del preven ac Qeuacory annulbo ypor Oeuacador y nullor ala rey za werquieno Dodosy qratelquiese 8 tomen

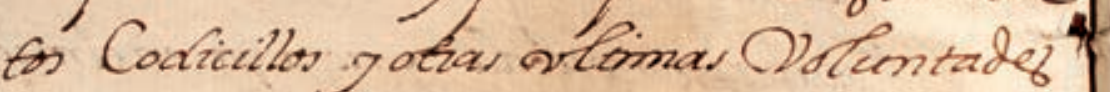
gariporiciones de mis biend queyo antes de agora aya hecto yoralenado, Mpordidencueuo deg rado ydemi vienta raiencia, en agueliame fores Dita modo formaymmera quean for

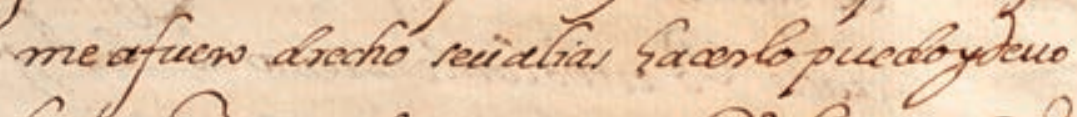

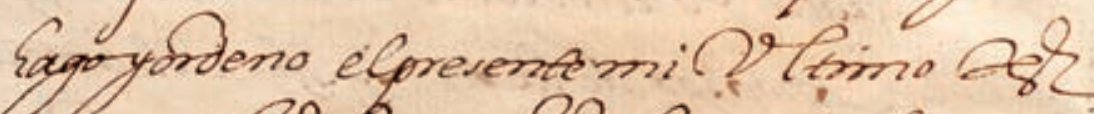
tamente Ol tima OAtrental or tina ciony diposicionale folormis biei muebles ofition doridequiere Squidor y por laverent Somanera fiecuentel

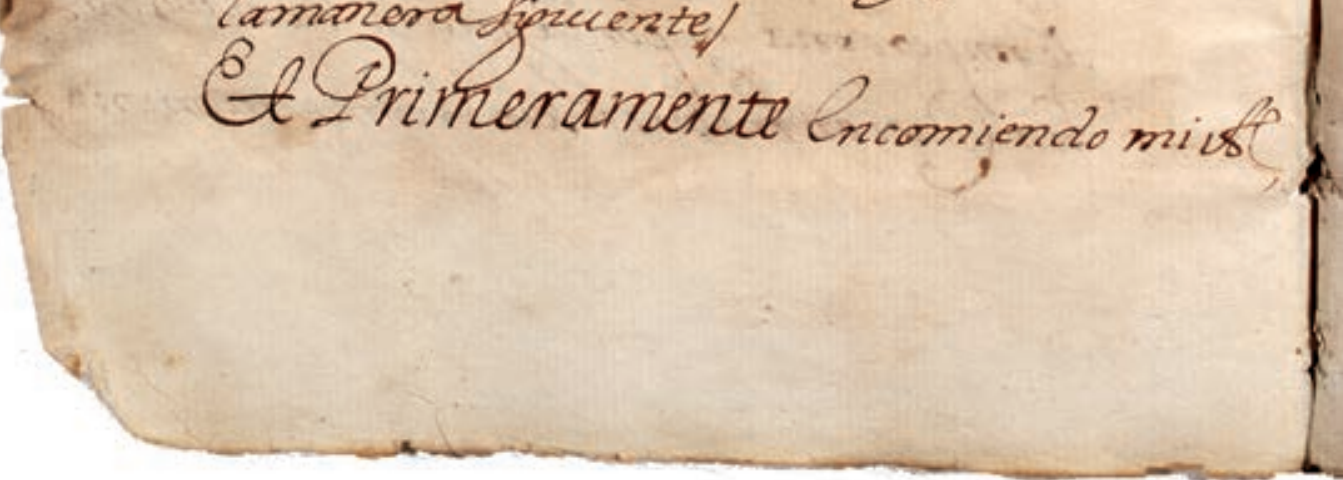


ma a Wrósenon Dios oridobordeaquella aquien humilmente suplico quepues lase, dimie consu vacratissima tongre laquera.

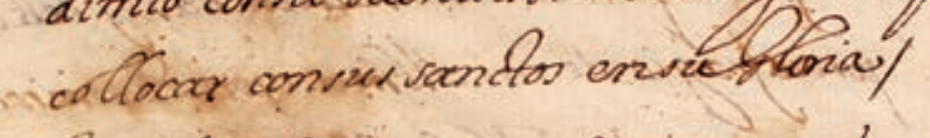

- ClPM Quiero ordenoy mando quefiem pre que to muriere mi duenso sea enterrado en la dicha Iglevia debareo intaparte ylue, gar enque re acostumbron enterrar Cosde, mas Canonigos della mir charirrimos hes maros, endonde quieso sehagan midefen fion Nouenay cauo decino bieny Conma damente aunque con to da Raneca yu impam padguna, Daraloqual quiono fetome de mis biener y que enella Segatte Gquequere, necessario y amis executores infearoritos Grentritol.

91 


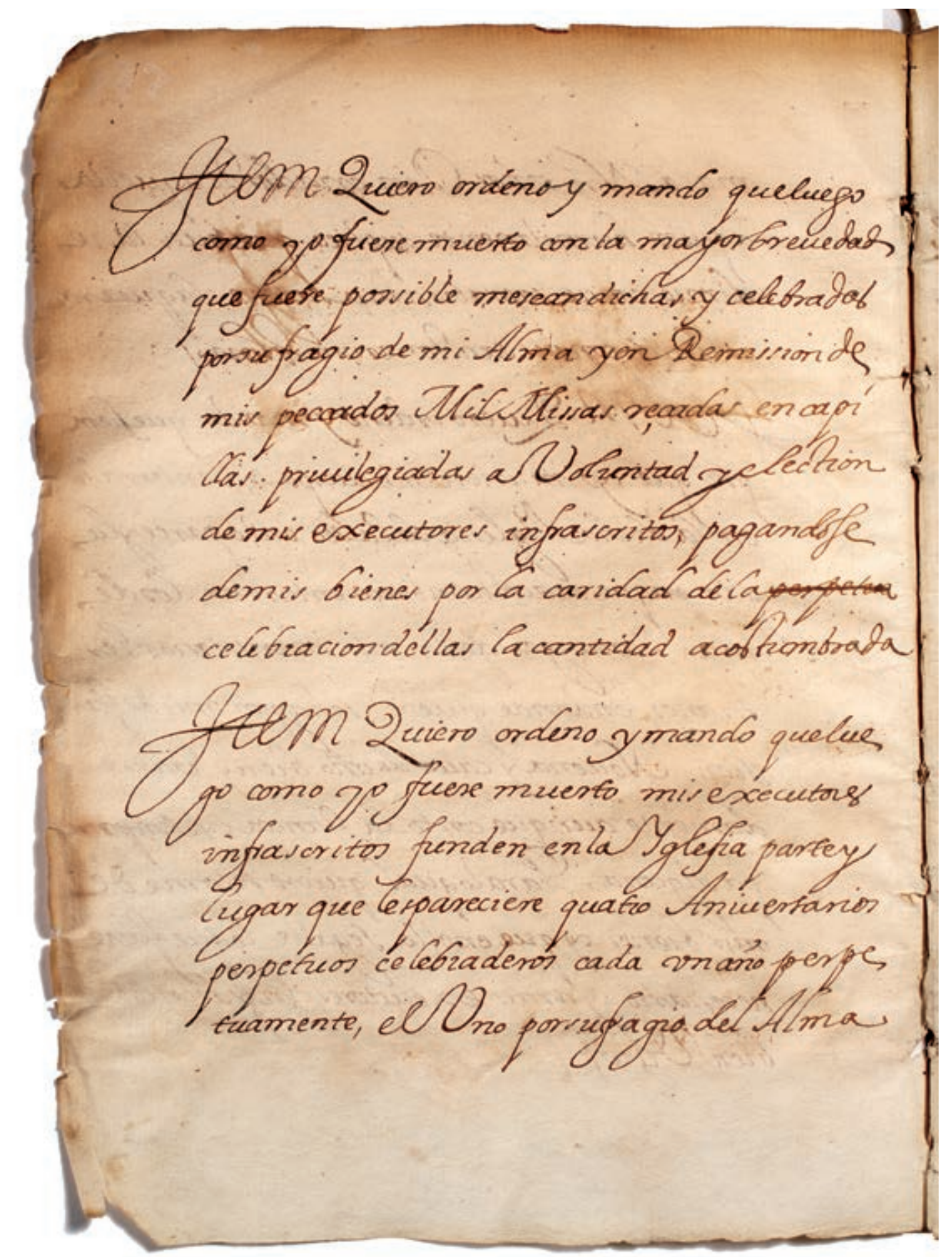




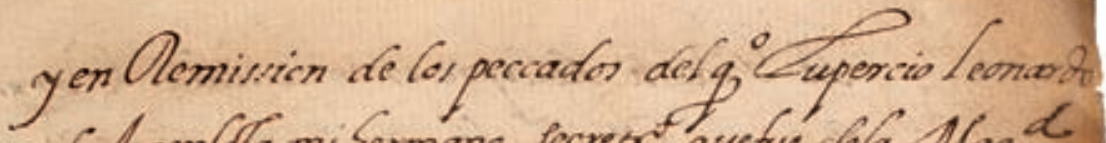
de Angenfola mi Sermano secrees. quefue dela Mag. Cesvarea dela Emperroib que ayagloria, ylostres ver eanies porsupragio de mi Alma yen vemission de. mipecauder y por nufragio detai Almar yen Memis jion delospecrados demispadres y Sermano qayan gloria, Dandore porla chanidad dela perpetiua ales bracion de los dichos aniuersarios la cantidad ne

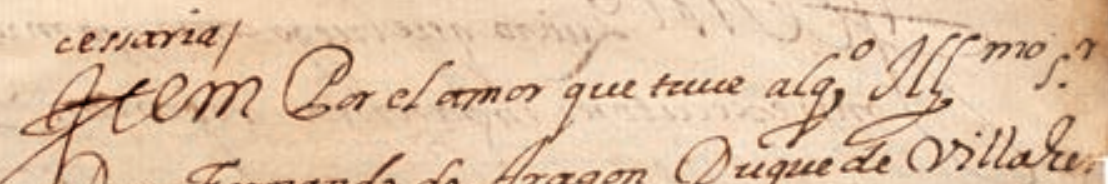
Don Femando de Aragon Duquede Orillake.

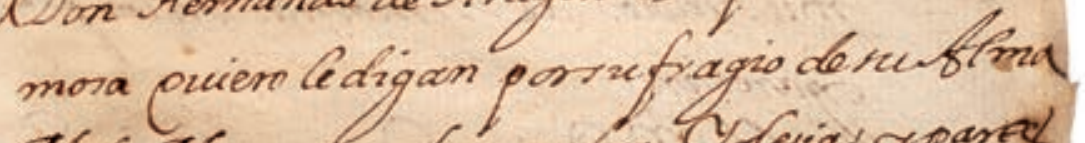

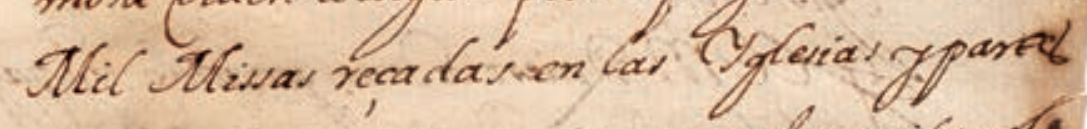
que pasecione amis ex eartores ingmesoritas gla charidad dellas sepague de milsbienesl

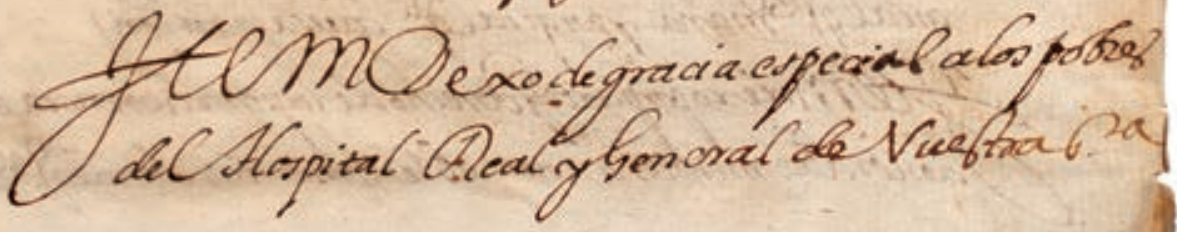

93 


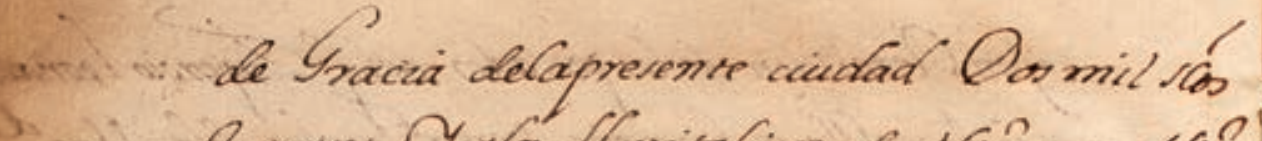
Gaqueres, Yalos Aospitalicos de Viño

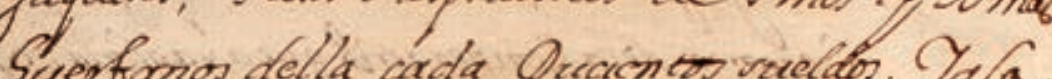
Saeranos della Capilla de la Madrede Dios del Pilar dela Oicha y presente cuidad othos Docientobs

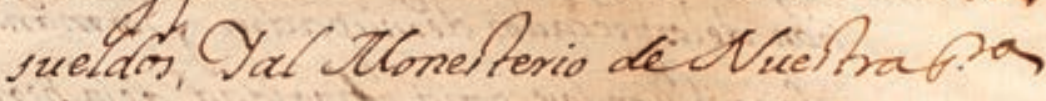

- de Honservate ofros Docientos suelaroy

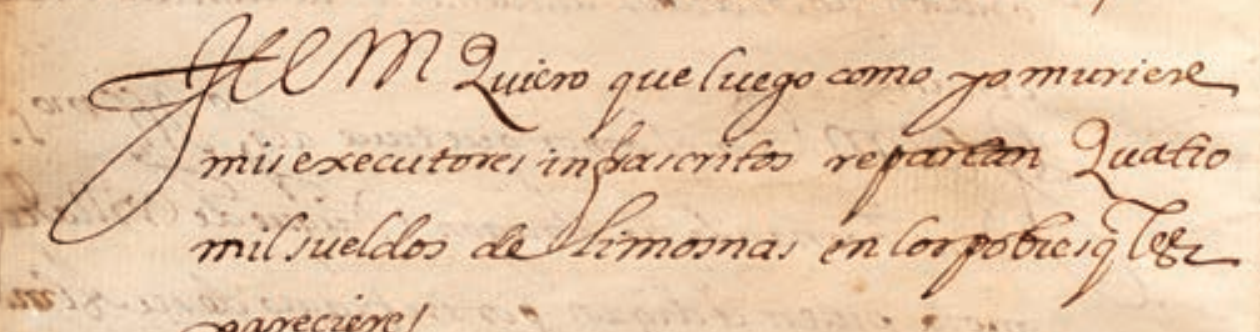
miverecutores inparmitos reparian quatio milsueldos de simosnai in lorporiglez sareczere

If tem Quien dono ymands rea pagadarya

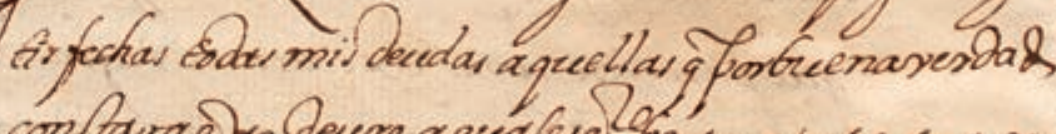

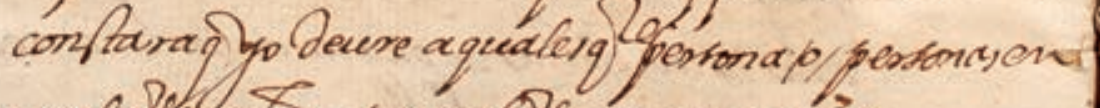

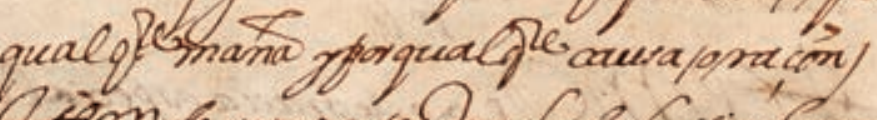

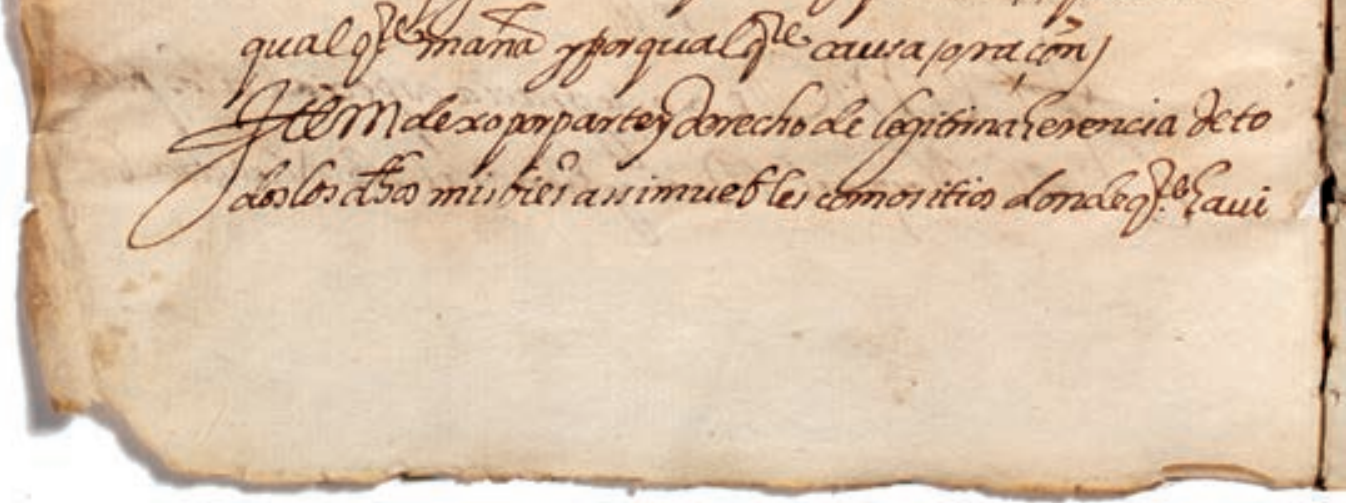




\section{SS).}

Los y porkauer aqualesquierepertona $\%$ pestonas que pante yolerecho destegitinake rencia on los dichor mis fienes predan prefe der Sacuery al ancin cada cinco vecloborpor fiener muebles yotendas ardobaldetierra en los monter commorer de ladicha y prevente cuidad porbienes sition on lo qual quicro ymandas teayan de tenesy eengen or con tentos safishechos ypagados deto da yqual quiere panter Derecho delegitsma kerencía que ontos dichos mil fienes puedanpretendes Sawery al cancax y que tan Stamente alcancen

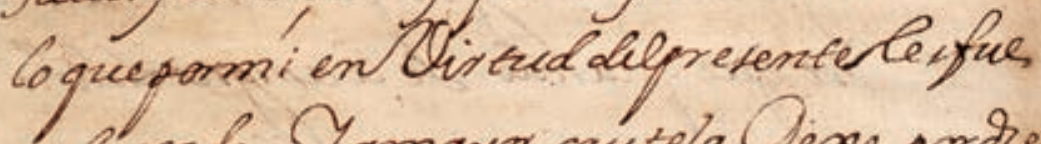
redexado, Yamayor cautela Desso pordes

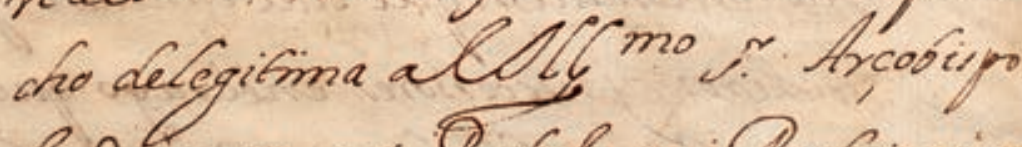
de Caragoca mi Prelado mi Areoriani on 


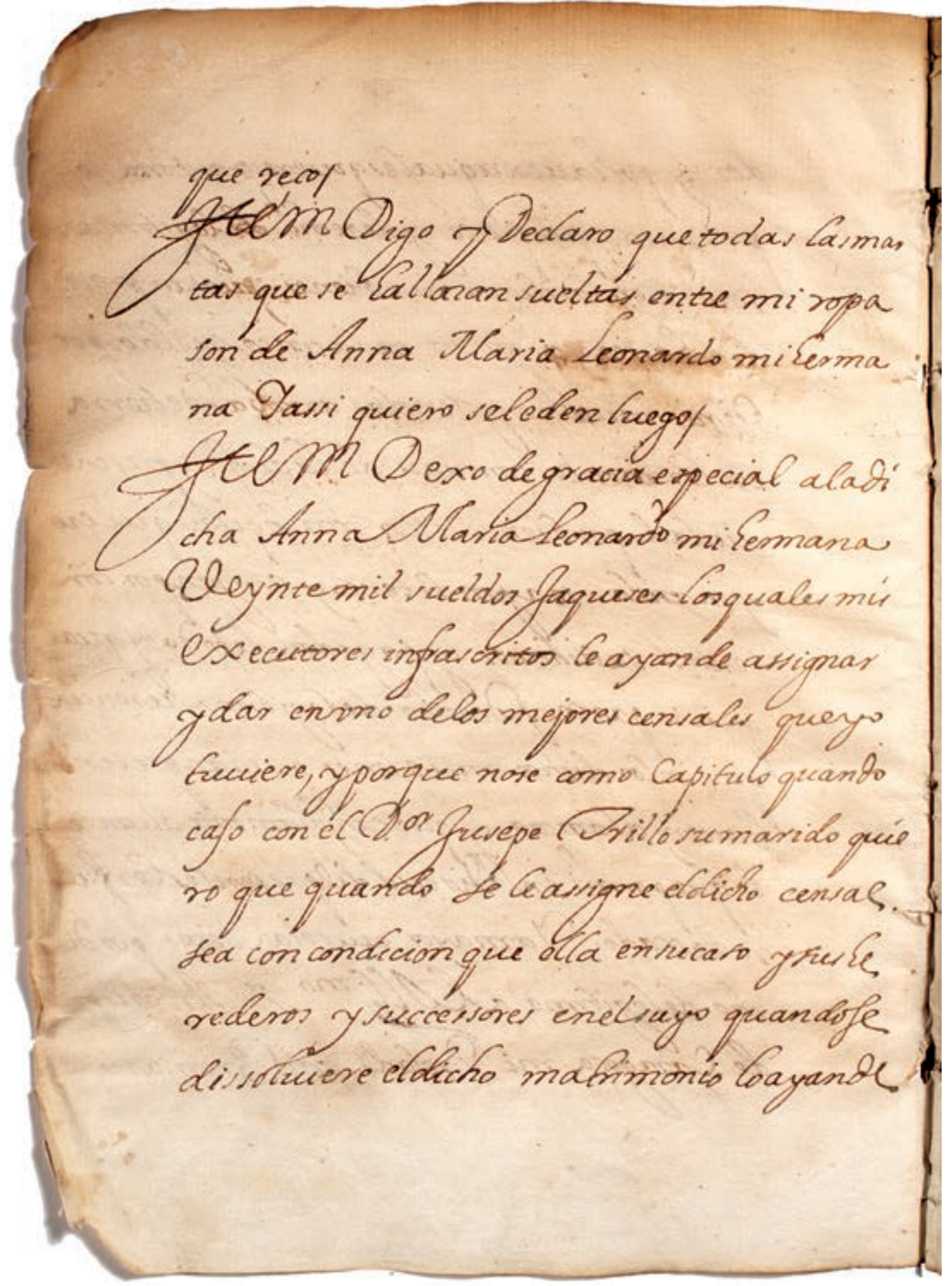


Lacas enteramente yim Liminucional guna, logual elalichoru morids aya decou
fontir assi Saliendose en racion dello Cos aftosqueconcuinieren parreguridad, deladicha mi Sermana a Octuntad, demir excecutore infraceritos/

1 lon Dexolegracia expecial a ti quel de Pilares Moiñ ycuidadars dela cuidad de Barbaftro ho cyntemil vuides Zaqueser Grquales mis executores ringatas Ceayan depagar convignandole Ca lilición cantidad en snolorenmas delos cenrales quealtimpo demimuentyo Eucieres pallospanecien confignarle, Corquals dichn leyntemil vueddos bexo aldro

97 
Miquel de Pilares onexpressa conticion Ipadto que etaya dediponor Dellos envus Sijon Eegieimos como Cepareciereyno enothos porfonas algronas/

He on Dexo degracia eppecial a los de Sijos y dercendientes de froncisco Iuerquete Y Sabel Dudela sumuger permana. . Le mi madre queayagloria Vefinos dela dicha ciudad de Balbag ho Suater leyn - temil sueldor faqueser Corqualer miseses cutores inpasoritos ayande repantin jobs Gibuyr entie los obredichor posclondeny delamaneraquelerpareciese Attinonien is ala necesidady Uipted quecadorno dellos Guviere yala Meparticionyolfifitic 
cion que Gosdichos miv éxecutores ficiene se aya destary sf te in reciaro alguno y cllos puedar pagarypaguen Gordso Qeyntemil ruados endinero de contado 10) enrnilo enmas deloscenialarqueyofic well m enseñar de tma Oexo degra cia especiar al muy Irgy 8 mo rom fray Seronimo OBaptifta de la Vuca eleto Lobipo de Balbagtro una Medalla queten go de Oro conel Mefiato hecho de Melieue, de Vuebro muy to Pade Pacelo Papa quinto conma empresa que allude ala cormaciondevisang In aqual thedalla dexo aldiche veñon Obispo por Lasmucha. ridulgenaras of aquellatione, yruplics a me

99 
Tenoria featemcido de encomendara Diosm llimal ftem Dexo degracia especial guenieriac de Amor a Don Aienrriquer de Calto Cano nige de la dicha Yglevia delaved Dos frebria nos primero ysegundo muy cariosor ybuenos que Vienen entre mulitson, Y pontamima causa desco De gracia especial a licenciado fuian Perels aleshreida Canonigo dela dra Yolefia dela fes on Tertutiono quetengo con Comento de Iamelio poser líbotancuriovo doctol

Otelm dexo degracia especial yenvenare de amor a Tlanin amberts. Ymiqueb eu dadmo dela dicha ciudrd Lodas Larboras que tengo del Mlarm y la Grelgarer Ytalia nau quevienen en las Saucto demiercritons 
S60.

gronde de lbomo।

All Pigi y declaro quevel tDan Germima de simentel Sijp del "Conde. ide Benazicente me hade Imbiar de Clilax en Piego deler. Marques de Seluer qua to viviles de chrifal Cos dos de losquales de

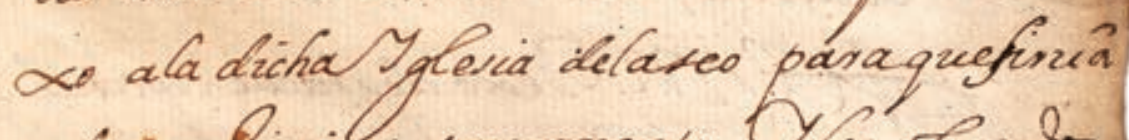
at sanftivisho sacromento; ty fos ofios dos dexolaladicha Iglevia denuefradeñora del iilar para elmirmo effertol

Tlom Dexo degracia especialyense ríb de amer a la reña Dorra Genonim. Caporta un Melicario quetengo bentrod ona bolsa huel yona cadenilla de oro of que aquel ef tapendrente y quincepiedso

101 
de Lucot pasasacense vina Mlanile Ple pr enveña de anor Dexódegra cia especial a Diego Secet Notario puto dedimeni de La dicha divida essra so pa quetengo de Damaico aforiada er reas/

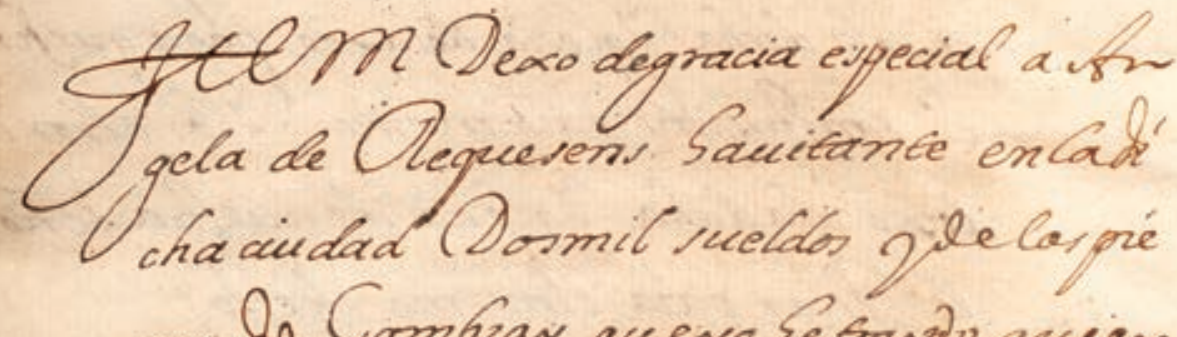
cas de cambzay queyo ke bayno qucers

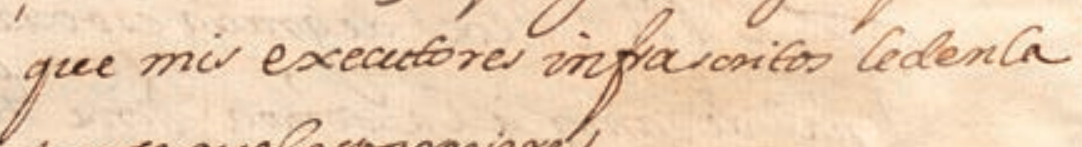
partequelespancienel,

fel Dexa degracia especial a lie. nomimo Nequeren. Notanil Peal safi tante en la dicha cuidad Mil sueldor 


$$
561
$$
I. Atlon Dexo degraciac especial a Peds Jencido Dosmicl sueldos Gaqueser, Hebm puieno que las Oeliquiar ang samos Alosarios uefar de otores yotras algunar que yo tre eraydo de Ptalia $y$ fon mas decurioridad quede Nalor Se ditribuyan dela manera gue parecierd ami Ecreden yexecutore in piascritor ta mandejfe dello eldicho mi seredero loque fuciereporbieny fuese De rugublo,

AtCm quiens queluego comoyofuere embie ala lso ma jonosa

Donafurana de Perneftan Duquera oe

Dilarermosa aguien yo romamence

103 
Sederreadoy deseo venuin in Areofiario

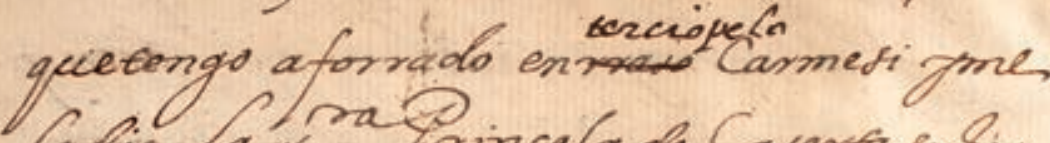
Gdia la ma Irincefa de Cavertafurer mana yfue dela pa Pona Tharia Manfrique sumadre, paraqueru $C_{6} \alpha$, Gode asu Alteca dela des ma inganta Mangarita lo ala ra Lor unfidelas lla. gas Sya deladicha ing ma Mania Uanrique/

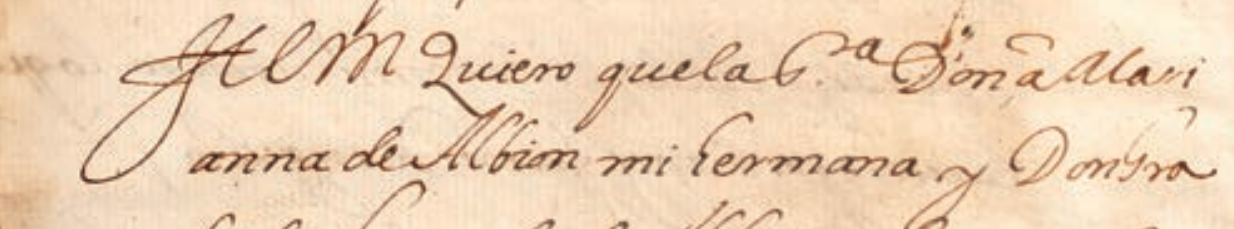
fiel Leonando de Alfion unijoy troino - mia no offtante Goqueyo abaxo dziponjo Eomen arusmanos ven Oelogico quew de Mlitan labrado de wiftaly muparia

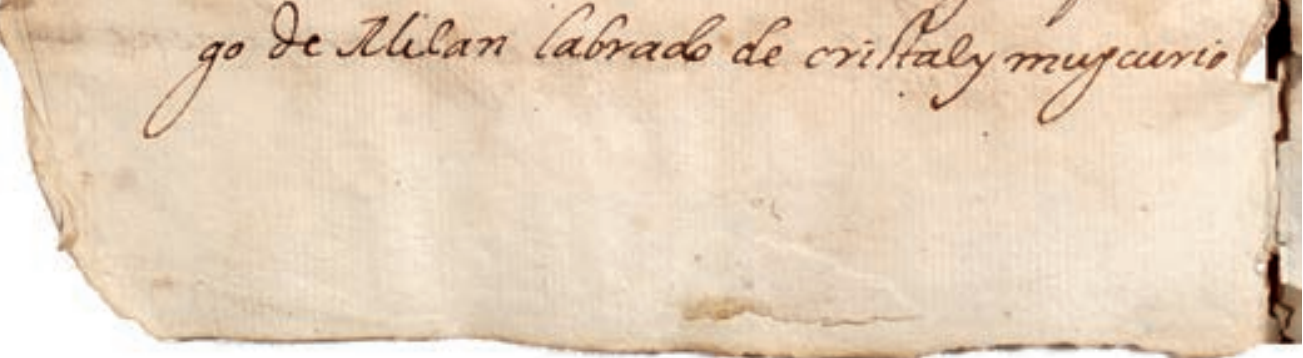


Lo Un lifrico de Oroesmaltedo quem dio la dicha Nalerincefa de Caserta on adena. De brocher quetiene terentapien of Or.ticario de Ono emaltardo green

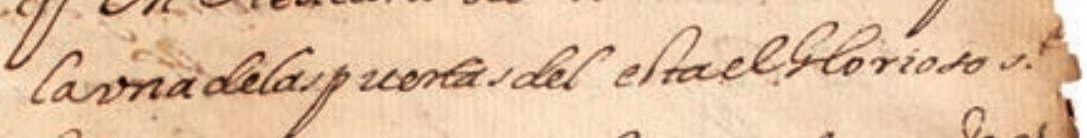
Genmimo Jiguatio rontijur que tengo des' meraldar muylincta yenademtiam tequetergo quicionquespequeñoerma - Cindoyrico pria que iengo devnama - que ceruno delar Htmoneda de COLyn - y fie rel Metrato dela illag delay Don Drelipperegundo, Sodoloquee quien querequarde porlos diores me Sermanay sorino yquequando ags fecavare Golen entenal de amormio a. mugerconguien recarare queyo quirie

105 


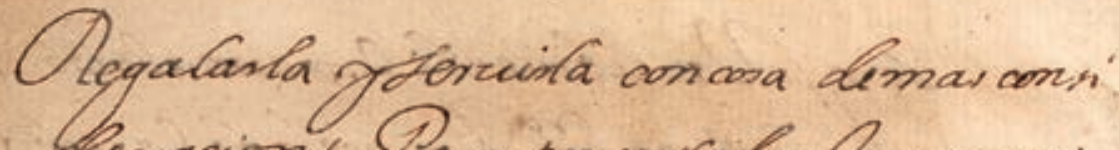
Senacion/ Pen porrentoduefomuy i Gueñoy uorioso me hapirecicha quepara quetuuierte memoria demi of acostaje

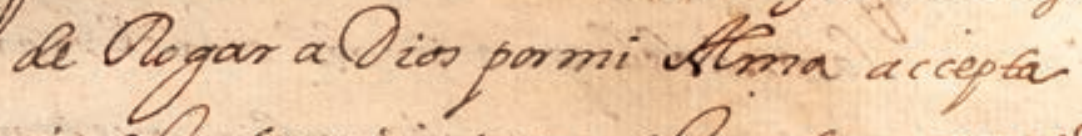
ria efte fenuicio pormug ba demivotid

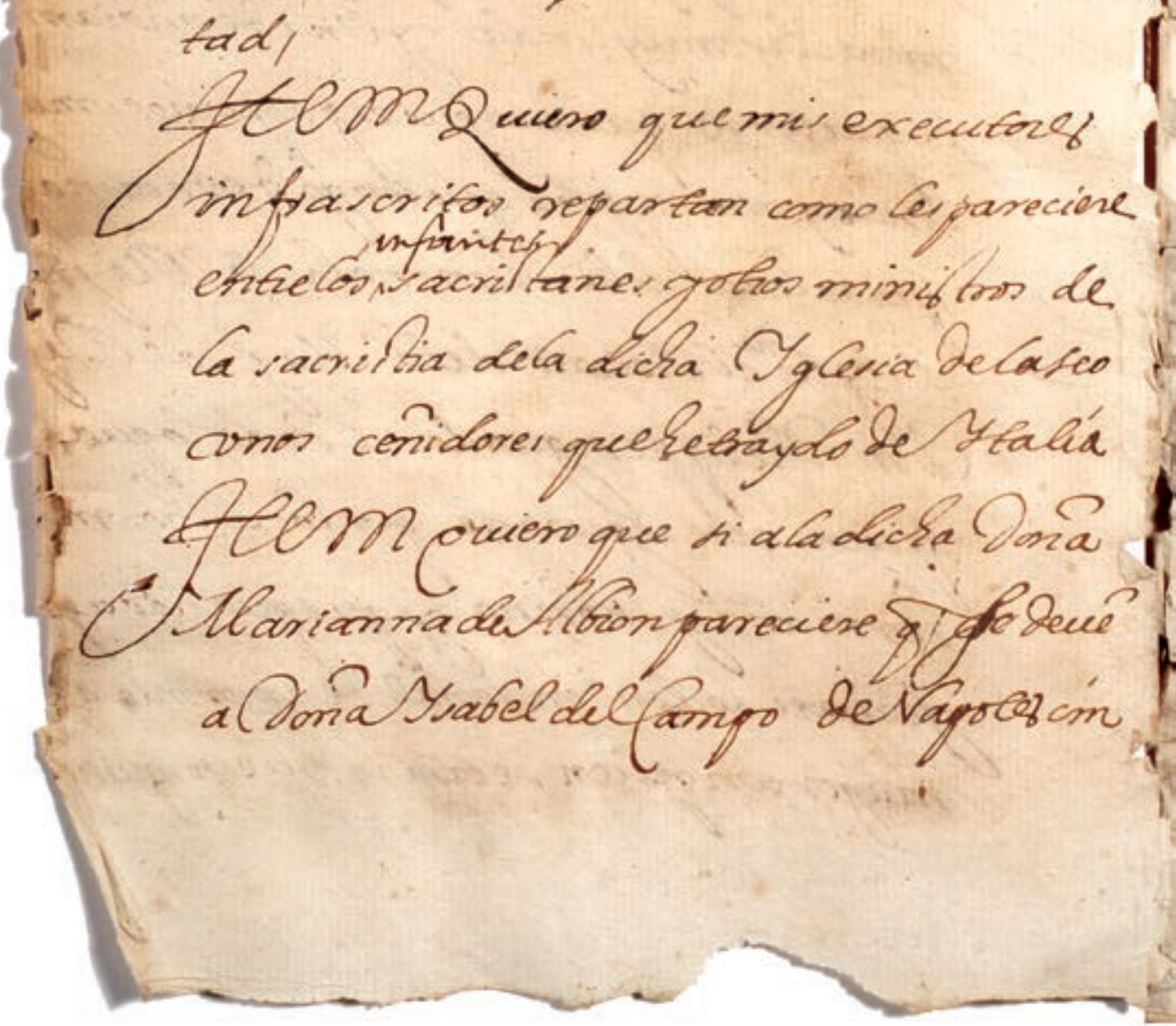


quenta Oucadonde aquellamoncela Selepaguen Guego de mubiens: All m Porquanto Eeententito quecel Q or Grien OBerbegal Canonigjs duladsay Y Glesia deta tio prétende queveledeuen Dormitsuceldos queeldie en a presenfecuidos paraqueyo Grtresse en Mladrid a C Capitan - Berbegalvulermariot lelogyalyo pora ra natengo minguna noticia acuerdon memona, Sero tampoco eciero quepor racondelle mequele mingungenende eforupule, Dotanto puien quecons con delos dichos Dosmil-uculdos feay. deftaryefte alogree eldicho Donfuar Bentiegal dixere, Demanona quectiel \&i verequetiencratifacion quelos $250 \mathrm{~d}$

107 


\section{I}

Domirirueldos nofuenon pagados al diaro Capitan Bonegaluremano Hetepargicen frego acl

AtPpr.Digay Declano quevienen dos copfes acliorosmios que me freten de Iffaliay que entredelos wiene else 1 qunds oftumen de los convejos de Cllar. quei de Thorcon enfrelosqualesvienerro muy penficicial al presente Meymo de. Aragon yque reldichs Tlarquerembiare the coniefs paraqueregonga eneldichsti Qro en lugár deticho conrejp tocante a Aragon greentilcaso delalicho botu men requite el alicho consep tocanec a - il Shagon y ofro queay toence afferice jot (1) queay focante alutboad lamano 


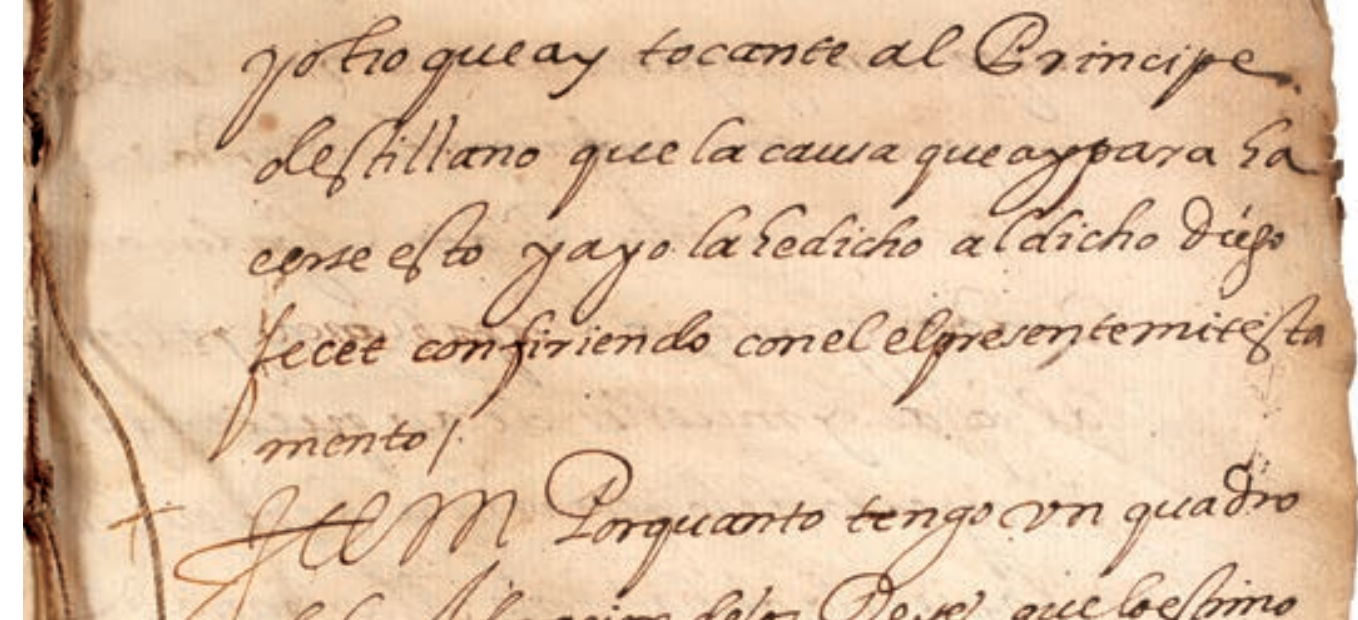

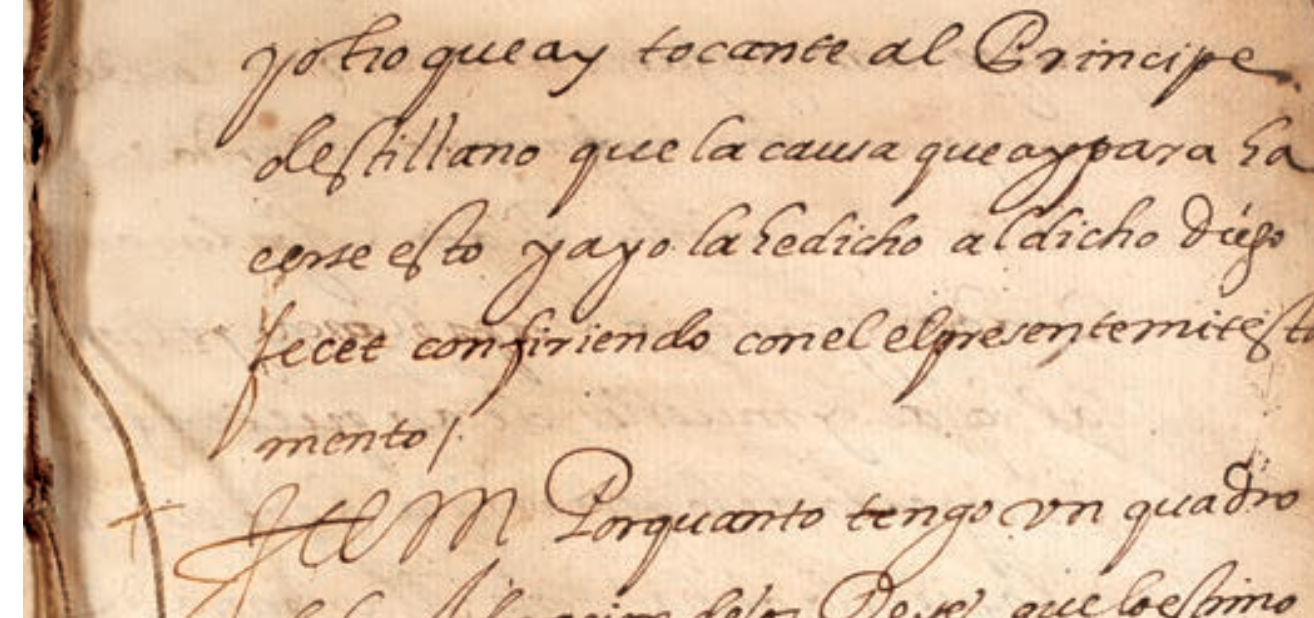

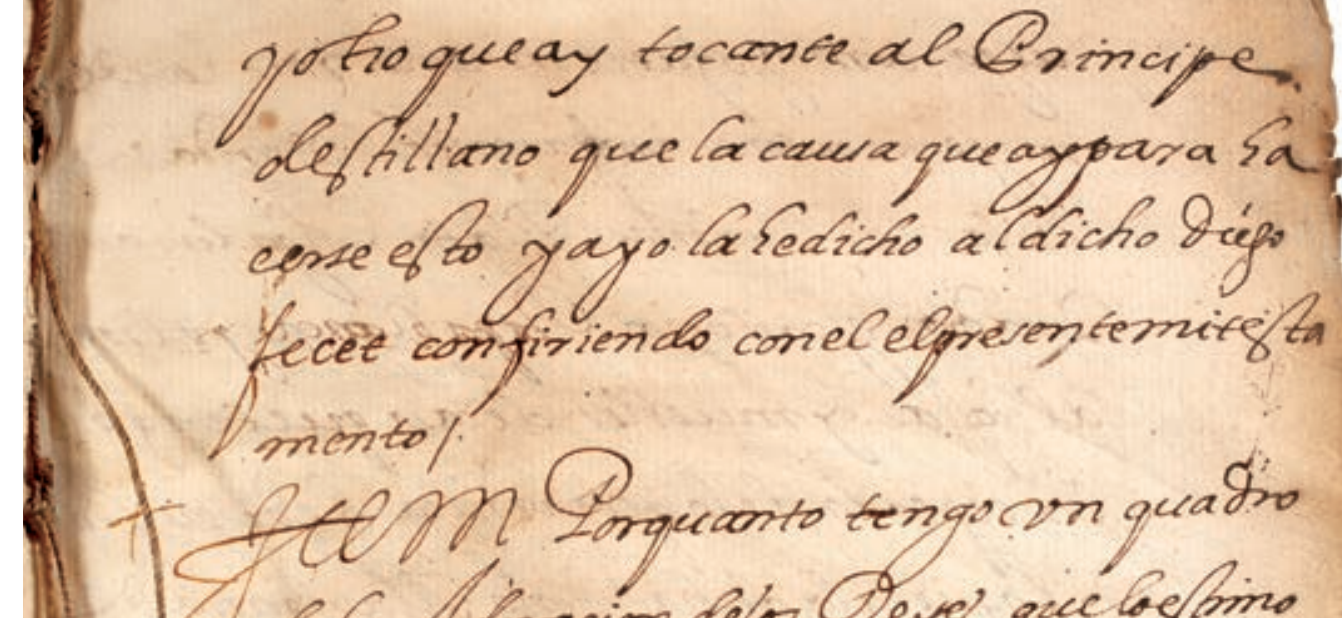

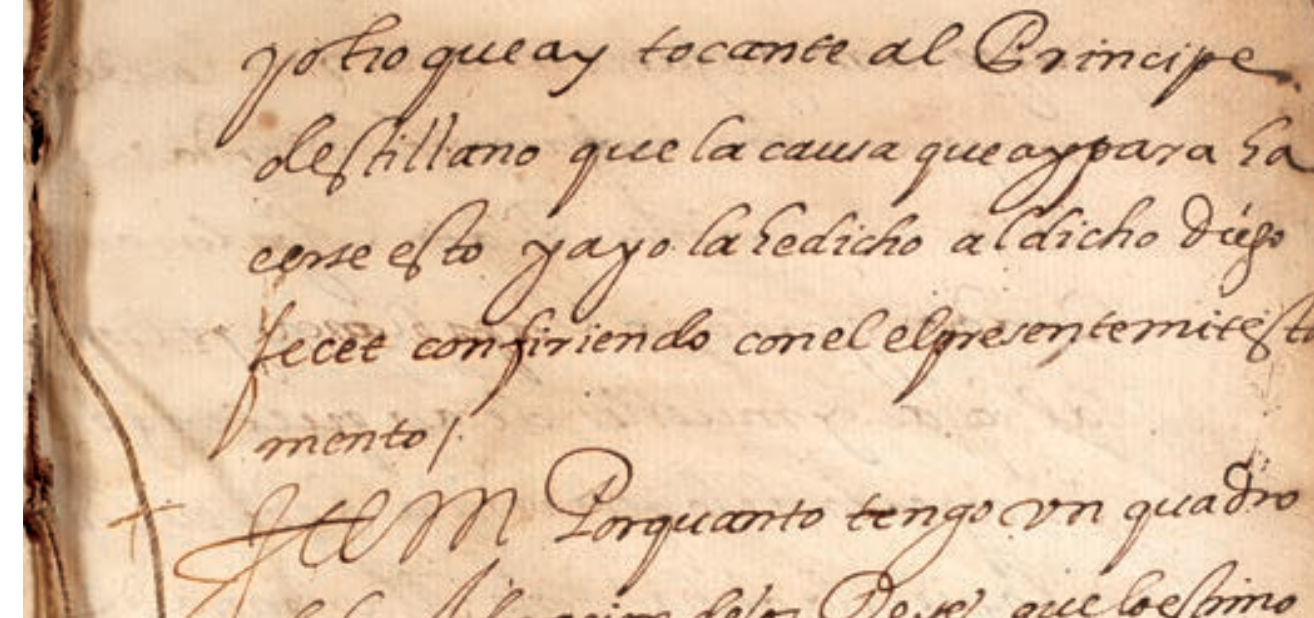

564.

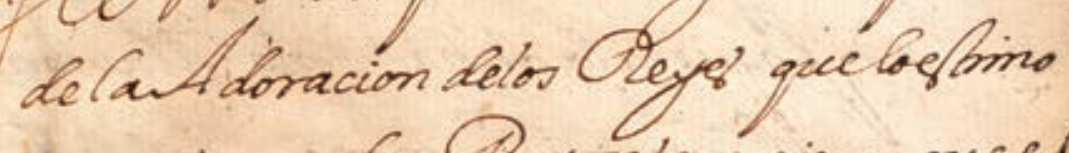
forecio mucho Portionto puiero quecel ficho Don rabiel leon ardo mivbuno tenga consenuey greasde eldicho puabo como cosa pamimuppreciadry ff timala y I Oios Cediere Eijos Ldexe Pinculato alquequese senó de rucasa palonquele fuccédierenenelia/

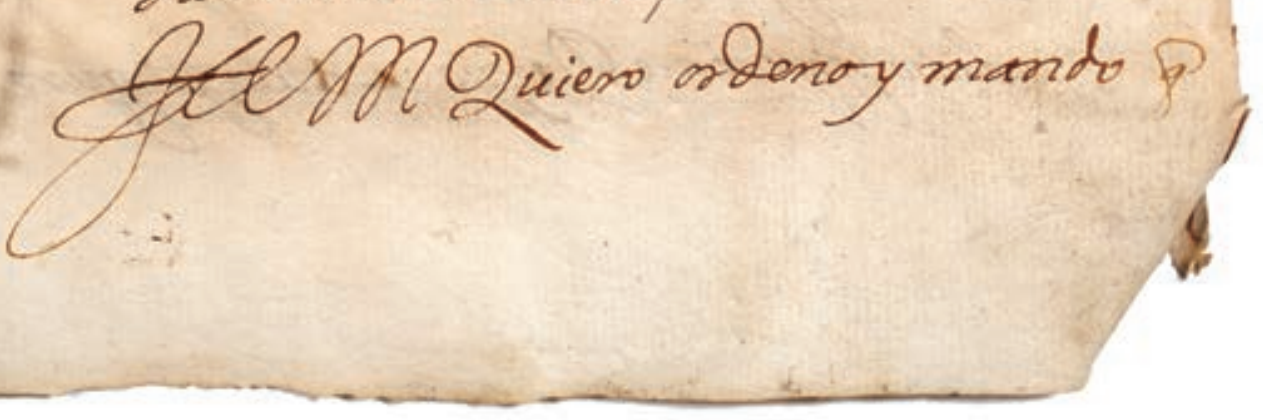

109 
Guepo amoyofucemuento mis lesde nyesecutier inflarenitos veendan todar a, Cadenas, Plata, Cofadunar:

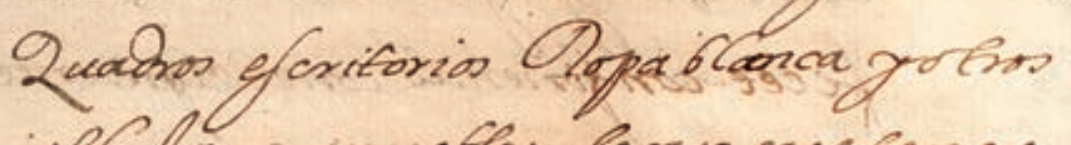
alsafas ymuetter decaraquetengo exceptads delogrecarriua kedizuelo - Coque dixdicha Dona Mariannade Aluion mi Cermana yaldicro Dor.

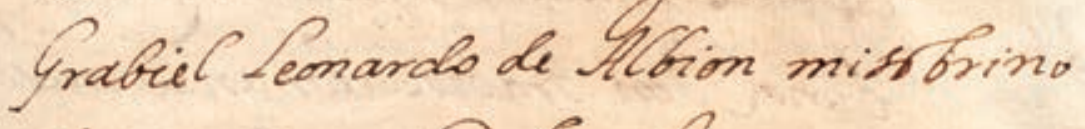
Cesparecieve sen Defugue to porevacausa. fequivieren quectar conclio/. Ytadoto queprocedien yferacare de fouravile

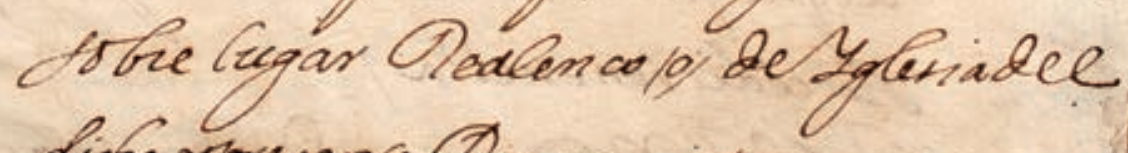
dicho yprevente Deymo a tutoyfeguero al

110 
nombra enfaur delalich Don sra biel teonardo de Alloion condrene Lin mia paraque asi logue deloso siedicho resultar y confonmeaclose. eargare quede uijeto dibs Paltos Cons' ciones of Incuets aque conformealo

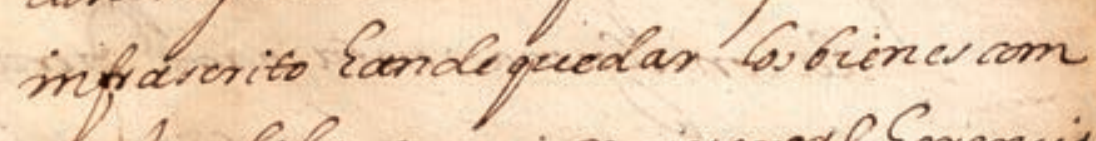
prerendidos en mi vmuersal Levenui inftaionital

- Alelpr Ponquanto yo amo muclo atadicha Anna Alania teonas bo mikermana pales quetenga muy complefente comodidad yte quelomi mo quiereyderea eldicko Don Grabiel Leonardo midorino fquelaglimayam.

111 
comos fueve pupopiamabe jnote

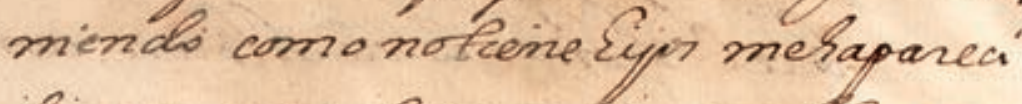
do que para deipones bontu fimale

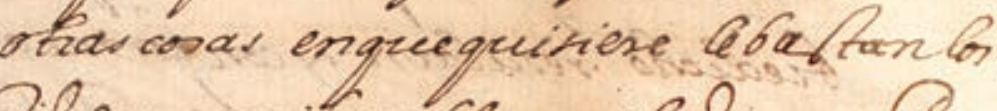
Cleyntemilsuclaros quecledero, boro parecen iqueer necerratio pecelc lace daconalquan renta pan derante furria fi amis excarores mipiaron

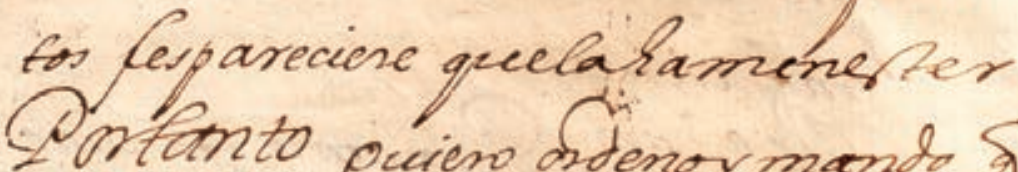

- potanto puieno ditengymando $\$$

Gofichos mir excectorex peanyantise et to y tequen rupositiliady neceridas $\gamma$ lajpuerca Demi Lacienda leconiené

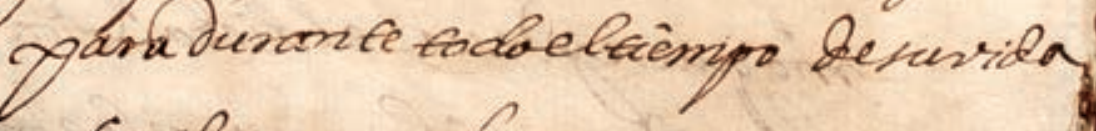

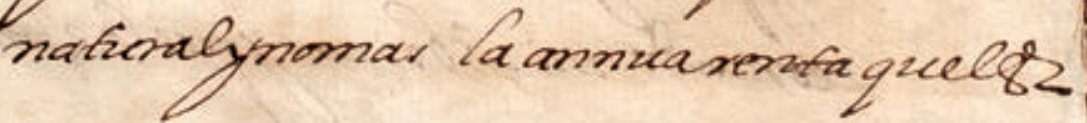




\section{0}

1

pareciere para aymala dexu Privinda Yquatios Porquese queecona mucko

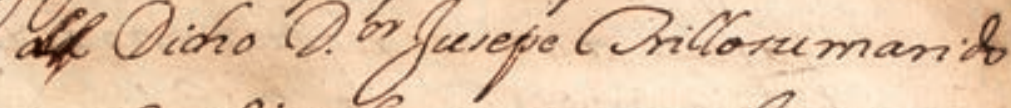
y yotambien omo conmucsateniuna y comoarenmano propio pucienoquar dichosmivexcutored preedom dar fouch tad dadiena mi cemaina Deque delatar te delarenta quecellarele consignare fa

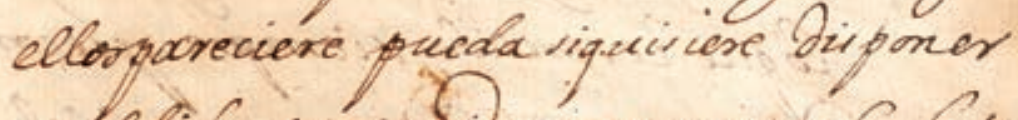
enélaticho wematito encaro quech leto

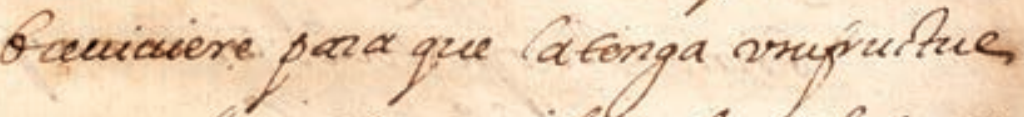
Pqoce aurante rusidanatuoultanto $x=$ Vear

(1)

1.

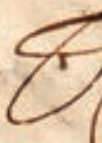

C. 2

uegoy encango mus a $\alpha$ of

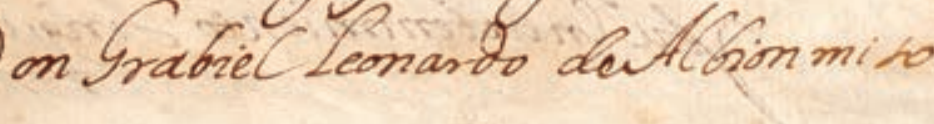


Srino que luego comoyoguesemicera

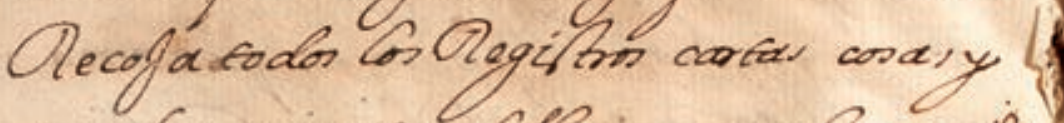
papeler to cantes difficio enqueresoruis delobin $\therefore$ ondede lemon enelentie

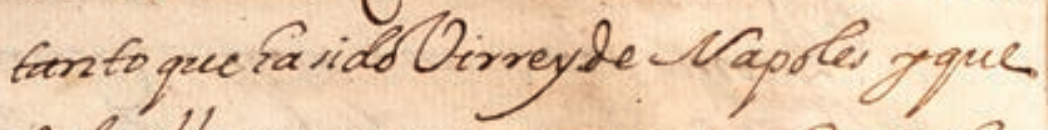
fodo ello conno cosa xanimportanté lo

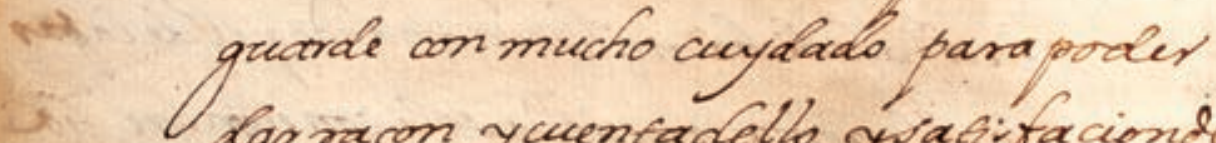

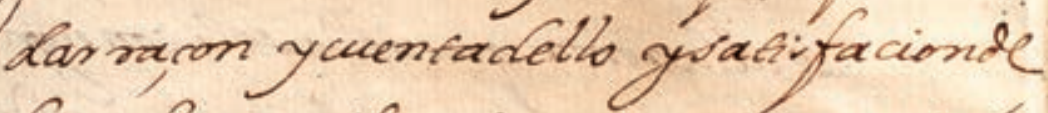

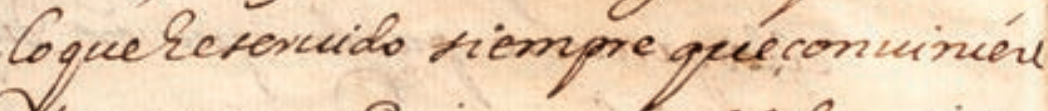

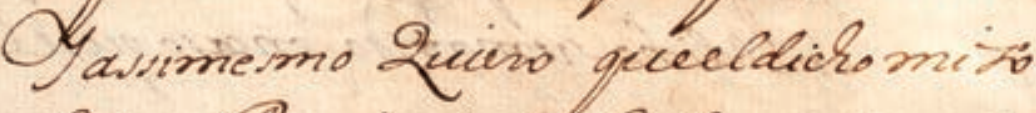

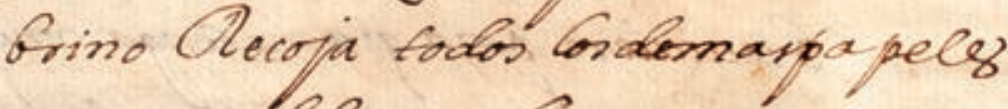
que cengo defuena, lesta, jaqueyopormi

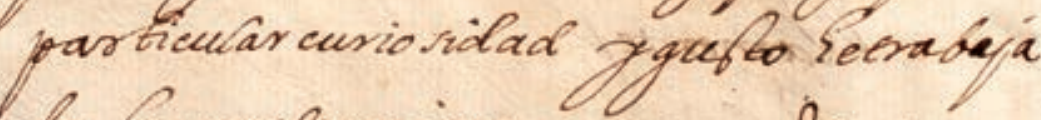
do conqualer quieso quequande

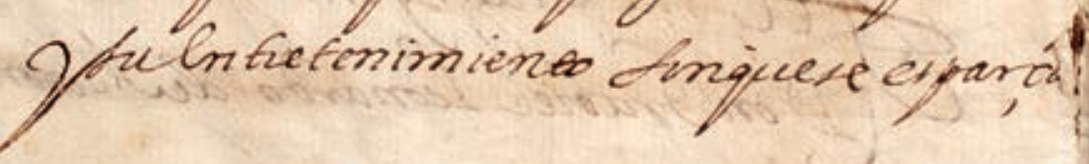




\section{(5).}

mi vayom amanos afena queenfedoto no mands quesequementobis!

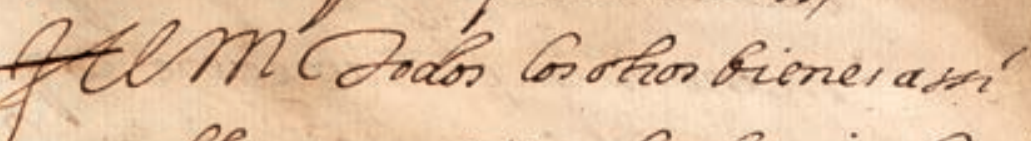
muefles conoritios dondequere Saur dosy poriauer mosyamipostenecienty y quepertenecerme pucaleny decuen forny Deuran engualquese manex y fiompo yporgualquiere curalo saco cosqualerquipo aqui kauenthe pornom orados y conpontados devialamenteyte grenguen delprevente Peymodeutrapon - quetsoraran lecho y cumplido toavlo Foredicho Dexolos depraciarperide y deaquels seneden mio voricural

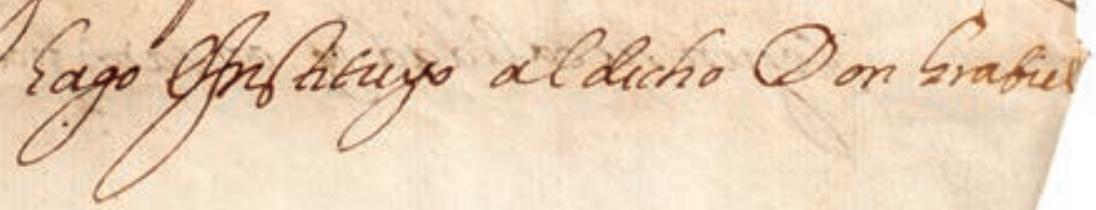


Ceonardo devtorion misorino con cal Palto Qincloy conticion onodeotia

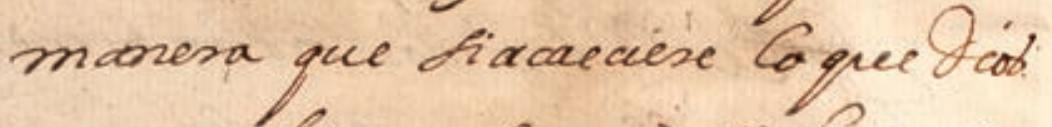

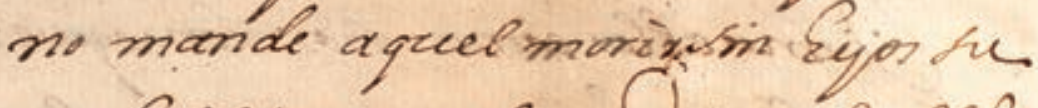
que legibinos mideroendienterd cllob? p) Tauinds muerts contaleisijor $a \vec{q}$ Cos acasciese morin menordecalad. aeporer teftor Que enqualquiesede os dichor aros mis es ecutore nn pafen tos o Lmayor paste allos ayou de deipo nery dispongan delos fiener conpul. iondidor en labredicha micumiver falrevencia enparienter mion prozs; fejur rucalialad en acripion limos 


\section{8}

nasyofia ofrapià, delamanen on

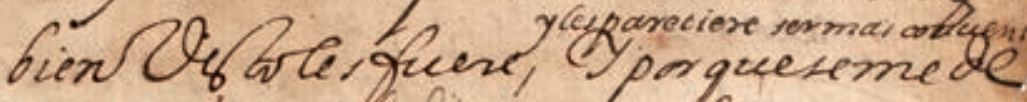

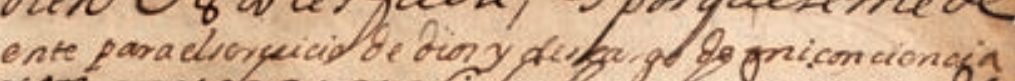
uen muchas contidacles de divenos de queyaclaicho mi Eencoso tienenofi wil quiens que aquel las cobse acehral enizfaucor condresedero mio como arriuk olipong on respecodelo queproderie del m, Platia, ymuerte queterande Uonder pana queloquents feazqare quede ruifeto alos mimonpar

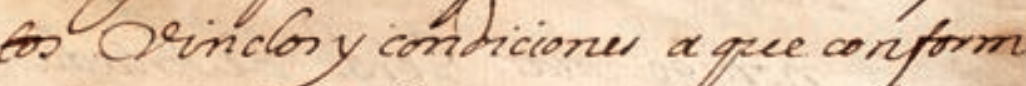
aloforearicho sandequedar fobrens compresentidos en la fobredicsamion uensalierencial Enelangtinnientale coural jen que forie ello no aya min 
guma froude loneargo mus a la coryainja

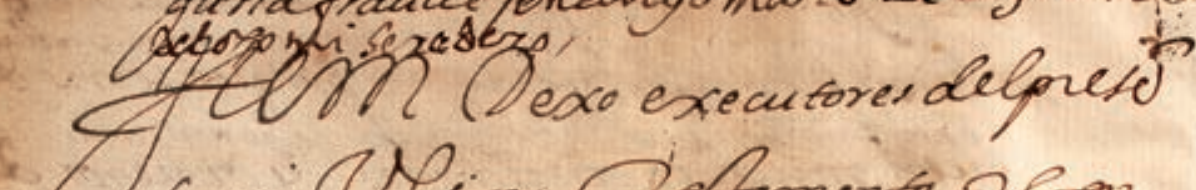
te mi Olimo Oefamento ?er neradores demi Ammay conciencia

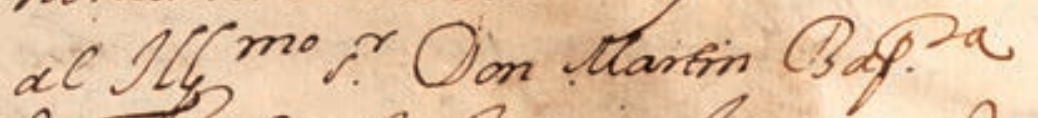
de La vica fur hicia de Hragon, yatow Alonso del Villalarndo baualieso do miciliads en ladicha cundad yacosas Donallanima Letloron, Don mariel. Leonards de Albion, el licenciadoya nonigo fian serds devifieda el bor fusepe Pillo y Inna Tharia Lomand fumuger fologo fecet atodospala, mayor gartedellos conades dorquals Aoy todo aguelpotenytacultad que ifa 


\section{9}

Execuiores Eftromentaxion conformeaffuew

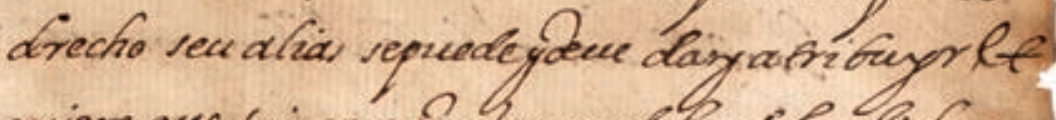

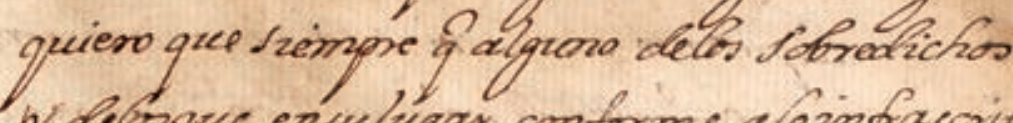

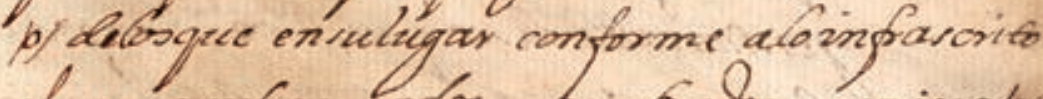
fueven rub rrogades phom trabos musierelo ix. Denumcraise que entalcasa ysimpre fa quel accieciere Goque queedaren po lamay pror fedells puedan nutrorogar eligin gnombras otioexes citor q vien vilo cesfuere en lagar delquera vienemuento por Olenunciado felmirmopoter,

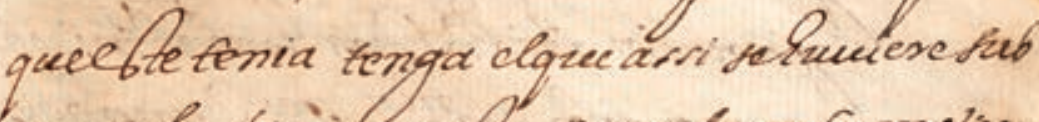
arogado dinize enef to se pucida entiometer ingunfues cecteriabtito mi oglar/

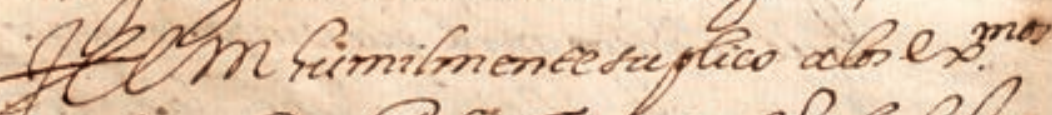
Seriorer Don Pedro Ternandefs de afmo

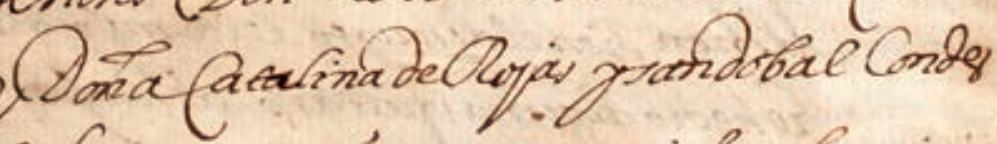
de Lemos mis seríne, sean sericidos deseciues 
us sur debaxo deviamparo yprotedion atabo Don Grabiel leonadosa Albion mi sobrino a Gual Ceipresento on lasritued ingenio buenal pares

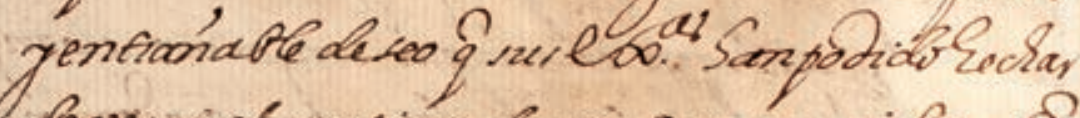
dever enel quetiene de acentar a feruines yo vien conlos veruicios proprios suyos flos desupa He ymion paraque cantsivanos losmon y

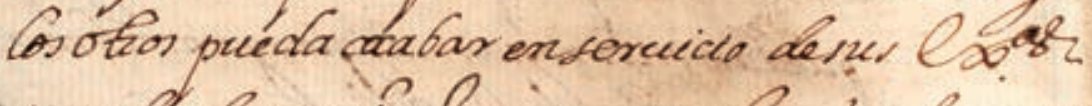
pues det ide suninel comenco a implearfe ence ysumilm Suplico aru efor. pongan elsujeto gy revuicion del abo. Den Serariel misofino en

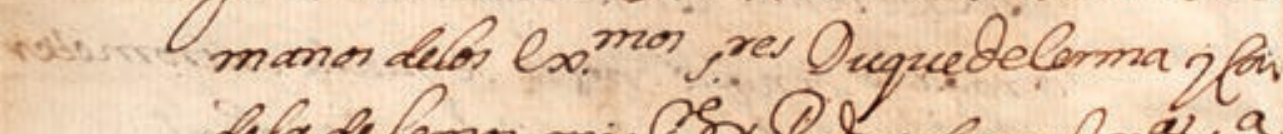

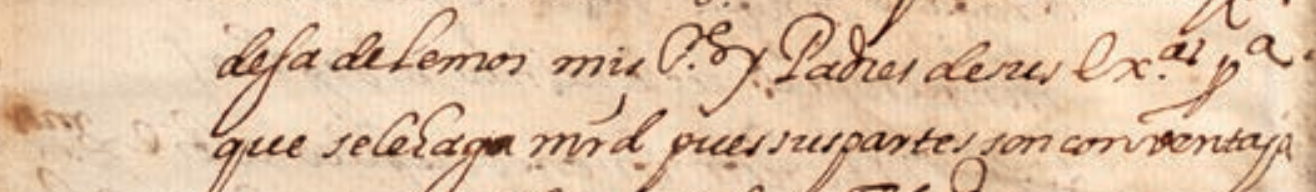
- que seleragu mod puessuspantes fon anventapa aproporito del convicio deru Thaf? Tme per

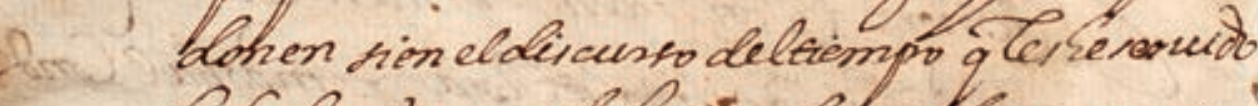

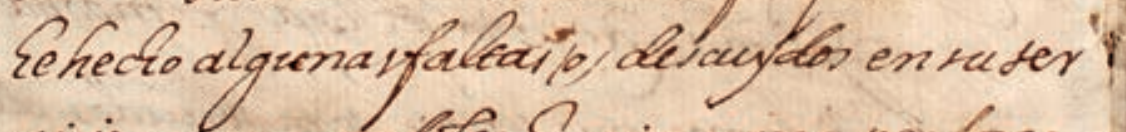
uicio asseguadister \& mingume pen fora 
ma Decoracon mi con mayofdereodeacer

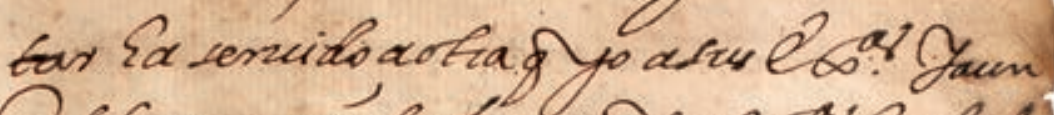

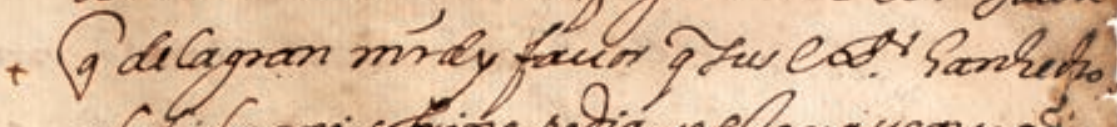

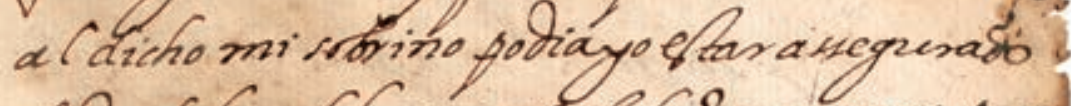

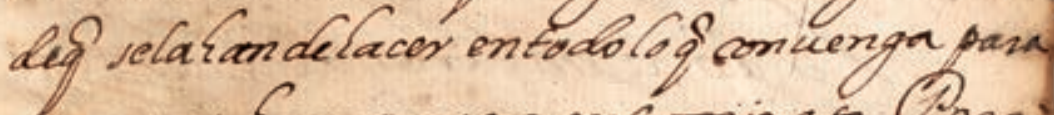
Aumayer Conrrayacrecentamiento beso por lagrantemura eongue le amo gporto mucho que metione oflejado pon furver tudy buenarparter notupotido enefterl fime fiance ercusarel nuplicar ef to anes 160. midedexarles prendatanpropia q aramia pasa fenmi lugas Cessiren yrupla mis fateas

Hepr siuplicomuy encarecidam. ala affil soma pra Ouquena Dono Ciana de Pernefan jalos ex mos ses Ouguer de Villa Remosa nuigipor ques. 


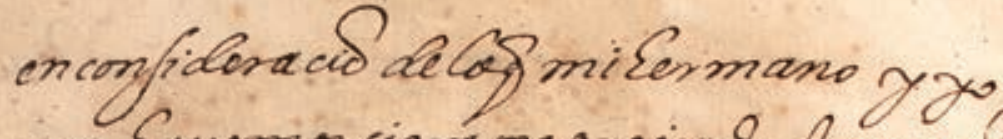
nor Lauemon siemprepreciad de oniator

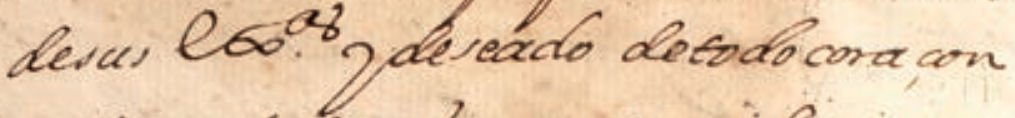

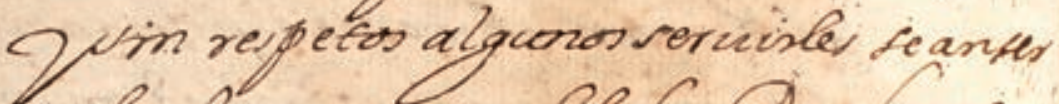
uidos deampanar delicho Oon Srabie Leonarto devtion mi sorino Sacien dote officio detenorer ytauneciendire,

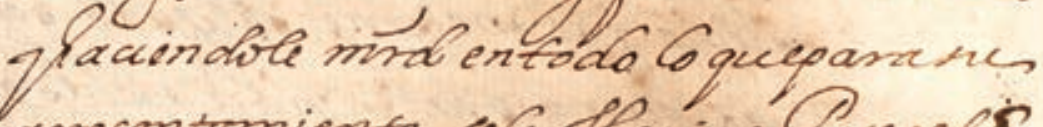
acrecentumiento fele ffreciese (acerelgi

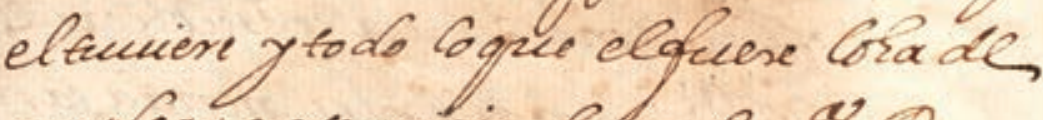

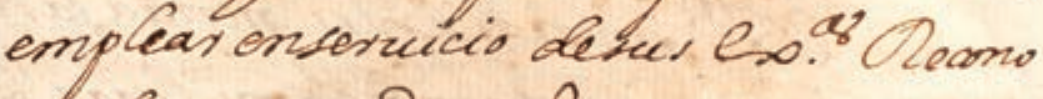
ciende iempre of rupatze yelyoytionos

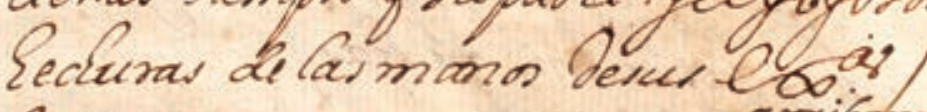

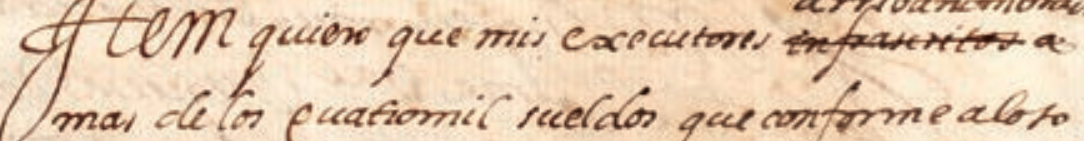
mar delor cuationil rueldos que onfomealoto Gredicie Sande repartio delimonas repartion ofio

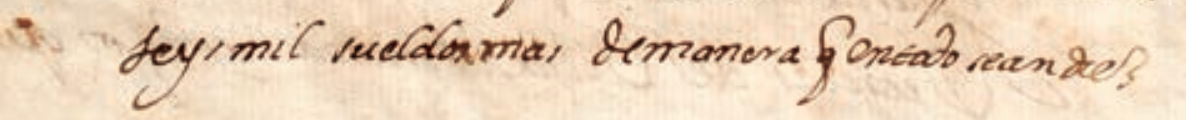




\section{5) 1 .}

milsueldor, Yarrimemo quieso que enere tos criades y criadas dela hicha mi Sermaria fme, tivuen en fra enformedad por el makajo Genella. tienen les repotrian seycienten suclalos fagustes comolespareciore/

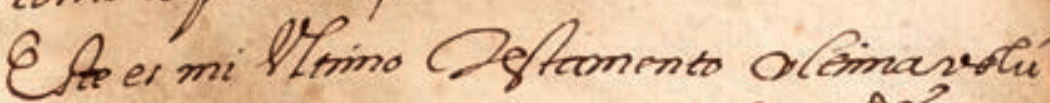
Ead ordinacion ydiporicion de todor for $\mathrm{fl}^{\prime}$ mi Fieno arimuebles como sitios dondequionesau dos y porkuer elqual quiero Galga por Ireobode

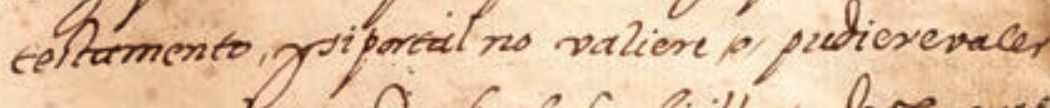
puier natga por Drecho de Codicillo lo dederagual quiere vtrma cofintad ondinacionpluporicio de orines quenforme aqueno srecho seudiar m

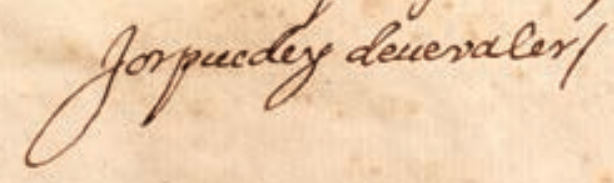




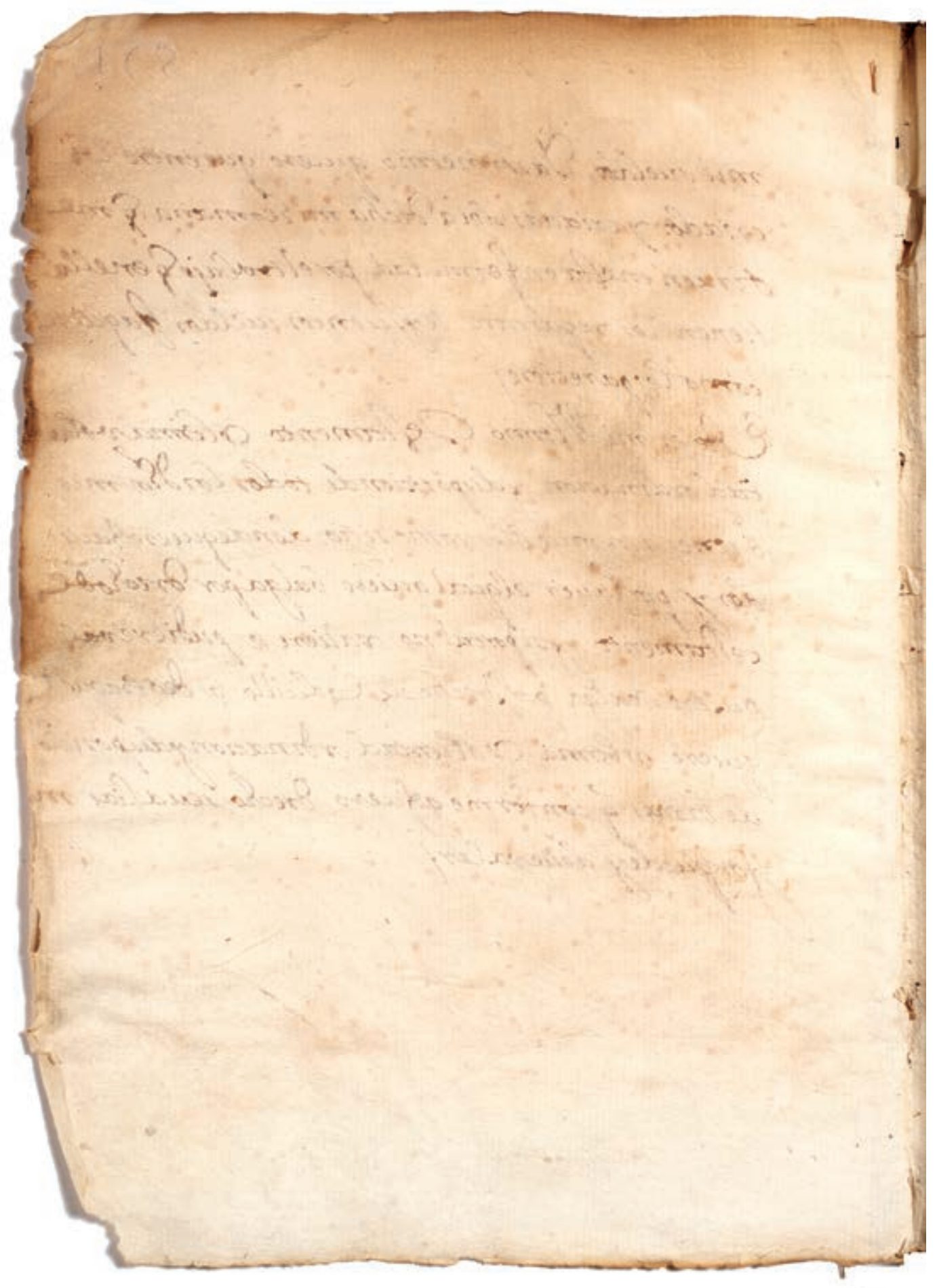




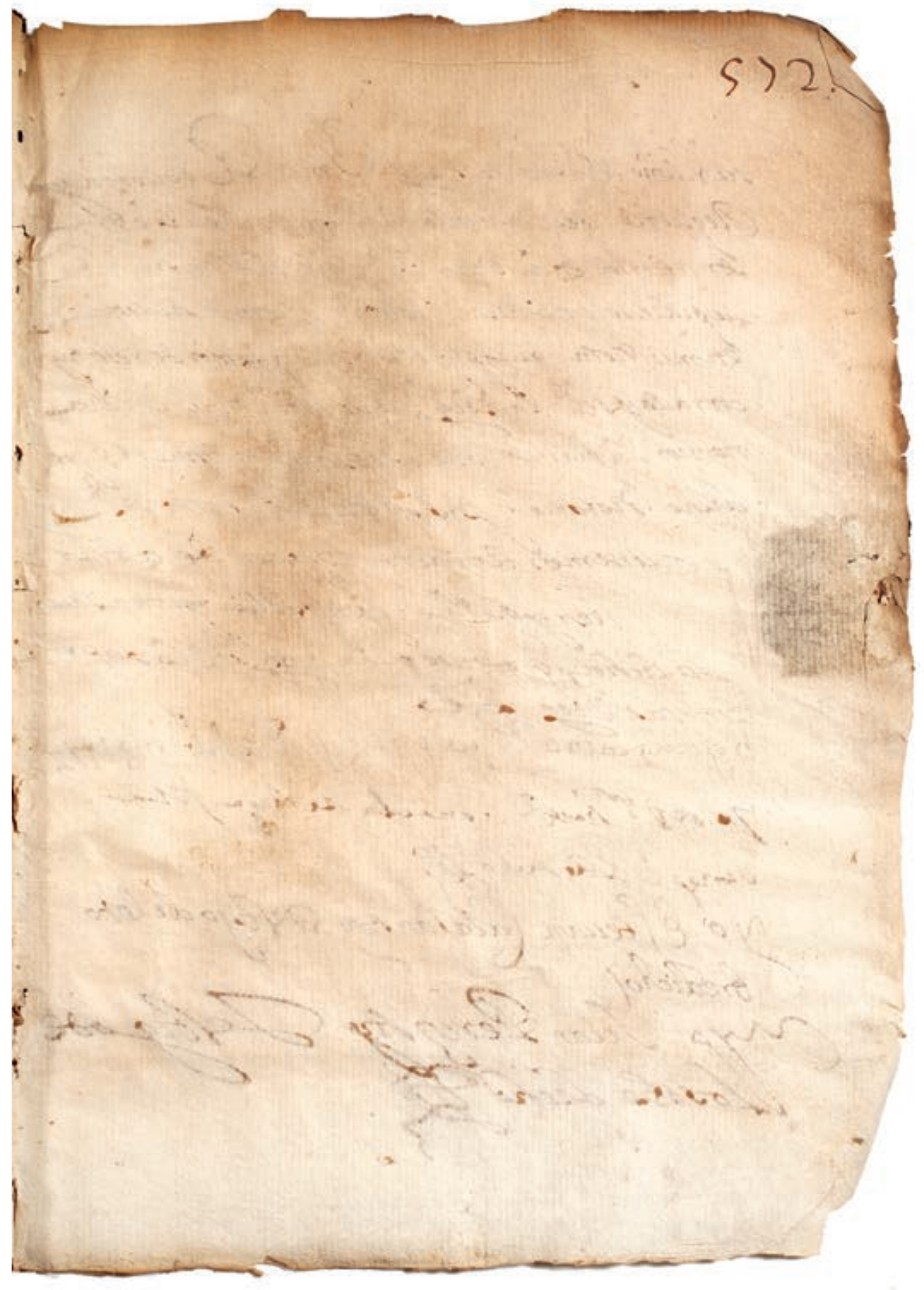




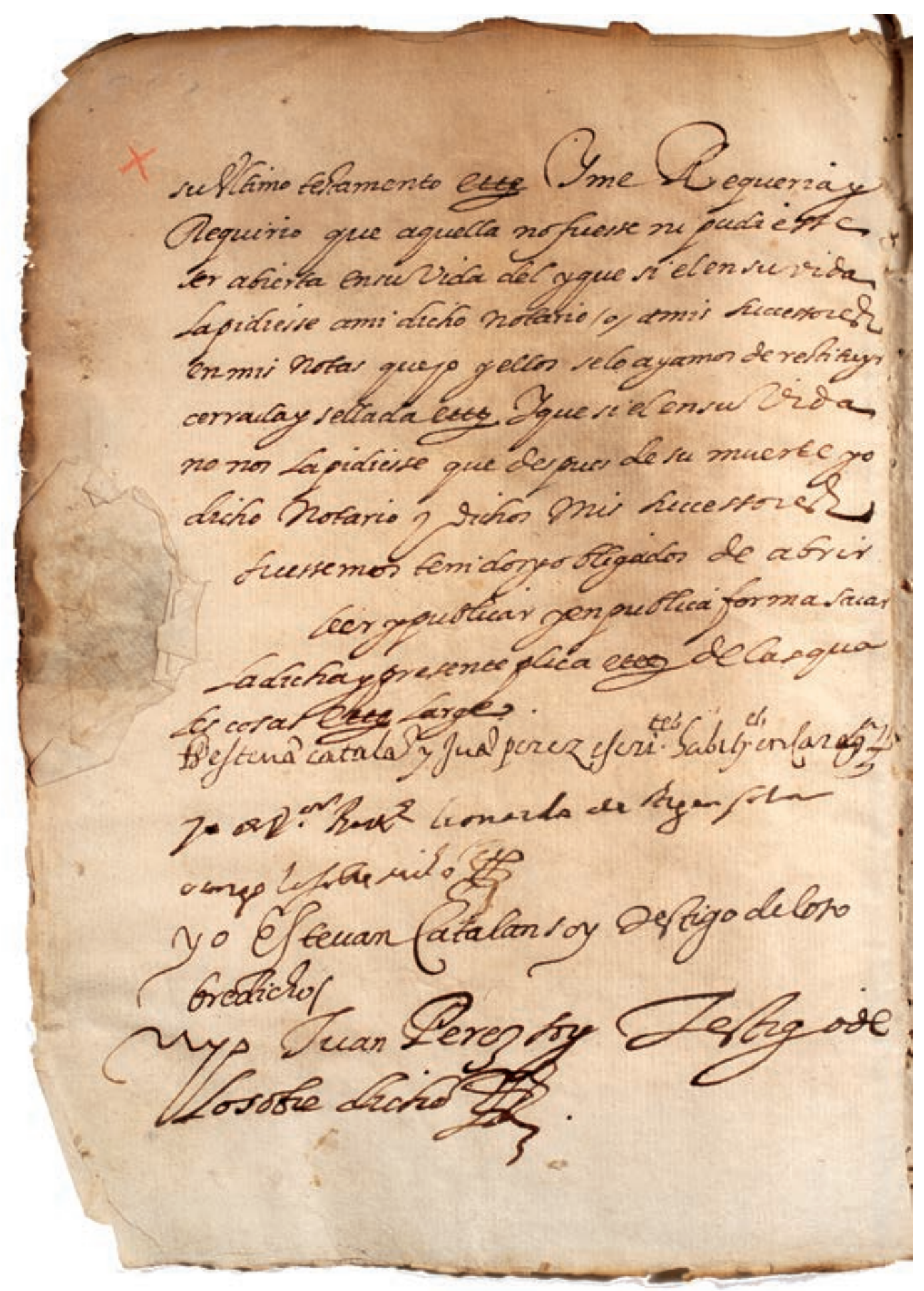




\section{5) 3 ?}

L

Eafi abierta tes das phofinada adicha phica Srquiere Dertamipovo

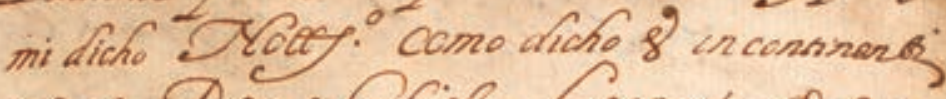
elvio Don Gabiel Leonado ae ctlbron, requirio 1 ormilicho e in fro rotges:

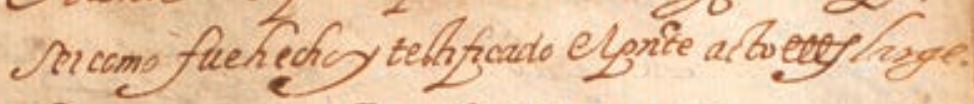
Ef. Inilupra Rraxe nominary.

I ferto que wandoteahio se noters. feavaran, Ios dobrepnetsor bigmien fer enaguli ferciopetoineizinfanter, ny ne

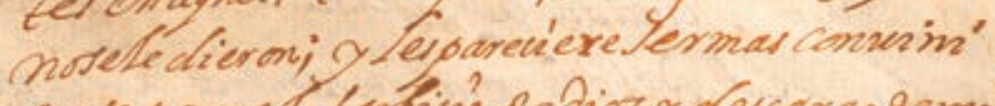
ente paracl Jerbivio debios o dercargs bemé

\& concienvia; arrina Hombragor: y o e enmentas donselete; al: 



\section{Bartolomé Leonardo de Argensola}

Fuente: Archivo Histórico de Protocolos Notariales de Zaragoza, Juan Jerónimo Navarro, 1631, f. 549v-573

[f. 549v] Die quarto mensis februarii anno MDCXXXI Cesarauguste.

[Nota al margen: «Carta pública de muerte»] Eodem die et loco, dentro de las casas de la propia habitación del quondam el doctor Bartolomé Leonardo de Argensola, canónigo que fue de la Aseo, iglesia metropolitana de dicha ciudad de Zaragoza, y cronista [f. 550] del presente reino de Aragón, que están sitiadas en la presente ciudad, en la plaza de San Bartolomé, parroquia de la Aseo, que confrontan con casas de [espacio en blanco] y con callizo que sale a la calle del Sepulcro y dicha plaza, en una cuadra del cuarto bajo de dichas casas, ante la presencia de mí, Juan Jerónimo Navarro, y de los testigos infrascritos pareció personalmente don Gabriel Leonardo de Albión, caballero domiciliado en la dicha ciudad, ejecutor que se dijo ser del último testamento, alma y conciencia del dicho quondam doctor Bartolomé Leonardo de Argensola, su tío, el cual dijo que, por cuanto le convenía probar en diversas partes y lugares del dicho y presente reino de Aragón, como de otros, [que] el dicho quondam doctor Bartolomé Leonardo de Argensola era muerto, que por tanto me [f. 550v] hacía e hizo ostensión a mí, dicho notario y los testigos infrascritos, del cuerpo, si quiere cadáver, del dicho quondam doctor Bartolomé Leonardo de Argensola, el cual estaba 
encima de una tarima, revestido con el hábito sacerdotal de decir misa, con el rostro descubierto, al cual yo, dicho notario, y los testigos infrascritos bien conocimos en el tiempo que vivía, el cual estaba ya difunto y sin alma. De las cuales cosas, etcétera, el dicho don Gabriel Leonardo de Albión, en dicho nombre, por conservación del derecho, etcétera, requirió por mí, dicho e infrascrito notario, ser, como fue hecho y testificado, el presente acto público, etcétera, large.

Testes Pedro de Sisamón y Francisco Antonio de Fuentes, escribientes, habitantes en Zaragoza.

Atesto que en el presente acto no hay sobrepuestos, rasos, enmendados, borrados ni interlineados.

[f. 551] [Nota al margen: «Aperción de testamento»] Eodem die et loco incontinenti, actus quasi continuo, ante la presencia de mí, dicho Juan Jerónimo Navarro, y de los testigos infrascritos pareció el dicho don Gabriel Leonardo de Albión, como ejecutor que se dijo ser sobredicho del último testamento del dicho quondam doctor Bartolomé Leonardo de Argensola, que a su noticia había llegado que el dicho quondam doctor Bartolomé Leonardo de Argensola había hecho y ordenado su último testamento, última voluntad, ordinación y disposición de todos sus bienes, así mobles como sitios, habidos y por haber dondequiere, el cual había dado y librado en poder y manos del quondam Diego Fecet, notario pú- 
blico y del número que fue de la dicha ciudad, en una plica de papel [f. 551v] cerrada y cosida y sellada, mediante acto hecho en la dicha ciudad de Zaragoza a diecisiete días del mes de agosto del año mil seiscientos dieciséis y por el dicho quondam Diego Fecet, notario, recibido y testificado, en el cual dicho testamento pretendía que el dicho quondam doctor Bartolomé Leonardo y de Argensola lo dejaba ejectuor. Et por cuanto aquel era muerto, según que por tenor del supra proxime continuado acto público de su muerte constaba, por tanto, que requería y requirió a mí, dicho e infrascrito notario, como comisario que soy de las notas del dicho quondam Diego Fecet, que abriese y publicase dicho testamento a fin y efecto de poner en ejecución la voluntad del dicho testador. Et incontinenti, yo, dicho notario, satisfaciendo a lo que era tenido y obligado, [f. 552] hice ostensión de la dicha plica del dicho testamento al dicho don Gabriel Leonardo de Albión y a los testigos infrascritos, la cual dicha plica, por ellos vista y reconocida, clara y manifiestamente les constó estar y que estaba cerrada, cosida y sellada así et según que al dicho quondam Diego Fecet le había sido dada y entregada por dicho quondam doctor Bartolomé Leonardo de Argensola. Et así vista y reconocida, yo, dicho notario, [f. 552v] abrí y de palabra a palabra leí la dicha plica, cuyo tenor es el siguiente: [el resto de este folio está inutilizado por el notario mediante tres líneas espirales trazadas verticalmente] 
[f. 553] Die decimo septimo mensis augusti anno M..$^{\circ}$ DCXVI. ${ }^{\circ}$ Cesarauguste.

[Nota al margen: «Testamento»] Eisdem die et loco, ante la presencia de mí, Diego Fecet, notario, y de los testigos infrascritos pareció personalmente constituido el doctor Bartolomé Leonardo de Argensola, canónigo de la Seo, iglesia metropolitana de la ciudad de Zaragoza, y cronista del reino de Aragón, domiciliado en la dicha ciudad, el cual, estando enfermo, etcétera, y por la gracia de Nuestro Señor Dios en su buen seso, etcétera, de grado, etcétera, dijo que había hecho y ordenado su último testamento, etcétera, el cual estaba escrito y se contenía dentro de la presente plica, la cual dio y libró en poder y manos de mí, dicho e infrascrito notario, presentes los testigos infrascritos, cerrada y alrededor con hilo blanco cosida y con un sello sobre hostia colorada sobre papel impreso en el dorso de la dicha y presente plica sellada, según que yo, dicho notario, y los testigos infrascritos ocularmente vimos, et que, revocando, etcétera, todos y cualesquiera testamentos, etcétera, quería y quiso que la escritura dentro de la dicha y presente plica escrita y contenida fuese y sea [el f. 553v está en blanco, y el texto sigue en el f. 572v]

[f. 554] En el nombre de Nuestro Señor Dios y de la gloriosísima Virgen María, madre suya y señora nuestra, como persona alguna en carne puesta de la muerte corporal escapar no pueda, y no 
haya en el mundo cosa alguna más cierta que la muerte, ni más incierta que su hora, la cual en el ánimo de todo fiel cristiano debe estar presente, por tanto, sea a todos manifiesto que yo, el licenciado Bartolome Leonardo de Argensola, canónigo de la Seo, iglesia metropolitana de la ciudad de Zaragoza, y en ella domiciliado, y cronista que soy del presente reino de Aragón, estando con alguna indisposición de mi persona, y por la gracia de Nuestro Señor Dios en mi buen seso, firme memoria y [f. 554v] palabra manifiesta, revocando y anulando, como por tenor del presente revoco y anulo, y por revocados y nulos doy, he y haber quiero, todos y cualesquiera testamentos, codicilos y otras últimas voluntades y disposiciones de mis bienes que yo antes de ahora haya hecho y ordenado, ahora de nuevo, de grado y de mi cierta ciencia, en aquellas mejores vía, modo, forma y manera que conforme a fuero, derecho, seu alias hacerlo puedo y debo, hago y ordeno el presente mi último testamento, última voluntad, ordenación y disposición de todos mis bienes muebles y sitios dondequiera habidos y por haber, en la manera siguiente:

Et primeramente, encomiendo mi al- [f. 555] ma a Nuestro Señor Dios, creador de aquella, a quien humilmente suplico que, pues la redimió con su sacratísima sangre, la quiera colocar con sus santos en su gloria.

Ítem, quiero, ordeno y mando que siempre que yo muriere mi cuerpo sea enterrado en la dicha iglesia de la Seo, en la parte y lugar 
que se acostumbran enterrar los demás canónigos de ella, mis carísimos hermanos, en donde quiero se hagan mis defunción, novena y cabo de año, bien y honradamente, aunque con toda llaneza y sin pompa alguna, para lo cual quiero se tome de mis bienes y que en ello se gaste lo que fuere necesario y a mis ejecutores infrascritos bien visto.

[f. 555v] Ítem, quiero, ordeno y mando que, luego como yo fuere muerto, con la mayor brevedad que fuere posible me sean dichas y celebradas por sufragio de mi alma y en remisión de mis pecados mil misas rezadas en capillas privilegiadas, a voluntad y elección de mis ejecutores infrascritos, pagándose de mis bienes por la caridad de la [tachado: «perpetua»] celebración de ellas la cantidad acostumbrada.

Ítem, quiero, ordeno y mando que, luego como yo fuere muerto, mis ejecutores infrascritos funden en la iglesia, parte y lugar que les pareciere cuatro aniversarios perpetuos, celebraderos cada un año perpetuamente, el uno por sufragio del alma [f. 556] y en remisión de los pecados del quondam Lupercio Leonardo de Argensola, mi hermano, secretario que fue de la majestad cesárea de la emperatriz, que haya gloria, y los tres restantes, por sufragio de mi alma y en remisión de mis pecados y por sufragio de las almas y en remisión de los pecados de mis padres y hermanos, que hayan gloria, dándose por la caridad de la perpetua celebración de los dichos aniversarios la cantidad necesaria. 
Ítem, por el amor que tuve al quondam ilustrísimo señor don Fernando de Aragón, duque de Villahermosa, quiero le digan por sufragio de su alma mil misas rezadas en las iglesias y partes que pareciere a mis ejecutores infrascritos y la caridad de ellas se pague de mis bienes.

Ítem, dejo de gracia especial a los pobres del Hospital Real y General de Nuestra Señora [f. 556v] de Gracia de la presente ciudad dos mil sueldos jaqueses, y a los hospitalicos de niños y niñas huérfanos de ella, cada, doscientos sueldos, y a la capilla de la Madre de Dios del Pilar de la dicha y presente ciudad, otros doscientos sueldos, y al monasterio de Nuestra Señora de Montserrat, otros doscientos sueldos.

Ítem, quiero que, luego como yo muriere, mis ejecutores infrascritos repartan cuatro mil sueldos de limosnas en los pobres que les pareciere.

Ítem, quiero, ordeno y mando sean pagadas y satisfechas todas mis deudas, aquellas que por buena verdad constará que yo deberé a cualesquiera persona o personas, en cualquiera manera y por cualquiera causa o razón.

Ítem, dejo por parte y derecho de legítima herencia de todos los dichos mis bienes, así muebles como sitios, dondequiera habi[f. 557] dos y por haber, a cualesquiera persona o personas que parte y derecho de legítima herencia en los dichos mis bienes puedan pre- 
tender haber y alcanzar, cada, cinco sueldos por bienes muebles y sendas arrobas de tierra en los montes comunes de la dicha y presente ciudad por bienes sitios, con lo cual quiero y mando se hayan de tener y tengan por contentos, satisfechos y pagados de toda y cualquiera parte y derecho de legítima herencia que en los dichos mis bienes puedan pretender haber y alcanzar, y que tan solamente alcancen lo que por mí en virtud del presente les fuere dejado, y a mayor cautela dejo por derecho de legítima al ilustrísimo señor arzobispo de Zaragoza, mi prelado, mi breviario con $[$ f. $557 \mathrm{v}$ ] que rezo.

Ítem, digo y declaro que todas las martas que se hallarán sueltas entre mi ropa son de Ana María Leonardo, mi hermana, así quiero se le den luego.

Ítem, dejo de gracia especial a la dicha Ana María Leonardo, mi hermana, veinte mil sueldos jaqueses, los cuales mis ejecutores infrascritos le hayan de asignar y dar en uno de los mejores censales que yo tuviere, y porque no sé cómo capituló cuando casó con el doctor Jusepe Trillo, su marido, quiero que cuando se le asigne el dicho censal sea con condición que ella en su caso, y sus herederos y sucesores en el suyo, cuando se disolviere el dicho matrimonio lo hayan de [f. 558] sacar enteramente y sin diminución alguna, lo cual el dicho su marido haya de consentir así, haciéndose en razón de ello los actos que convinieren para seguridad de la dicha mi hermana y a voluntad de mis ejecutores infrascritos. 
Ítem, dejo de gracia especial a Miguel de Pilares, notario y ciudadano de la ciudad de Barbastro, veinte mil sueldos jaqueses, los cuales mis ejecutores infrascritos le hayan de pagar consignándole la dicha cantidad en uno o en más de los censales que al tiempo de mi muerte yo tuviere y a ellos pareciere consignarle, los cuales dichos veinte mil sueldos dejo al dicho [f. 558v] Miguel de Pilares con expresa condición y pacto que él haya de disponer de ellos en sus hijos legítimos como le pareciere, y no en otras personas algunas.

Ítem, dejo de gracia especial a los [tachado: «dos»] hijos y descendientes de Francisco Guerguete e Isabel Tudela, su mujer y hermana de mi madre, que haya gloria, vecinos de la dicha ciudad de Barbastro, veinte mil sueldos jaqueses, los cuales mis ejecutores infrascritos hayan de repartir y distribuir entre los sobredichos por el orden y de la manera que les pareciere, atendiendo a la necesidad y virtud que cada uno de ellos tuviere, y a la repartición y distribu- [f. 559] ción que los dichos mis ejecutores hicieren se haya de estar y esté sin recurso alguno, y ellos puedan pagar y paguen los dichos veinte mil sueldos en dinero de contado o en uno o en más de los censales que yo tuviere.

Ítem, en señal de amor dejo de gracia especial al muy ilustre y reverendísimo señor don fray Jerónimo Batista de Lanuza, electo obispo de Barbastro, una medalla que tengo de oro con el retrato 
hecho de relieve de nuestro muy santo padre Paulo Papa Quinto, con una empresa que alude a la coronación de su santidad, la cual medalla dejo al señor obispo por las muchas indulgencias que aquella tiene, y suplico a su [f. 559v] señoría sea servido de encomendar a Dios mi alma.

Ítem, dejo de gracia especial y en señal de amor a don Enrique de Castro, canónigo de la dicha iglesia de la Seo, dos breviarios primero y segundo, muy curiosos y buenos, que vienen entre mis libros, y por la misma causa dejo de gracia especial al licenciado Juan Pérez de Artieda, canónigo de la dicha iglesia de la Seo, un Tertuliano que tengo con comento de Pamelio, por ser libro tan curioso y docto.

Ítem, dejo de gracia especial y en señal de amor a Martín Lamberto Íniguez, ciudadano de la dicha ciudad, todas las obras que tengo del Marín y las vulgares italianas que vienen en las gavetas de mi escritorio [f. 560] grande de ébano.

Ítem, digo y declaro que el señor don Jerónimo de Pimentel, hijo del conde de Benavente, me ha de enviar de Milán, en pliego del señor marqués de Gelves, cuatro viriles de cristal, los dos de los cuales dejo a la dicha iglesia de la Seo para que sirvan al Santísimo Sacramento, y los otros dos dejo a la dicha iglesia de Nuestra Señora del Pilar para el mismo efecto. 
Ítem, dejo de gracia especial y en señal de amor a la señora doña Jerónima Zaporta un relicario que tengo dentro de una bolsa azul y una cadenilla de oro de que aquel está pendiente, y quince piedras [f. 560v] de Puzol para hacerse unas manillas.

Ítem, en señal de amor dejo de gracia especial a Diego Fecet, notario público del número de la dicha ciudad, una ropa que tengo de damasco aforrada en martas.

Ítem, dejo de gracia especial a Ángela de Requeséns, habitante en la dicha ciudad, dos mil sueldos, y de las piezas de Cambrai que yo he traído quiero que mis ejecutores infrascritos le den la parte que les pareciere.

Ítem, dejo de gracia especial a Jerónimo Requeséns, notario real, habitante en la dicha ciudad, mil sueldos.

[f. 561] Ítem, dejo de gracia especial a Pedro Monroy, criado mío, por lo bien que me ha servido, dos mil sueldos jaqueses.

Ítem, quiero que las reliquias, bálsamos, rosarios, cosas de olores y otras algunas que yo he traído de Italia, y son más de curiosidad que de valor, se distribuyan de la manera que pareciere a mis heredero y ejecutores infrascritos, tomándose de ello el dicho mi heredero lo que tuviere por bien y fuere de su gusto.

Ítem, quiero que, luego como yo fuere muerto, se envíe a la excelentísima señora doña Juana de Pernestán, duquesa de Villa- 
hermosa, a quien yo sumamente [f. 561v] he deseado y deseo servir, un breviario que tengo aforrado en [interlineado: «terciopelo»; tachado «raso»] carmesí y me lo dio la señora princesa de Caserta, su hermana, y fue de la señora doña María Manrique, su madre, para que su excelencia lo dé a su alteza de la serenísima infanta Margarita o a la señora sor Luisa de las Llagas, hija de la dicha señora doña María Manrique.

Ítem, quiero que la señora doña Mariana de Albión, mi hermana, y don Gabriel Leonardo de Albión, su hijo y sobrino mío, no obstante lo que yo abajo dispongo, tomen a sus manos un relojico que tengo de Milán, labrado de cristal y muy curio[f. 562] so, y un librico de oro esmaltado que me dio la dicha señora princesa de Caserta, y una cadena de broches que tiene sesenta piezas, y un relicario de oro esmaltado que en la una de las puertas de él está el glorioso san Jerónimo, y cuatro sortijas que tengo de esmeraldas muy lindas, y una de un diamante que tengo, que, aunque es pequeño, es muy lindo y rico, y otra que tengo de un camafeo que se hubo de la almoneda del rey nuestro señor y tiene el retrato de la majestad del rey don Felipe Segundo, todo lo cual quiero que se guarde por los dichos mi hermana y sobrino y que, cuando aquel se casare, lo den en señal de amormío a la mujer con quien se casare, que yo quisiera [f. 562v] regalarla y servirla con cosa de más consideración, pero por ser todo esto muy bueno y curioso me ha parecido que, para 
que tuviese memoria de mí y se acordase de rogar a Dios por mi alma, aceptaría este servicio por muestra de mi voluntad.

Ítem, quiero que mis ejecutores infrascritos repartan como les pareciere entre los [interlineado: «infantes»], sacristanes y otros ministros de la sacristía de la dicha iglesia de la Seo unos ceñidores que he traído de Italia.

Ítem, quiero que, si a la dicha doña Mariana de Albión pareciere que se deben a doña Isabel del Campo, de Nápoles, cin- [f. 563] cuenta ducados de aquella moneda, se le paguen luego de mis bienes.

Ítem, por cuanto he entendido que el doctor Juan Berbegal, canónigo de la dicha iglesia de la Seo, pretende que se le deben dos mil sueldos que él dio en la presente ciudad para que yo los diese en Madrid al capitán Berbegal, su hermano [interlineado: «y que no se le dieron»], de lo cual yo por ahora no tengo ninguna noticia, acuerdo ni memoria, pero tampoco quiero que por razón de ello me quede ningún género de escrúpulo, por tanto, quiero que en razón de los dichos dos mil sueldos se haya de estar y esté a lo que el dicho doctor Juan Berbegal dijere, de manera que si él dijere que tiene satisfacción que los dichos [f. 563v] dos mil sueldos no fueron pagados al dicho capitán Berbegal, su hermano, se le paguen luego a él.

Ítem, digo y declaro que vienen dos cofres de libros míos que me traen de Italia, y que entre ellos viene el segundo volumen de 
los consejos del marqués de Morcón, entre los cuales viene uno muy perjudicial al presente reino de Aragón, y que si el dicho marqués enviare otro consejo para que se ponga en el dicho libro en lugar del dicho consejo tocante a Aragón, que en tal caso del dicho volumen se quite el dicho consejo tocante a Aragón y otro que hay tocante a Judice, y otro que hay tocante al abad Lamaña, [f. 564] y otro que hay tocante al príncipe de Estillano, que la causa que hay para hacerse esto ya yo la he dicho al dicho Diego Fecet, confiriendo con él el presente mi testamento.

Ítem, por cuanto tengo un cuadro de la Adoración de los Reyes que lo estimo y aprecio mucho, por tanto, quiero que el dicho don Gabriel Leonardo, mi sobrino, tenga, conserve y guarde el dicho cuadro como cosa por mí muy preciada y estimada, y si Dios le diere hijos lo deje vinculado al que fuere señor de su casa y a los que le sucedieren en ella.

Ítem, quiero, ordeno y mando que, [f. 564v] luego como yo fuere muerto, mis heredero y ejecutores infrascritos vendan todas las cadenas, plata, colgaduras, cuadros, escritorios, ropa blanca y otros alhajas y muebles de casa que tengo, exceptuado de lo que arriba he dispuesto y lo que a la dicha doña Mariana de Albión, mi hermana, y al dicho don Gabriel Leonardo de Albión, mi sobrino, les pareciere ser de su gusto y por esta causa se quisieren quedar con ello. Y todo lo que procediere y se sacare de lo que así 
se vendiese, quiero que se cargue a censal sobre lugar realengo o de iglesia del dicho y presente reino, a tuto y seguro, a [f. 565] nombre y a favor del dicho don Gabriel Leonardo de Albión, como heredero mío, para que, así, lo que de lo sobredicho resultare y conforme a ello se cargare quede sujeto a los pactos, condiciones y vínculos a que conforme a lo infrascrito han de quedar los bienes comprehendidos en mi universal herencia infrascrita.

Ítem, por cuanto yo amo mucho a la dicha Ana María Leonardo, mi hermana, y deseo que tenga muy competente comodidad, y sé que lo mismo quiere y desea el dicho don Gabriel Leonardo, mi sobrino, y que la estima y ama [f. 565v] como si fuese su propia madre, y no teniendo, como no tiene, hijos, me ha parecido que, para disponer por su alma u otras cosas en que quisiere, le bastan los veinte mil sueldos que le dejo, pero paréceme que es necesario que se le acuda con alguna renta para durante su vida si a mis ejecutores infrascritos les pareciere que la ha menester. Por tanto, quiero, ordeno y mando que los dichos mis ejecutores vean y arbitren esto y, según su posibilidad y necesidad y las fuerzas de mi hacienda, le consignen para durante todo el tiempo de su vida natural y no más la anua renta que les [f. 566] pareciere para ayuda de su vivienda y gastos. Y porque sé que ama mucho al dicho doctor Jusepe Trillo, su marido, y yo también lo amo con mucha ternura y como a hermano propio, quiero que los dichos 
mis ejecutores puedan dar facultad a la dicha mi hermana de que, de la parte de la renta que a ella se le consignare y a ellos pareciere, pueda si quisiere disponer en el dicho su marido, en caso que él le sobreviviere, para que la tenga, usufructúe y goce durante su vida natural tan solamente.

Ítem, ruego y encargo mucho al dicho don Gabriel Leonardo de Albión, mi so- [f. 566v] brino, que, luego como yo fuese muerto, recoja todos los registros, cartas, cosas y papeles tocantes al oficio en que he servido al excelentísimo señor conde de Lemos en el entretanto que ha sido virrey de Nápoles, y que todo ello, como cosa tan importante, lo guarde con mucho cuidado para poder dar razón y cuenta de ello y satisfacción de lo que he servido siempre que conviniere. Y asimismo quiero que el dicho mi sobrino recoja todos los demás papeles que tengo de buenas letras y que yo, por mi particular curiosidad y gusto, he trabajado, los cuales quiero que guarde para sí y su entretenimiento, sin que se esparzan [f. 567] ni vayan a manos ajenas. Que en fe de esto, no mando que se quemen todos.

Ítem, todos los otros bienes, así muebles como sitios, dondequiera habidos y por haber, míos y a mí pertenecientes y que pertenecerme pueden y deben, podrán y deberán, en cualquier manera y tiempo y por cualquier causa o razón, los cuales quiero aquí haber y he por nombrados y confrontados debidamente y 
según fuero del presente reino de Aragón, y que sobrarán hecho y cumplido todo lo sobredicho, déjolos de gracia especial, y de aquellos heredero mío universal hago e instituyo al dicho don Gabriel [f. 567v] Leonardo de Albión, mi sobrino, con tal pacto, vínculo y condición, y no de otra manera, que si acaeciese, lo que Dios no mande, aquel morir sin hijos suyos legítimos ni descendientes de ellos, o, habiendo muerto con tales hijos, aquellos acaeciese morir menores de edad de poder testar, que en cualquiera de los dichos casos mis ejecutores infrascritos, o la mayor parte de ellos, hayan de disponer y dispongan de los bienes comprehendidos en la sobredicha mi universal herencia en parientes míos pobres según su calidad y en sacrificios, limos- [f. 568] nas y otras obras pías de la manera que bien visto les fuere [interlineado: «y les pareciere ser más conveniente para el servicio de Dios y descargo de mi conciencia»]. Y porque se me deben muchas cantidades de dineros de que ya el dicho mi heredero tiene noticia, quiero que aquel las cobre y cargue a censal en su favor como heredero mío, como arriba lo dispongo en respecto de lo que procediere del oro, plata y muebles que se han de vender, para que lo que así se cargare quede sujeto a los mismos pactos, vínculos y condiciones a que conforme a lo sobredicho han de quedar los bienes comprehendidos en la sobredicha mi universal herencia, en el cumplimiento de lo cual y en que sobre ello no haya nin- [f. 568v] guna fraude, encargo mucho la conciencia del dicho mi heredero. 
Ítem, dejo ejecutores del presente mi último testamento y exoneradores de mi ánima y conciencia al ilustrísimo don Martín Batista de Lanuza, justicia de Aragón, y a don Alonso de Villalpando, caballero domiciliado en la dicha ciudad, y a los dichos doña Mariana de Albión, don Gabriel Leonardo de Albión, el licenciado y canónigo Juan Pérez de Artieda, el doctor Jusepe Trillo y Ana María Leonardo, su mujer, y Diego Fecet, a todos o a la mayor parte de ellos concordes, a los cuales doy todo aquel poder y facultad que a [f. 569] ejecutores testamentarios conforme a fuero, derecho, seu alias, se puede y debe dar y atribuir, et quiero que, siempre que alguno de los sobredichos o de los que en su lugar conforme a lo infrascrito fueren subrogados y nombrados muriere o renunciare, que en tal caso, y siempre que aquel acaeciere, los que quedaren o la mayor parte de ellos puedan subrogar, elegir y nombrar otro ejecutor que bien visto les fuere en lugar del que hubiere muerto o renunciado, y el mismo poder que este tenía tenga el que así se hubiere subrogado, sin que en esto se pueda entrometer ningún juez eclesiástico ni seglar.

Ítem, humilmente suplico a los excelentísimos señores don Pedro Fernández de Castro y doña Catalina de Rojas y Sandoval, condes de Lemos, mis señores, sean servidos de recibir [f. 569v] debajo de su amparo y protección al dicho don Ga- 
briel Leonardo de Albión, mi sobrino, al cual los presento con la virtud, ingenio, buenas partes y entrañable deseo que sus excelencias han podido echar de ver en él que tiene de acertar a servirles, y también con los servicios propios suyos y los de su padre y míos, para que, continuando los unos y los otros, pueda acabar en servicio de sus excelencias, pues desde su niñez comenzó a emplearse en él, y humilmente suplico a sus excelencias pongan el sujeto y servicios del dicho don Gabriel, mi sobrino, en manos de los excelentísimos señores duque de Lerma y condesa de Lemos, mis señores y padres de sus excelencias, para que se le haga merced, pues sus partes son con ventaja a propósito del servicio de su majestad, y me perdonen si en el discurso del tiempo que les he servido he hecho algunas faltas o descuidos en su servicio, asegurándoles que ninguna persona [f. 570] más de corazón ni con mayor deseo de acertar ha servido a otra que yo a sus excelencias. Y aunque de la gran merced y favor que sus excelencias han hecho al dicho mi sobrino podía yo estar asegurado de que se la han de hacer en todo lo que convenga para su mayor honra y acrecentamiento, pero por la gran ternura con que le amo y por lo mucho que me tiene obligado por su virtud y buenas partes, no he podido en este último trance excusar el suplicar esto a sus excelencias, ni de dejarles prenda tan propia y cara mía para que en mi lugar les sirva y supla mis faltas. 
Ítem, suplico muy encarecidamente a la dicha excelentísima duquesa doña Juana de Pernestán y a los excelentísimos señores duques de Villahermosa, sus hijos, que [f. 570v] en consideración de lo que mi hermano y yo nos habemos siempre preciado de criados de sus excelencias y deseado de todo corazón y sin respetos algunos servirles, sean servidos de amparar al dicho don Gabriel Leonardo de Albión, mi sobrino, haciéndole oficio de señores y favoreciéndole y haciéndole merced en todo lo que para su acrecentamiento se le ofreciere, pues el que él tuviere y todo lo que él fuere lo ha de emplear en servicio de sus excelencias, reconociendo siempre que su padre y él y yo somos hechuras de las manos de sus excelencias.

Ítem, quiero que mis ejecutores arriba nombrados, a más de los cuatro mil sueldos que conforme a lo sobredicho han de repartir de limosnas, repartan otros seis mil sueldos más, de manera que en todo sean diez [f. 571] mil sueldos, y asimismo quiero que entre los criados y criadas de la dicha mi hermana que me sirven en esta enfermedad, por el trabajo que en ella tienen, les repartan seiscientos sueldos jaqueses como les pareciere.

Este es mi último testamento, última voluntad, ordinación y disposición de todos los dichos mis bienes así muebles como sitios, dondequiera habidos y por haber, el cual quiero valga por derecho de testamento. Y si por tal no valiere o pudiere valer, quiero 
valga por derecho de codicilo o de otra cualquiera última voluntad, ordinación y disposición de bienes que conforme a fuero, derecho, seu alias, mejor puede y debe valer.

[Los f. 571v y 572 están en blanco.]

[f. 572v] su último testamento, etcétera, y me requería y requirió que aquella no fuese ni pudiese ser abierta en su vida de él, y que si él en su vida la pidiese a mí, dicho notario, o a mis sucesores en mis notas, que yo y ellos se lo hayamos de restituir cerrada y sellada, etcétera, y que si él en su vida no nos la pidiese, que después de su muerte yo, dicho notario, y dichos mis sucesores fuésemos tenidos y obligados de abrir, leer y publicar y en pública forma sacar la dicha y presente plica, etcétera, de las cuales cosas, etcétera, large.

Testes Esteban Catalán y Juan Pérez, escribientes, habitantes en Zaragoza.

Yo, el doctor Bartolomé Leonardo de Argensola, otorgo lo sobredicho.

Yo, Esteban Catalán, soy testigo de lo sobredicho.

Yo, Juan Pérez, soy testigo de lo sobredicho.

[f. 573] Et así abierta, leída y publicada la dicha plica, siquiere testamento, por mí, dicho notario, como dicho es, incontinenti el 
dicho don Gabriel Leonardo de Albión requirió por mí, dicho e infrascrito notario, ser, como fue hecho y testificado, el presente acto, etcétera, large.

Testes qui supra proxime nominantes.

Atesto que, cuando se abrió dicho testamento, se hallaron los sobrepuestos siguientes en aquel: terciopelo, ni, infantes, y que no se le dieron, y les pareciere ser más conveniente para el servicio de Dios y descargo de mi conciencia, arriba nombrados, y de enmendado donde se le, al. 


\section{Índice}

El legado patrimonial de «los Leonardos» a través de sus testamentos

Jesús Gascón Pérez ...........................................................................

Reproducción facsimilar y transcripción de los testamentos de los hermanos Argensola .................................................................. 41

Lupercio Leonardo de Argensola ................................................... 43

Bartolomé Leonardo de Argensola............................................... 77 



Acabose de imprimir este volumen, que contiene las últimas voluntades que Lupercio y Bartolomé Leonardo de Argensola ordenaron «porque ninguna prevención para morir puede ser anticipada, según los peligros que hay en la vida », el 6 de noviembre de 2009, fecha en que se conmemora el 417 aniversario de la muerte de don Fernando de Aragón, $\mathrm{V}$ duque de Villahermosa, de cuya persona y linaje ambos hermanos «nos habemos siempre preciado de criados de sus excelencias y deseado de todo corazón y sin respetos algunos servirles»

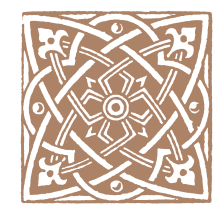


Larumbe. Textos Aragoneses

ISBN 97-884-92774-58-6
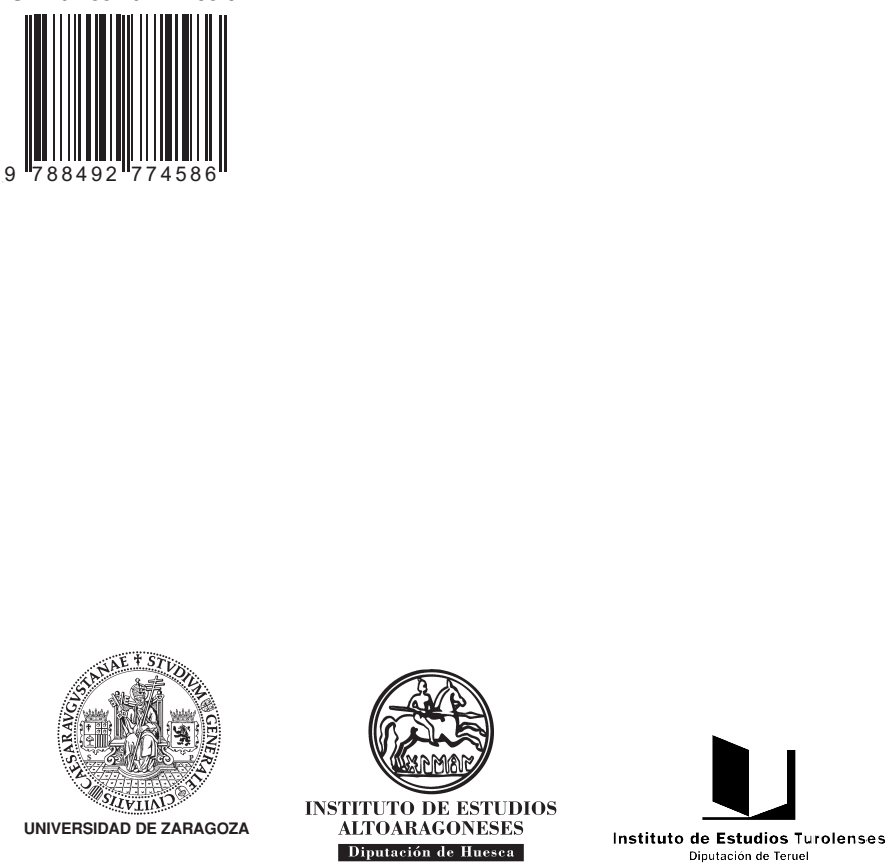